\title{
Enhancing the effectiveness of the utility energy supply chain in integrated steel manufacturing
}

\author{
Girish Sudhir Bhave \\ West Virginia University
}

Follow this and additional works at: https://researchrepository.wvu.edu/etd

\section{Recommended Citation}

Bhave, Girish Sudhir, "Enhancing the effectiveness of the utility energy supply chain in integrated steel manufacturing" (2003). Graduate Theses, Dissertations, and Problem Reports. 1312.

https://researchrepository.wvu.edu/etd/1312

This Thesis is protected by copyright and/or related rights. It has been brought to you by the The Research Repository @ WVU with permission from the rights-holder(s). You are free to use this Thesis in any way that is permitted by the copyright and related rights legislation that applies to your use. For other uses you must obtain permission from the rights-holder(s) directly, unless additional rights are indicated by a Creative Commons license in the record and/ or on the work itself. This Thesis has been accepted for inclusion in WVU Graduate Theses, Dissertations, and Problem Reports collection by an authorized administrator of The Research Repository @ WVU. For more information, please contact researchrepository@mail.wvu.edu. 


\title{
Enhancing the Effectiveness of the Utility Energy Supply Chain in Integrated Steel Manufacturing
}

\author{
Girish Sudhir Bhave \\ Thesis submitted to the \\ College of Engineering and Mineral Resources \\ at West Virginia University \\ in partial fulfillment of the requirements \\ for the degree of \\ Master of Science \\ in \\ Industrial Engineering \\ B Gopalakrishnan, Ph.D., Chairman \\ Larry Banta, Ph.D., Co-chairman \\ Ralph Plummer, Ph.D. \\ Richard Turton, Ph.D.
}

Department of Industrial and Management Systems Engineering

Morgantown, West Virginia

2003

Keywords: Energy Supply chain, Steam Systems, Simulation, Integrated Steel Industry, Energy Analysis 


\title{
ABSTRACT \\ Enhancing the Effectiveness of the Utility Energy Supply Chain in Integrated Steel Manufacturing
}

\author{
Girish Sudhir Bhave
}

The iron and steel industry is energy intensive. The steel industry accounts for 2-3 $\%$ of total US energy consumption. The energy costs account for $12-15 \%$ of the total cost of manufacturing steel. Cogeneration is done by most of the integrated steel producers for on-site electricity generation. The steel industries use different utility systems, and $90 \%$ of the industry uses standard steam boilers, steam turbines and BOP (Basic Oxygen Process). The boilers produce steam which is used for power generation and production processes. The system consumes oil, natural gas and blast furnace gas (BFG) to produce this steam and electricity. It is difficult to modulate the machines and manage the system optimally because the boilers may not react to sudden changes in steam loads and fuel availability. Minimizing the fuel cost is an important issue. This could result in the plant using large quantities of purchased fuel and wasting the free sources of energy; such as the BFG to flare and venting BOP steam.

The utility systems in the steel industry, consisting of boilers and turbines, can be considered as a Supply Chain. The venting of free available energy is a major problem with this "Energy Supply Chain". The solution to this problem is to integrate and link all the system components so that they react together to control the dynamics of the system.

The aim of this research is to design and develop a simulation model for the utility energy supply chain in the steel industry with the help of collected data and validate the model. This model can be used to analyze different control strategies and for generating control and operating strategy decisions. 


\section{ACKNOWLEDGEMENTS}

I would like to wholeheartedly thank my advisor Dr. B. Gopalakrishnan and Dr. L. Banta for their continued support, guidance and encouragement during the course of this research work. I also wish to thank Dr. R. Turton and Dr. Ralph Plummer, my committee members, for their advice and support.

Above all, I wish to thank god, my parents and all my friends for their constant support and blessings and enabling my success and happiness in all my pursuits and endeavors in life. 


\section{Table of Contents}

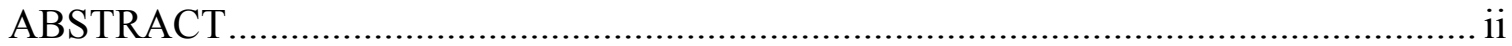

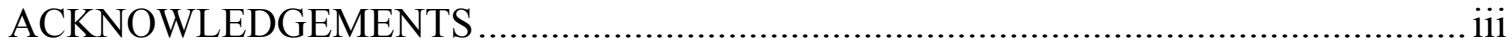

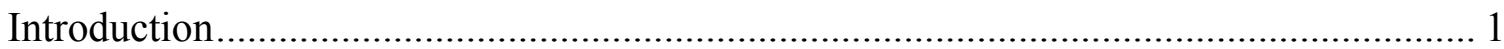

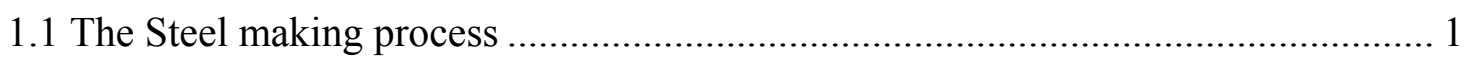

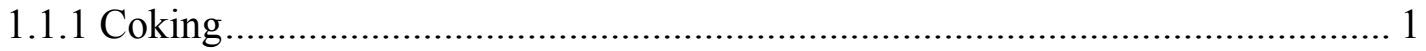

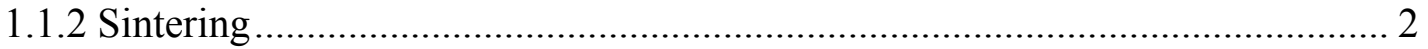

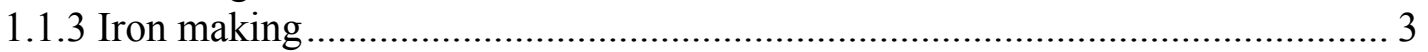

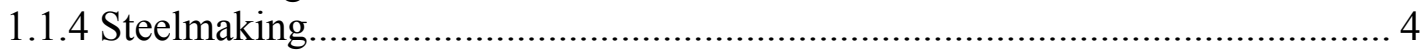

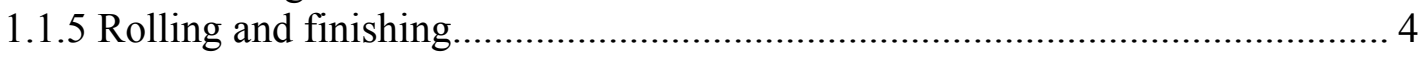

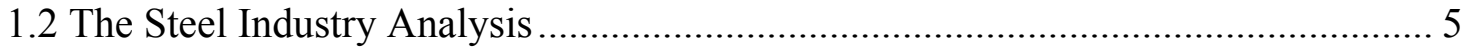

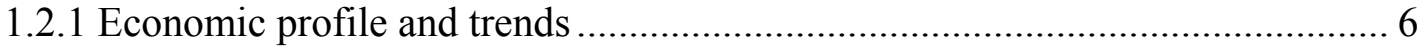

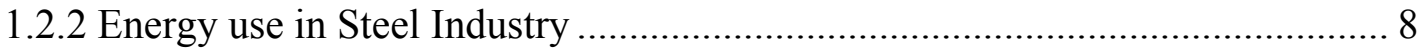

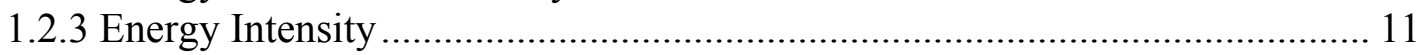

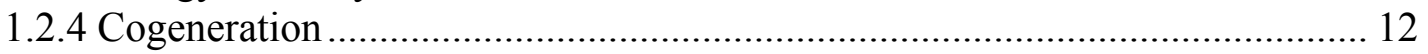

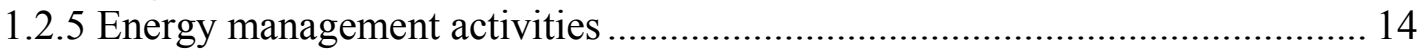

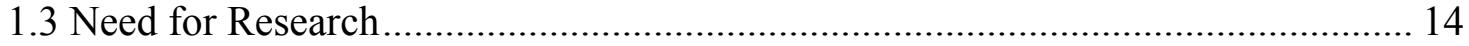

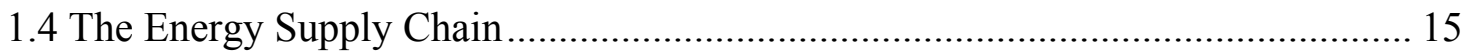

1.4.1 Problems in the Energy Supply Chain ........................................................ 16

1.4.2 Solution to the problem of the Energy Supply Chain ....................................... 17

1.5 Solution Approach ....................................................................................... 17

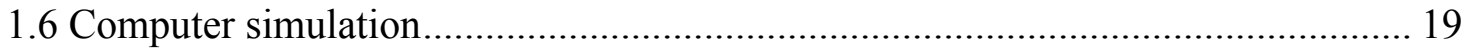

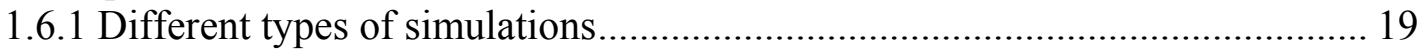

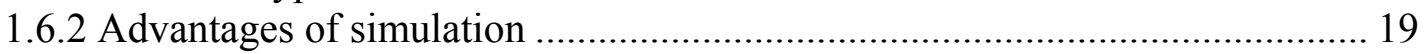

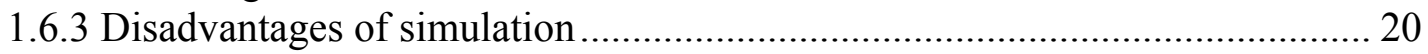

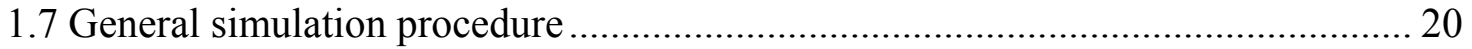

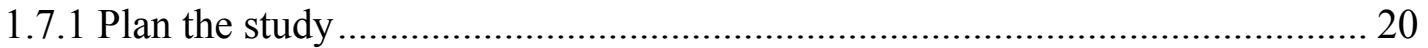

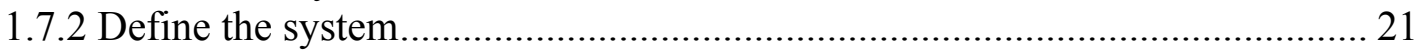

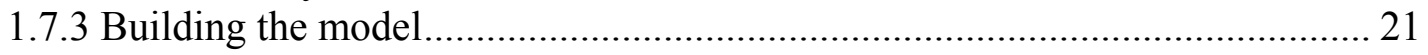

1.7.4 Conducting experiments ....................................................................... 21

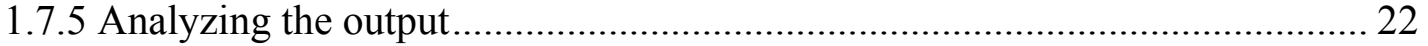

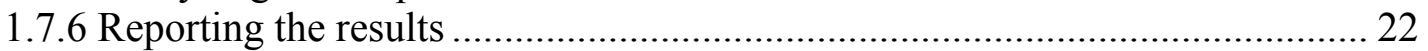

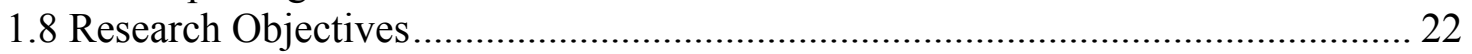

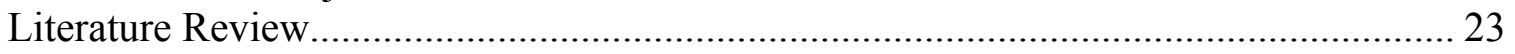

2.1 Energy conservation measures in steel industry …………………….................. 23

2.2 Mathematical programming applications in integrated steel plants ...................... 24

2.2.1 National steel planning models.................................................................. 25

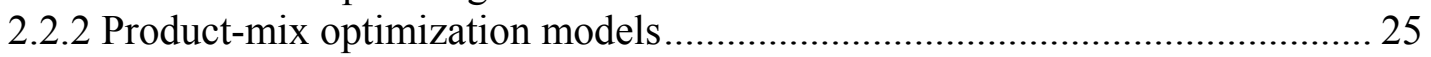

2.2.3 Mathematical models for energy in integrated steel plants ............................. 26

2.2.4 Other areas where mathematical programming is used in a steel industry...... 27

2.3 Simulation approach for developing models ..................................................... 27

2.4 Utility system management and operational optimization...................................... 28

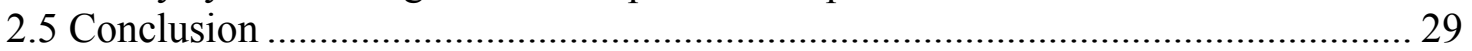

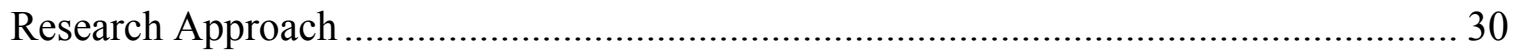

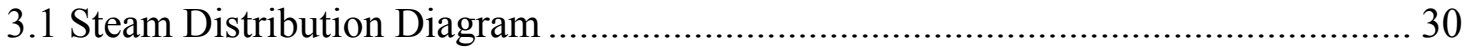




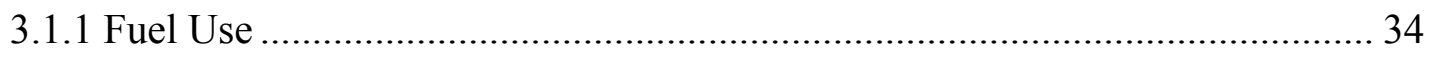

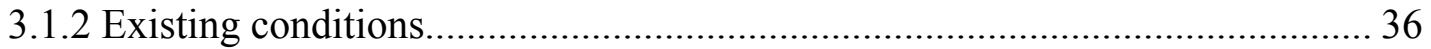

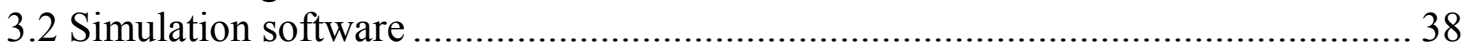

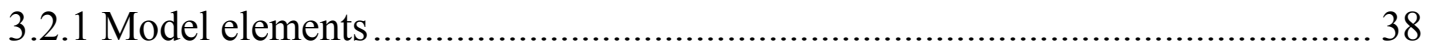

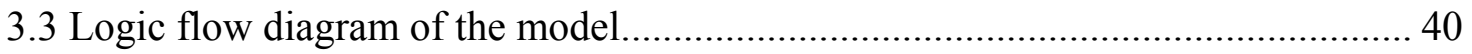

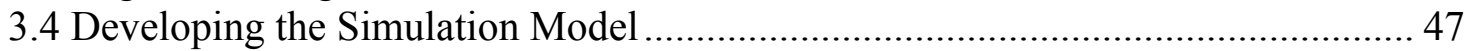

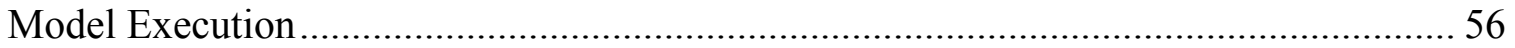

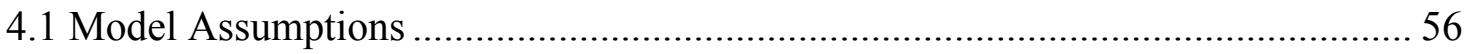

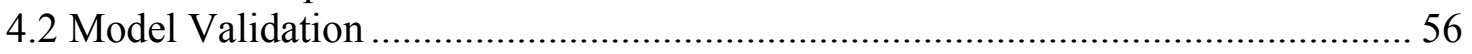

4.3 Conducting Experiments with the simulation model.............................................. 59

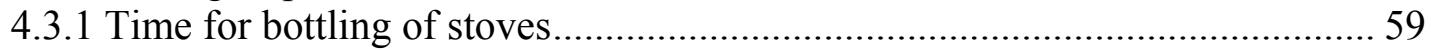

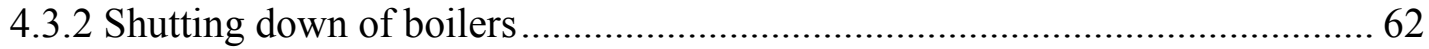

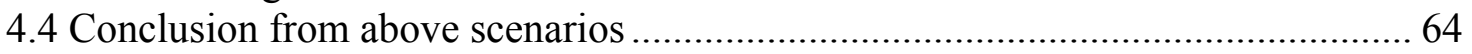

4.5 Reducing the amount of steam vented from the accumulator................................. 64

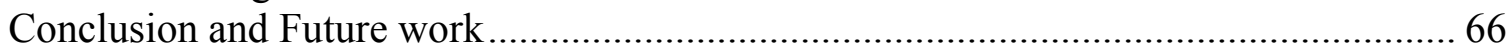

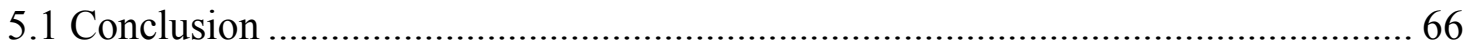

5.2 Future work

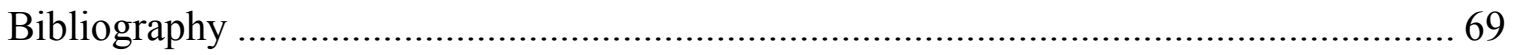

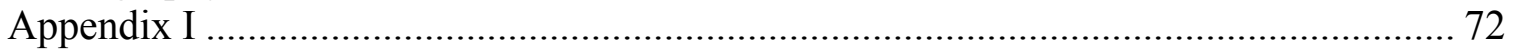

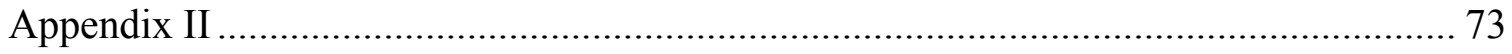

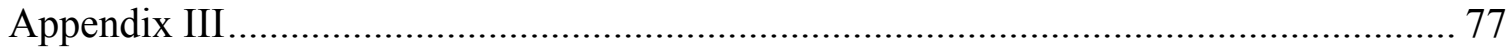

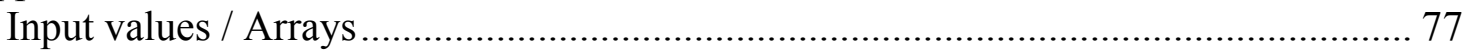

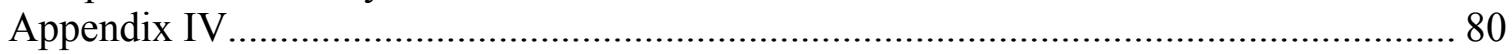

I] Relationship between volume of steam in accumulator and corresponding pressure 80 II] Relationship between volume of steam in high pressure header and corresponding

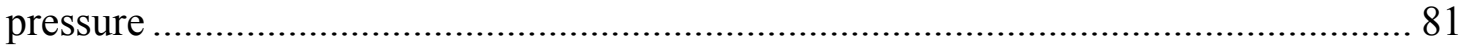

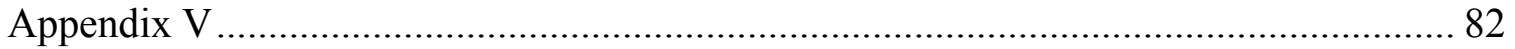

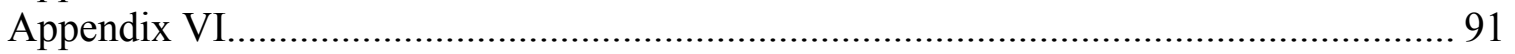

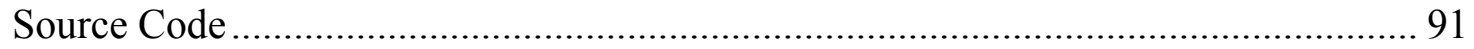




\section{List of Figures}

Figure 1.1: Schematic view of iron and steel production [23] ..................................... 2

Figure 1.2: Value of shipments (1987-1997) …………......................................... 7

Figure 1.3: Labor Productivity (Labor Output per Hour, indexed to 1987) ....................... 8

Figure 1.4: Energy use by fuel in Steel Industry (1994)................................................ 9

Figure 1.5: Energy expenditures - 1994 ................................................................... 11

Figure 1.6: Energy intensity (Btu / \$ shipments) ......................................................... 12

Figure 1.7: Energy purchases for heat and power as a percent of shipment.................... 12

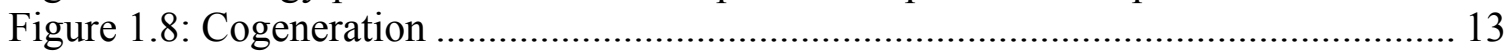

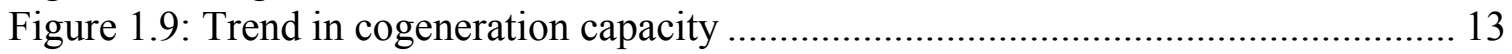

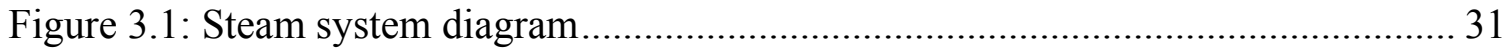

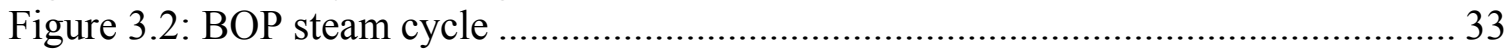

Figure 3.3: Percentage LP Steam Available through different sources ........................... 33

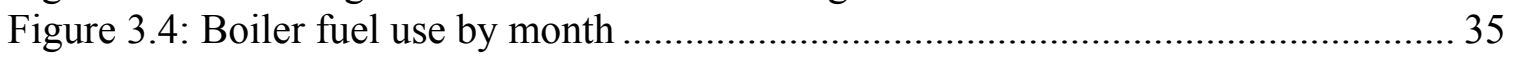

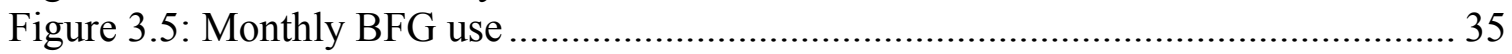

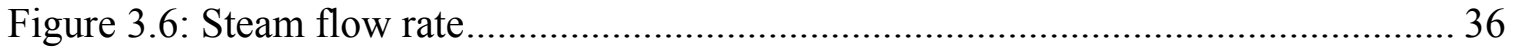

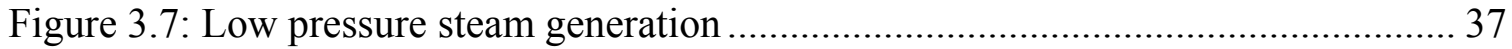

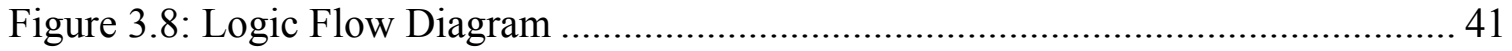

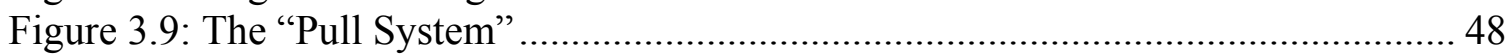

Figure 3.10: The pull system and push system on low pressure side ............................. 50

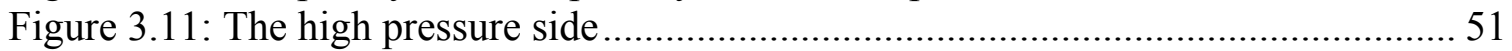

Figure 4.1: BOP and Venting (Data Exported from the software) .................................. 57

Figure 4.2: BOP and Venting (From the collected data) ................................................ 58

Figure 4.3: LP Header Pressure (From the data exported from software)........................ 58

Figure 4.4: LP Header Pressures (From the collected data) ............................................ 59

Figure 4.5: Flaring when stoves are bottled while BOP is on-blow ………………......... 60

Figure 4.6: Flaring when stoves are bottled while BOP is off-blow ………………........... 61

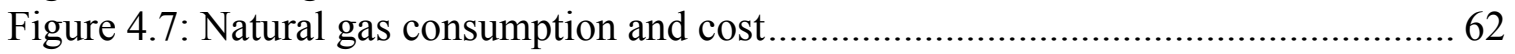

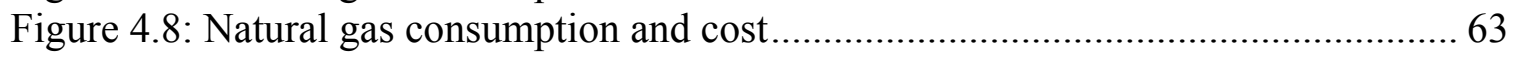

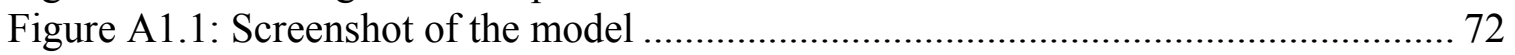

Figure A4.1: Graph of Pressure vs. Specific Volume.................................................... 80

Figure A4.2: Graph of Specific Volume vs. Pressure...................................................... 81 


\section{List of Tables}

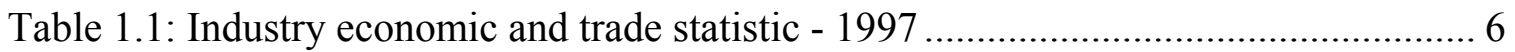

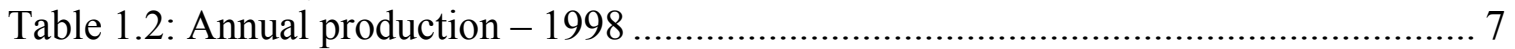

Table 1.3: Total energy used in Steel Industries.......................................................... 9

Table 1.4: Energy use by major processes - 1997 [24] ................................................. 10

Table 1.5: Energy management activities - 1994 ……………..................................... 14

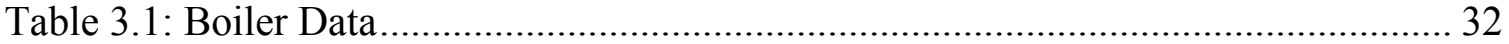

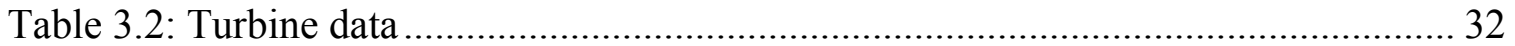

Table 3.3: Ramp rates for boilers and turbines .......................................................... 34

Table 3.4: Relationship for the boiler efficiency ....................................................... 52

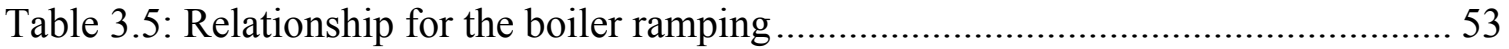

Table 3.6: Relationship for the turbine steam flow rate................................................ 54

Table A1.1: Color Coding Scheme ……………………............................................. 72

Table A2.1: List of variables ................................................................................ 73

Table A3.1: Array Name - arrboltur[] (Array for boilers, turbine and desuperheater data)

Table A3.2: Array Name - arrsetpt[] (Array for various set points and initial values).... 78

Table A3.3: Array Name: Cummsec[] and boparr[] (Arrays for BOP arrivals, one is for the minute and other for the value ) .................................................................. 79

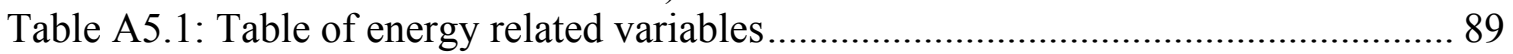




\section{Chapter 1 Introduction}

Steel is an integral part of life. The consumption of steel shows the strength of the economy. Today in competition with the materials such as plastic, aluminum, sintered powdered products and composites, steel still remains dominant on both low cost and

high tonnage basis. Steel forms an essential raw material for buildings, automobiles and many consumer products. The steel industry uses a few raw materials to produce a large variety of products, thus known as a few-to-many industry.

\subsection{The Steel making process}

The steel production system includes the mining industries providing raw material inputs of iron ore, coke and limestone; the iron and steel industry itself; steel fabrication industries and the steel scrap-processing industry which collects, separates, cleans and grades the discarded steel scrap for recycling.

Iron and steel making is a complex subject but it can be categorized in to five major groups of activities [23]-

$>$ Coking

$>$ Sintering

$>$ Iron making

$>$ Steelmaking

$>$ Final rolling and finishing

The schematic diagram of the process is as shown in Figure 1.1. Each of these processes are described below.

\subsubsection{Coking}

This is a process of heating coal in the absence of air thus separating some noncarbon constituents of coal from the product (coke). Coke is about $90 \%$ carbon. The noncarbon constituents are water and sulfur which are carried off in a gas stream. This coke is used as fuel and a source of carbon monoxide in the blast furnace [23]. 


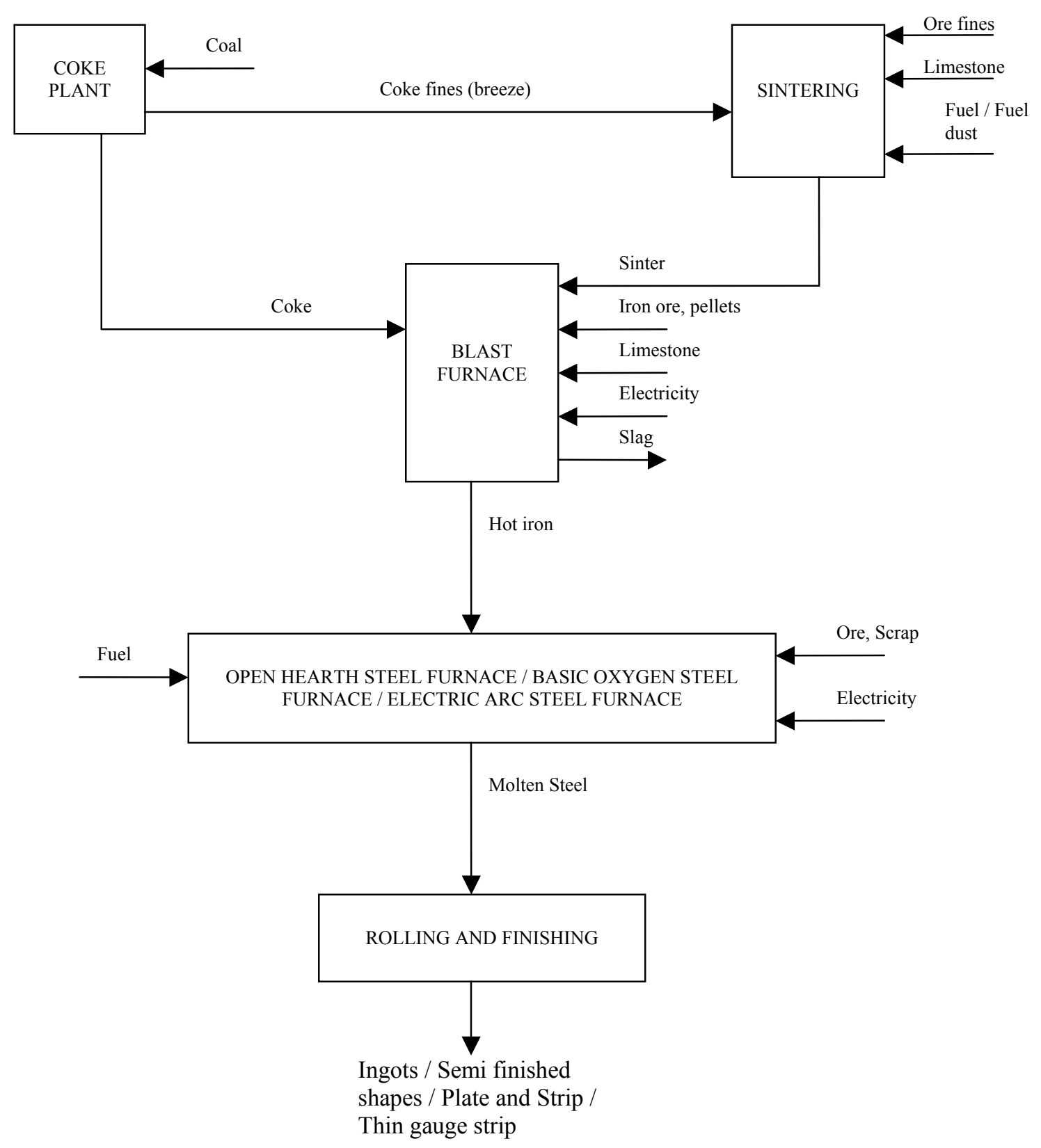

Figure 1.1: Schematic view of iron and steel production [23]

\subsubsection{Sintering}

In sintering, fine ore particles are agglomerated into a porous mass for charging into the blast furnace. Here heat is applied from the combustion of coke to a mixture of ore and flux charge. Limestone is used as a flux charge. Sintering is used to increase the 
efficiency of blast furnaces. It does this by decreasing the dust loss, the coke requirement, and the weight of flux required. The process also helps in making use of iron ore fines and the recovered blast furnace flue dust [23].

\subsubsection{Iron making}

Molten iron is produced by reduction of iron ore in the blast furnace. The ores and the iron bearing materials are charged from the top of the furnace. Along with this predetermined amounts of limestone and coke are also added. Preheated air is blown into the charge from the bottom of the furnace to burn the coke and the descending mass. The gas, from the burning of coke, reduces the stock of materials as they move in opposite directions. The lime from limestone and other bases in the charge fuses with the acid part of the ores and creates a slag that floats on the molten iron and is removed from the furnace periodically. Thus, iron is removed from the non-metallic part of the ore and from the impurities such as sulfur and manganese. Molten iron is removed from the bottom of the furnace [23].

As the hot air passes through the blast furnace, it is converted into blast furnace gas (BFG). One cubic foot of hot air entering the furnace becomes approximately 1.35 cubic foot of blast furnace gas, as it is discharged from the top of the furnace. This gas is then directed through the cleaning equipment, where it is cooled and cleaned. This is a free source of energy and is used to generate electricity and also used by the stove system.

The hot air blown in the blast furnace is preheated in the stoves. The blast furnace stove heats the air which actually reduces the iron ore to iron. The stove is made up of a combustion chamber and a large mass of refractory bricks. The stove operates in two phases. The first one is the 'on-gas' phase, where the bricks are heated by burning the blast furnace gas enriched with natural gas in the combustions chamber. The hot exhaust is then passed through the bricks to heat them up. In the second phase the 'on-blast' phase, normal air gets heated up as it is forced through heated bricks. This air is then passed to the blast furnace for iron production. A stove that has been heated and is waiting to go 'on-blast' is referred to as "Bottled" [26]. 


\subsubsection{Steelmaking}

The blast furnace is designed to reduce the iron oxides and to separate the iron from large quantities of impurities in the ore. Steelmaking from molten iron or scrap involves removal of relatively small amounts of certain impurities from the metallic charge through oxidation. Molten iron has impurities such as silicon, manganese, phosphorus and sulfur. These impurities are oxidized and they are removed by solution in furnace slag. There are metallic elements, called tramps, which appear in steel scrap and to a small extent in molten steel which also need to be removed. This process is called tramp-dilution. The hot metal from the blast furnace is charged with a range of scraps. The proportion of hot metal and total scrap in the charge is constrained to some extent by the furnace type. Total charge quantities are based on requirements for total elemental iron output, allowing for losses in flue dust and slag. The steelmaking can be done by the following processes [23]-

1. The open hearth furnace

2. The basic oxygen furnace

3. The electric arc furnace

In the open hearth furnace, a long, shallow charge bath of iron bearing materials is heated by radiation from a flame. The fuel used may be natural gas, coke oven gas, fuel oil, coal tar or a combination of these. Oxygen may or may not be injected. In case of the basic oxygen furnace pure oxygen is introduced from above the surface of the bath of molten iron. Electric power is used as a source of heat in the electric arc furnace. Graphite rods are placed above the cold charge to produce an arc which melts the scrap [23].

\subsubsection{Rolling and finishing}

In rolling and finishing, the molten steel is converted into semi-finished products. The molten steel is poured into ingot mould, and then allowed to cool and solidify into suitable shapes for further processing. The ingots are then removed from the mould, reheated and rolled in semi-finished shapes. These semi-finished shapes are then converted to finished products by further hot and cold rolling, surface coating and galvanizing [23]. 


\subsection{The Steel Industry Analysis}

The steel industry is important for economic competitiveness and national security. The steel industry products are used in all sectors of economy. Steel is used in bridges, automobiles, railroads, skyscrapers and also in appliances. Currently, most of the steel grades used, including high strength steel, are lighter and more versatile than those available 10 years ago. Again, steel is the most recyclable material and has an overall recycling rate of 68 percent [24].

There are more than 1200 firms operating in this sector. The US steel industry is a $\$ 50+$ billion enterprise excluding downstream processing, which can push this value up to $\$ 75$ billion. The US steel industry is made up of integrated producers and electric arc furnace producers (EAF). Both produce flat-rolled, structural and tubular products. Integrated steel producers produce steel starting from iron ore and coal.

The integrated steel producers have integrated not only the steel making process but also other functions and requirements of the industry. The EAF producers start with scrap steel. They are also called mini-mills. As compared to the integrated steel producers, they have smaller manufacturing costs, and their product range is smaller. They produce lower quality products, particularly bars and structural shapes. Mini-mills are generally more efficient, have better human resources practices and the ability to implement new technology.

In today's scenario, the integrated mills have stopped coke production and are being converted to EAF mills, while some EAF producers have integrated back to iron production and provide complex finishing. Thus the distinction between the two industries has narrowed. The mini-mills have captured the market due to their lower costs and subsequent lower prices, but integrated producers, in response, have shifted to more complex products with higher quality. The integrated steel mills are relatively small in number, currently there are about 20 mills [24].

The steel industry employs about 154,000 people nation-wide and is one of the largest energy consumers in the manufacturing sector. It has invested more than $\$ 7$ million in environmental controls. 


\subsubsection{Economic profile and trends}

The steel industry contributes up to $5 \%$ of the total US manufacturing GDP. Major transformation has occurred since the recession in the late 1980's. There is investment in new processes and technologies and this has also led to the closing of some mills. Today, the industry employs about 150,000 workers and wages are 50\% higher than the average for all US manufacturing sectors. The industry also creates 50,000 additional jobs for down stream processing. The United States produces about 107 million tons of raw steel (1998), which contributes to $13 \%$ of the world steel production and thus makes US the largest producer of steel in the world. The US steel industry, still experience acute competition from Asian countries. The industries return on sales is $3 \%$ for 1997 as well as 1998. The steel industry economics and trade statistics are shown in the Table 1.1 [24].

\begin{tabular}{|c|c|}
\hline Value of shipments & \$75.9 billion \\
\hline Employment & $211,900 *$ \\
\hline $\begin{array}{l}\text { Average hourly wages } \\
\text { (Production workers) }\end{array}$ & $\$ 19.61$ \\
\hline Capital Expenditures & $\$ 3.39$ billion \\
\hline R \& D Expenditures** & $\$ 414$ million \\
\hline Trade Imports & $\$ 16.1$ billion \\
\hline Trade Exports & $\$ 5.5$ billion \\
\hline
\end{tabular}

Table 1.1: Industry economic and trade statistic - 1997

The shipments for steel have been increasing steadily since the $1990 \mathrm{~s}$. Downsizing and consolidation have reduced the raw steel production by $30 \%$ since 1980 , but capacity utilization has increased to $90 \%$. Figure 1.2 shows the trends in the value of shipments [24]. 


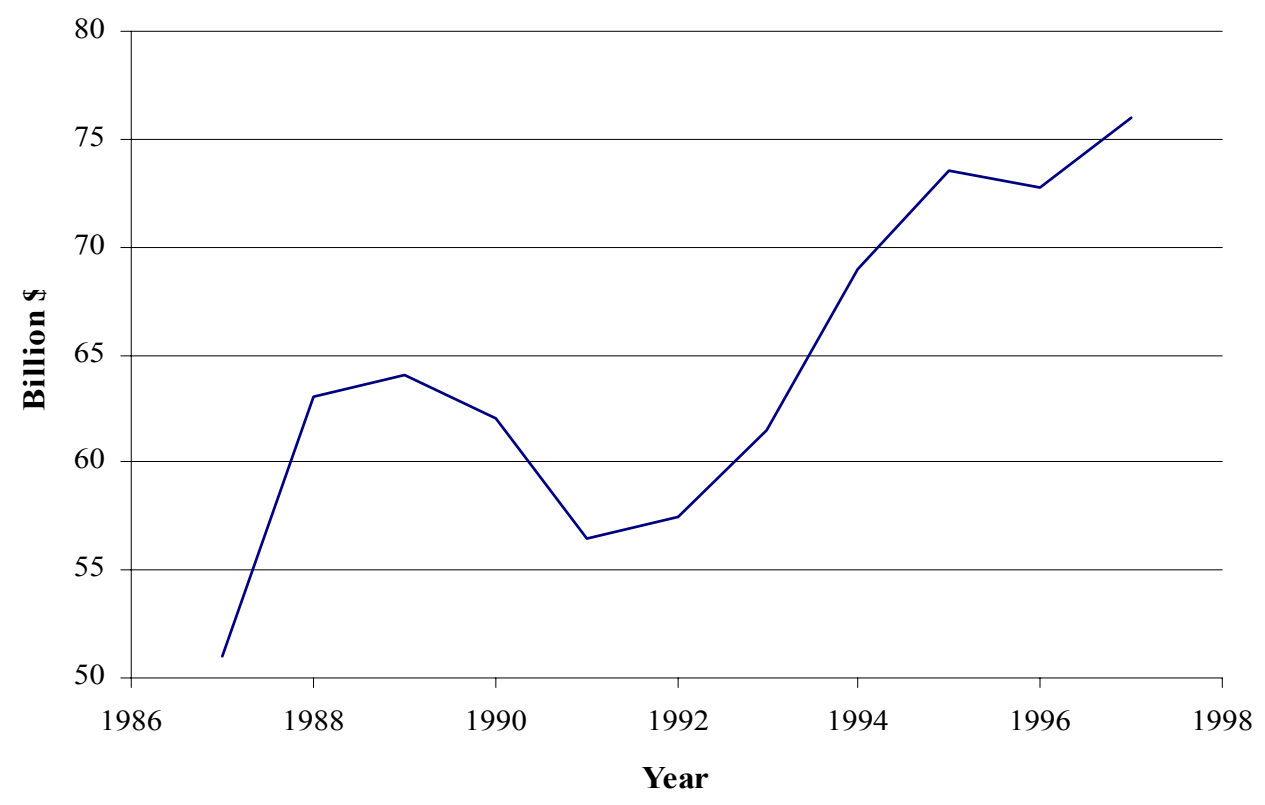

Figure 1.2: Value of shipments (1987-1997)

\begin{tabular}{|l|l|}
\hline Raw Steel Grade & $\mathbf{1 9 9 8}$ Production \\
\hline Carbon & 97.0 million tons \\
\hline Alloy & 9.5 million tons \\
\hline Stainless & 2.2 million tons \\
\hline Total & $\mathbf{1 0 8 . 7}$ million tons \\
\hline
\end{tabular}

Table 1.2: Annual production - 1998

Table 1.2 shows the annual production of steel in 1998 [24]. About 60 million tons were produced by the basic oxygen furnace process and the remaining 50 million by electric arc furnace process. The major products of the steel mill were sheets, bars, rods, plates, structural shapes, and strips.

The man hours required for producing a ton of steel has been reduced from 10 to less than 4 . This $60 \%$ drop is basically due to the new processes and technologies, new facilities, increased employee training and new product development. As the production processes are now technologically sophisticated, they need skilled workers; consequently unskilled workers are trained and educated. The 1998 hourly earning was $\$ 20.10$ and the employment cost per hour including benefits was \$34.57. Figure 1.3 shows the labor productivity as a percent of that in 1987 [24]. 


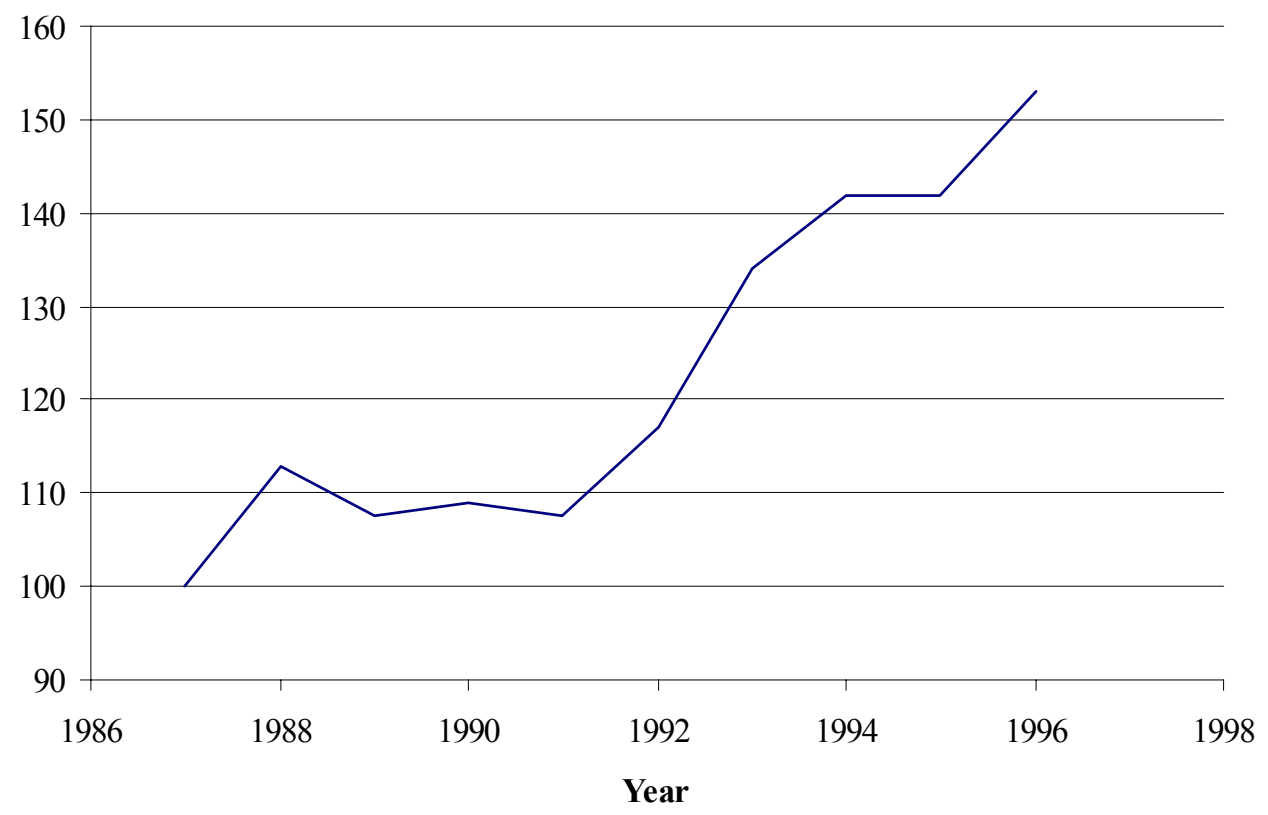

Figure 1.3: Labor Productivity (Labor Output per Hour, indexed to 1987)

\subsubsection{Energy use in Steel Industry}

The steel industry accounts for $2-3 \%$ of total US energy consumption. The energy is used to supply heat and power for the plant operations and also as a raw material in production of blast furnace coke. According to a recent manufacturing energy consumption survey, in 1994 the US steel industry consumed 2 quads (quadrillion Btu or $\left.10^{15} \mathrm{Btu}\right)$ of energy. This study includes the losses incurred during the distribution, generation, and transmission of electricity. According to the data complied by the American Iron and Steel Institute, in 1997, 1.8 quads of energy were consumed including the electrical losses. This is about $2.5 \%$ of the total domestic energy consumed in the US and about $8 \%$ of the manufacturing energy use. Table 1.3 shows the energy usage in the corresponding years [24]. 


\begin{tabular}{|c|c|}
\hline Year & $\begin{array}{c}\text { Total Energy used } \\
\text { (Trillion Btu's) }\end{array}$ \\
\hline 1985 & 1,869 \\
\hline 1988 & 2,067 \\
\hline 1991 & 1,673 \\
\hline 1994 & 1,983 \\
\hline
\end{tabular}

\section{Table 1.3: Total energy used in Steel Industries}

The major source of the energy consumed is coal. This accounts for nearly $50 \%$ of the energy. The other two major contributors are natural gas and electricity. During the steel making process, there are two by-product fuels generated; the coke oven gas, and the blast furnace gas. These fuels are recovered for steam generation, preheating blast furnace air, and supplying heat to other plant processes. Figure 1.4 shows the energy use by fuel type in the steel industry [24]. The total energy consumed was 1,993 trillion Btus in 1994 including electric losses.

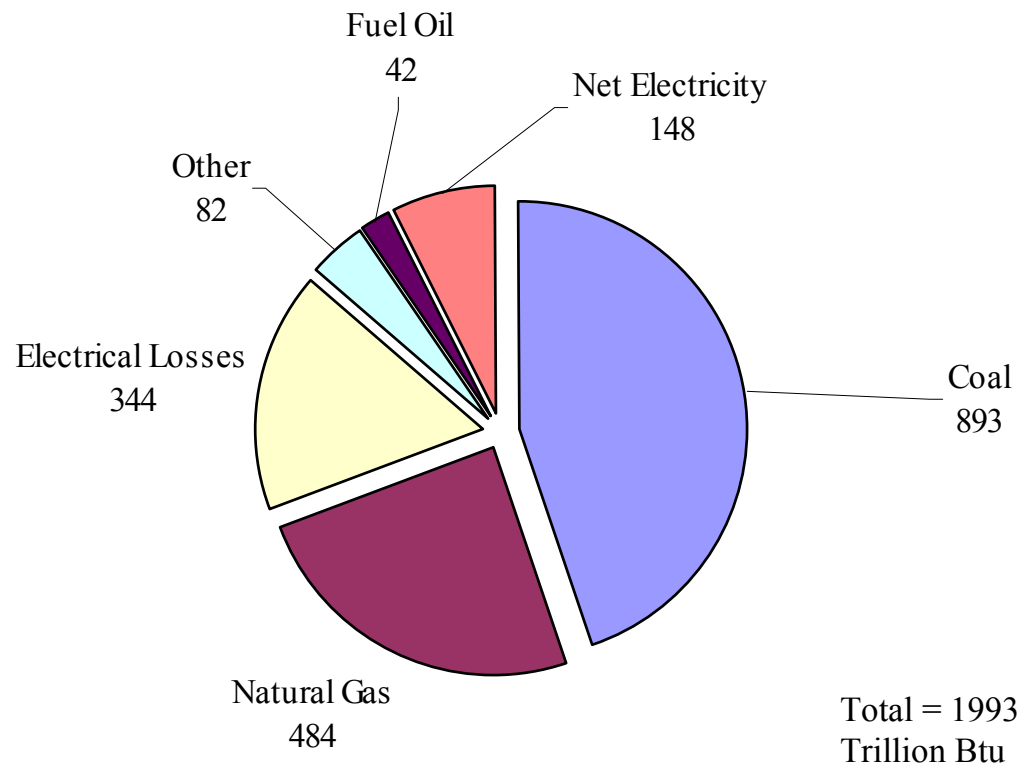

* losses incurred during the distribution, generation, and transmission of electricity All values are in Trillion Btu's.

\section{Figure 1.4: Energy use by fuel in Steel Industry (1994)}

The energy required to reduce iron ore to liquid pig iron in the blast furnace is about $40 \%$ of the total energy input to the steel industry. The energy input to the blast 
furnace is derived from coke, made from coal in the coke ovens. Supplemental fuels are also used in this process. For process heating, including electric arc furnace and reheating furnaces, $25 \%$ of the energy is used. To generate process steam the steel industry uses natural gas and the by-product gases such as coke oven gas and blast furnace gas. For equipment, heat, light and cooling facilities electricity is used.

As stated above, the steel industry can be categorized in different parts. Table 1.4 shows the energy use of major processes for 1997.

\begin{tabular}{|c|c|}
\hline Process & \% of Total \\
\hline Sintering & 2 \\
\hline Coke making & 0 \\
\hline Iron making & 39 \\
\hline BOF Steelmaking & 3 \\
\hline EAF Steelmaking & 13 \\
\hline Casting & 3 \\
\hline Boilers & 11 \\
\hline Cogeneration & 5 \\
\hline Subtotal & 77 \\
\hline $\begin{array}{c}\text { All other processes } \\
\text { (reheating, rolling, finishing, etc)* }\end{array}$ & 24 \\
\hline Total & 100 \\
\hline *Taken as the difference between known total industry and known subtotal use $^{\text {ing }}$
\end{tabular}

Table 1.4: Energy use by major processes - 1997 [24]

The energy costs account for $12-15 \%$ of the total cost of manufacturing steel. In 1994, the steel industry consumed about $9 \%$ of the total energy consumed in the manufacturing sector. Figure 1.5 shows the energy expenditures in billions of dollars. The total energy expenditure here is $\$ 6$ billions [24]. 


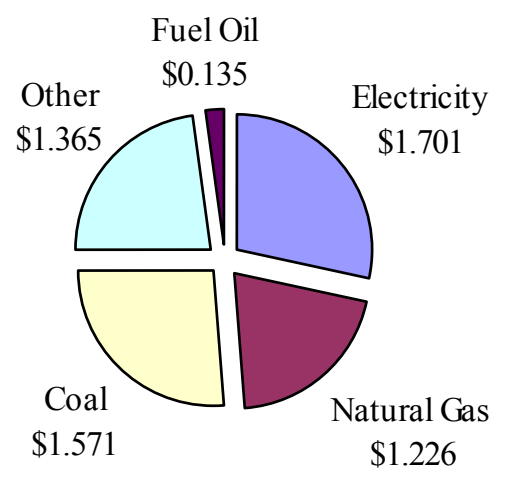

Total $=\$ 6$ Billion

\section{Figure 1.5: Energy expenditures - 1994}

\subsubsection{Energy Intensity}

The US iron and steel industry has reduced its energy intensiveness by $45 \%$ since 1975 by energy conservation measures, and process improvements. The average energy intensity of producing semi-finished steel at integrated mills using basic oxygen furnace (BOF) steelmaking was 20 million Btu/ton and that for the EAF steelmaking was 8 million Btu/ton. Figure 1.6 shows the energy intensity over the period 1985 to 1994. Figure 1.7 shows the trend as a percent of shipments [24]. 


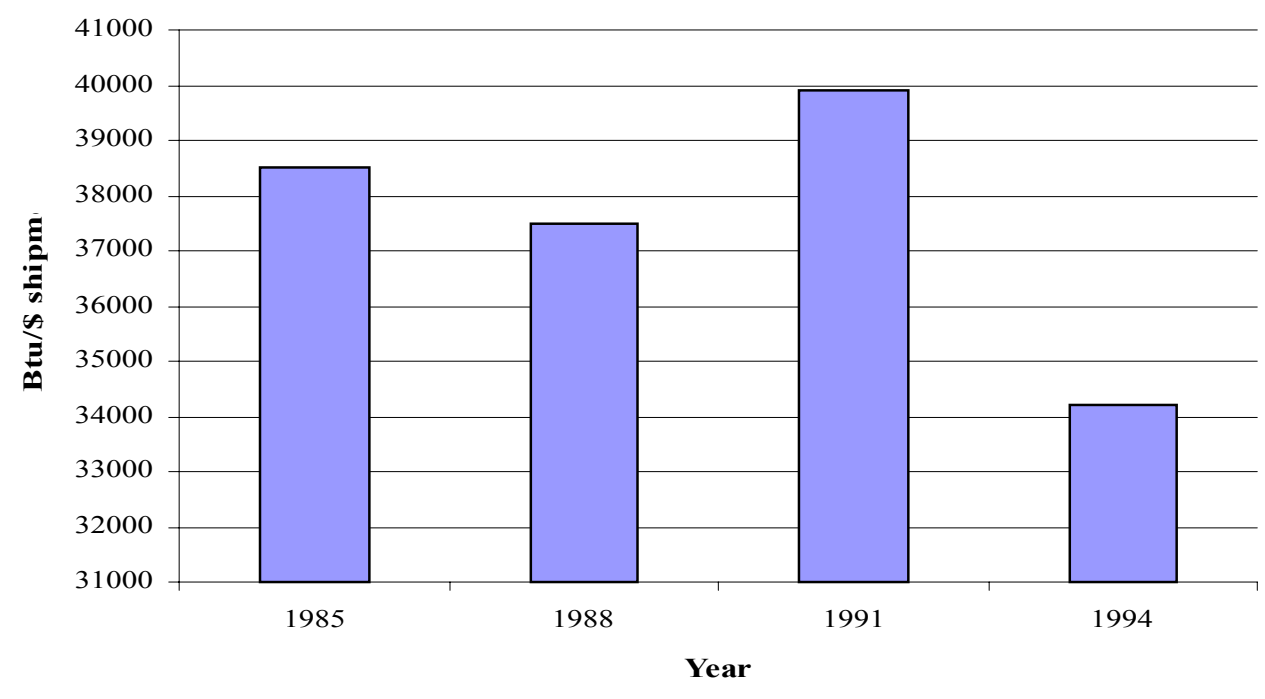

Figure 1.6: Energy intensity (Btu / \$ shipments)

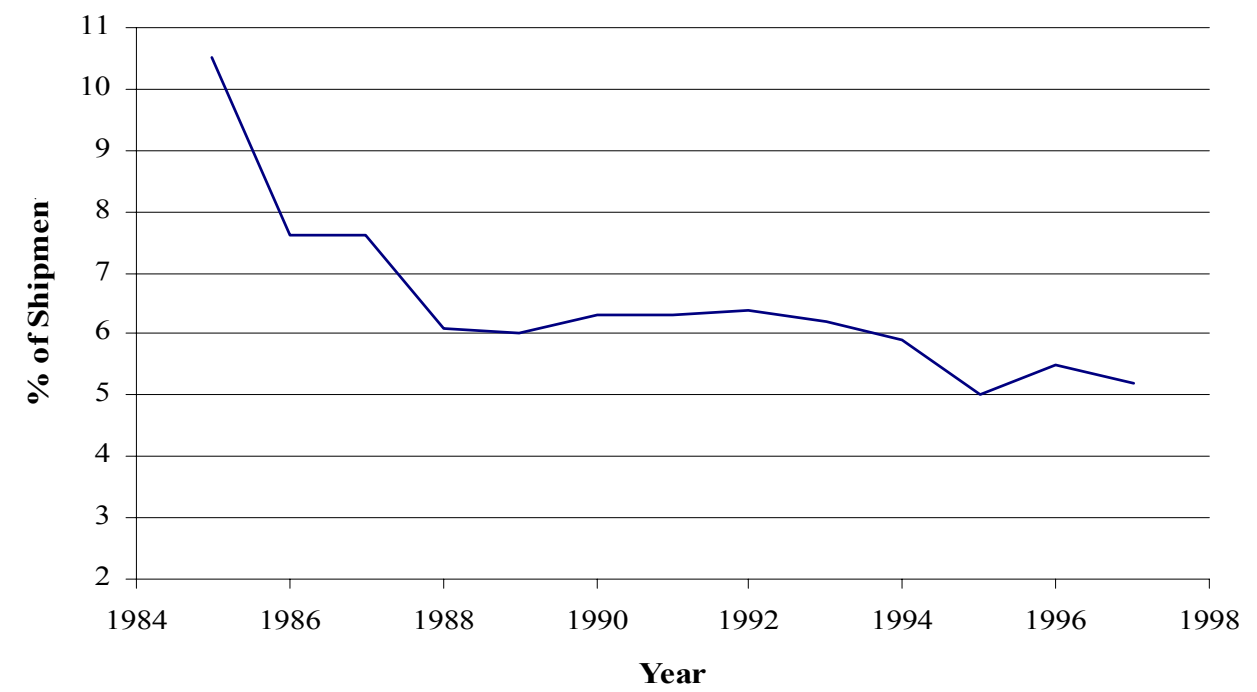

Figure 1.7: Energy purchases for heat and power as a percent of shipment

\subsubsection{Cogeneration}

Cogeneration is done by most of the integrated steel producers for on-site electricity generation. This accounts for $10 \%$ of the total electricity used by the steel industry. The competitive advantage of cogeneration over purchased electricity is that due to high thermal efficiencies, excess electricity can be sold back to the grid. Figure 1.8 
shows the contribution of cogeneration to net use of electricity in dollars. Figure 1.9 shows trends in the cogeneration capacities over years [24].

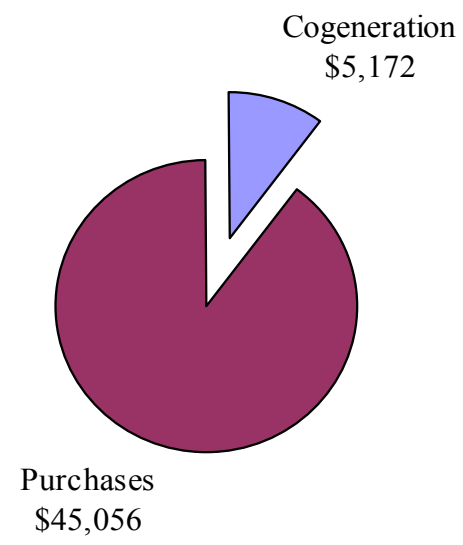

Figure 1.8: Cogeneration

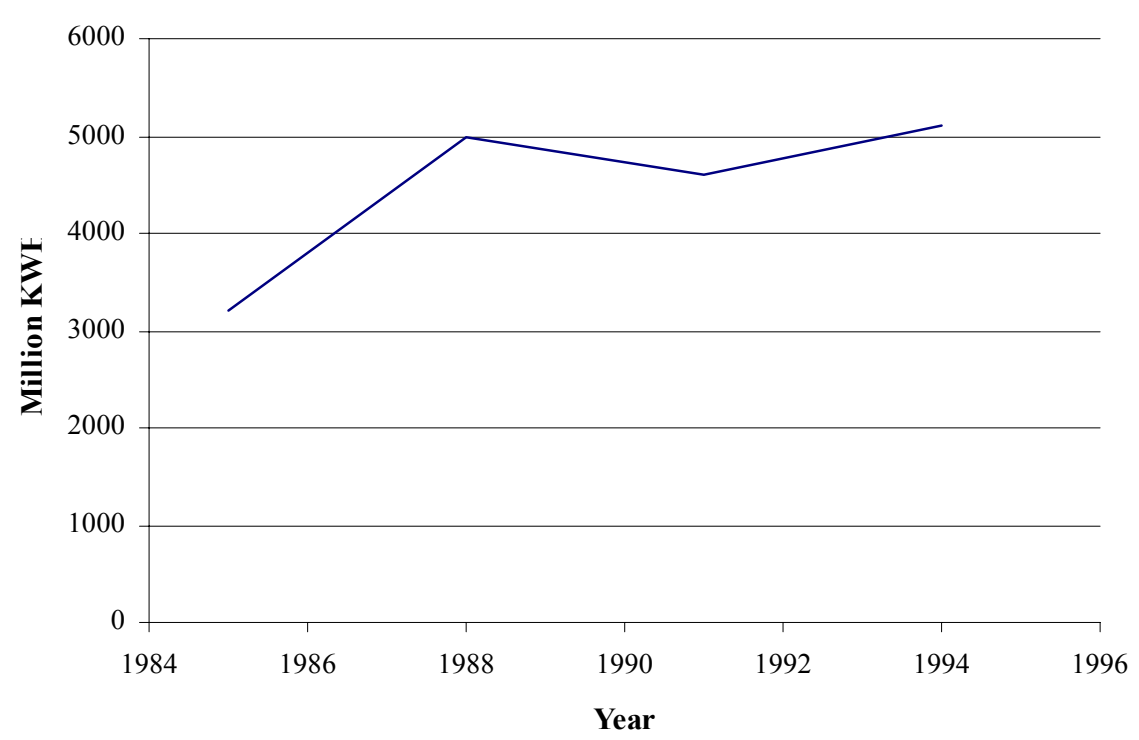

Figure 1.9: Trend in cogeneration capacity

These cogeneration operations in the steel industry are conventional systems that use steam boilers and steam turbines. Cogeneration is observed in integrated steel plants since they produce a lot of waste gases such as coke oven gas and blast furnace gas. The 
mini-mills generally have a low demand for steam and thus most of the cogeneration is observed in integrated steel mills. About $90 \%$ of cogeneration activities are in the integrated steel plants.

\subsubsection{Energy management activities}

To improve energy efficiency, many energy management activities are carried out by the industry. The top four reported activities are purchasing electricity under special rate (time-of-use rates), electricity load control, energy audits, and power factor correction or improvement. About $61 \%$ of the steel industry population engages in one of the energy management activities. Table 1.5 lists the energy management activities as reported in 1994 [24].

\begin{tabular}{|c|c|c|}
\hline Activities & $\begin{array}{c}\text { \% steel industry } \\
\text { population }\end{array}$ & $\begin{array}{c}\text { \% consumed energy } \\
\text { for heat and power }\end{array}$ \\
\hline Energy Audits & 33.1 & 67.9 \\
\hline $\begin{array}{c}\text { Electricity load } \\
\text { control }\end{array}$ & 42.3 & 68 \\
\hline $\begin{array}{c}\text { Power factor } \\
\text { correction or } \\
\text { improvement }\end{array}$ & 26.1 & 47.6 \\
\hline $\begin{array}{c}\text { Special rate } \\
\text { schedule }\end{array}$ & 45.4 & 77.7 \\
\hline
\end{tabular}

Table 1.5: Energy management activities - 1994

\subsection{Need for Research}

As stated earlier, the energy for steel production accounts for nearly $2-3 \%$ of US energy consumption. Also, it can be seen from Figure 1.4 that natural gas (purchased energy) is one of the major contributors of energy use. The natural gas cost is $20 \%$ of the total energy costs. From Table 1.4 it is seen that the boilers consume $11 \%$ of the total energy and cogeneration accounts for $5 \%$. Thus the utility energy is an important factor for energy conservation. The steel industries use different utility systems, but as stated earlier 90\% use standard steam boilers, steam turbines and BOP (Basic Oxygen Plant). The boilers produce steam which is used for power generation and production processes. The system consumes oil, natural gas, and blast furnace gas (BFG) to produce this steam 
and electricity. It is difficult to modulate the machines and manage the system optimally because the boilers may not react to sudden changes in steam loads and fuel availability. Thus, minimizing the fuel cost is a big issue. This could result in, the plant using large quantities of purchased fuel and wasting the free sources of energy; such as the BFG to flare and venting BOP steam. Thus research in this area of the Utility Energy Supply Chain will prove to be very useful for the steel industry for reducing their energy costs and becoming energy efficient.

\subsection{The Energy Supply Chain}

A "Supply Chain" is a network of facilities and distribution options that performs the function of procurement of materials, transformation of these materials into intermediate and finished products, and the distribution of these finished products to customers [28]. Supply chains occur in the service as well as manufacturing industries,

although the complexity can vary from industry to industry. "Supply chain management" is a strategy through which these different functions can be integrated [28].

Consider an integrated steel manufacturing industry. The utility systems in the steel industry, consisting of boilers and turbines, can be considered as a Supply Chain. The purchased fuel, natural gas, used as a fuel for the boiler is analogous to the procurement of material. In addition to the purchased fuel, the steel industry uses the blast furnace gas as a free form of fuel for the boilers. These fuels are used to generate the high pressure steam, which is the intermediate product, used by the turbines and further converted into low pressure steam, the final product, which is supplied to the Users of this steam. The Users here are the downstream users such as the tin mill, galvanizing mill, etc. In addition, the low pressure steam generated from the BOP (Basic Oxygen Process) process adds up to the final product low pressure steam. The users form the customers of the supply chain. A good operations strategy must be developed so that this "Energy Supply Chain" can be properly integrated so as to optimize the use of purchased fuel and maximize the use of free fuel and free steam from the BOP. 


\subsubsection{Problems in the Energy Supply Chain}

During the production of pig iron large amounts of blast furnace gas and waste heat steam is produced. This is a free source of energy and must be used instantaneously. The blast furnace gas is then used by the boilers to generate steam. Similarly, during steelmaking large amounts of heat are generated, which can be used to generate steam by the waste heat boilers. The free by-product energy is cyclical and dynamic in nature. If not used instantaneously it is lost. To capture the energy, the steel industries have computerized controls on their system components and thus capture about $95 \%$ of the byproduct energy to generate the steam and electric power. The remaining $5 \%$ is still lost to the atmosphere.

In an integrated steel plant, the optimal management of the boilers and the steam distribution system is difficult because of the interaction among the variables. The most important variable among them is the steam production from the waste heat generated in the steel-making. This steam production is cyclical. The steam from the waste heat boilers is then transferred to the accumulators. The steam is released to the low pressure header at 200 psig. The operating practice is that the accumulator is charged up to a set point pressure and the steam is vented to atmosphere if the pressure increases above that. Thus some steam is vented periodically to prevent the overcharging of the accumulator.

The boilers may not react to sudden changes in steam loads. All the boilers can burn either blast furnace gas which is a free fuel (by-product while producing steel) or purchased fuels (natural gas). Presently the amount of steam required (user demand) is higher than what the boilers can produce with the available BFG. Thus the required deficit is filled by the use of natural gas. It is desired to minimize the amount of purchased fuel used by the boilers. It is also observed that there are times when more BFG is produced than that can be consumed by the boilers, thus the BFG must be flared. Most of the flaring occurs during the summer months when the total demand is low, but even when the steam demand is high some BFG is flared due to blast furnace stove bottling the cyclical nature of net BFG production, and the cyclical nature of BOP steam production. 
Thus it can be seen clearly that the venting of the low pressure steam and the flaring of the free fuel, BFG, results in the buying of excess natural gas and low energy efficiency. Again, due to the large number of variables involved, it is difficult to define an operating strategy. In the present situation, the management of these machines is not coordinated and this results in wasting free energy. This is a typical problem in the steel industry and is referred to as "Controlling dynamic system fluctuations involving large amount of by-product energy".

\subsubsection{Solution to the problem of the Energy Supply Chain}

Even with the computerized controls on the system equipment, some energy is still vented to the atmosphere. This happens because the computer controlled systems function well as stand alone units. The major focus is to make each process a stand alone unit and to add sensors and controls to make the process more efficient. For example, the boiler with new computerized controls makes the boiler process more efficient as it controls the pressure, temperature, fuel flows, etc perfectly. But this boiler is not linked with the blast furnace, from where the fuel for the boiler comes.

The solution to this problem is linking the major complex unit operations to control dynamic system changes. Thus all the system components must be linked together for integrating the process, so that they anticipate dynamic energy fluctuations and make decisions. This will provide a real time communication data flow between different operating units and all of these units react together to control the dynamics of the system. Finally this will result in reducing the vented BFG and the steam from the BOP boilers.

\subsection{Solution Approach}

Different approaches can be used for solving the above mentioned problem. Mathematical modelling and simulation are widely used by the industries for designing new processes and to improve the operations of the existing processes. Modelling, simulation and optimization are done to reduce the costs, increase the efficiency, to get a greater understanding of the problem, knowledge management and decision support. 
Mathematical optimization is used when we try to optimize a characteristic of a process under a given set of conditions. Optimization is that part of mathematics where we find the best solution. To build the model the problem must be expressed in mathematical relationships. After the model is built, it is solved to get a good solution of the problem. Thus optimization is generally used for structured problems. The problem at hand involves many variables and the interactions among them. So modeling such a system with this tool will be complex and time consuming. Such a approach is good only when the model is simple. There will be simple formulas to answer the questions and can be evaluated numerically. In most of the cases, people study models that are complicated thus valid models for them are also complicated. An exact mathematical solution to the problem may not exist.

Knowledge-based systems or expert systems attempt to model or mimic human reasoning (artificial intelligence). The idea behind the development of expert system is to conserve and transfer knowledge from an expert. So, it involves extracting relevant knowledge from the human expert and then the design of rules with the help of computing software which can be used to solve the problem. For the problem faced in the steel industry, in-depth knowledge of the system is not available. And again due to the dynamic nature of the problem, it is not well structured. Thus application of an expert system is not possible in this case.

The main goal here is to integrate all the system components, link them, so that they react to the dynamic fluctuations simultaneously so as to optimize the fuel used and be energy efficient. Dynamic simulation can be used in this case as it accounts for process transients, from initial state to final state. Secondly, simulation is easier to apply than the mathematical methods and also easier to explain to management. Thus the goal of understanding the process and trying to integrate the equipment can be achieved with dynamic simulations. The simulation model, which will mimic the existing situation, can be used to develop new operating strategies and for optimization of fuel and steam management. This simulation model will also help in understanding the energy supply chain. With the help of this model, the collected data can be put to proper use and used to develop knowledge about the system and make it energy efficient. 
Without this simulation model it will be very difficult to analyze the system, as for any change it is required to experiment with the actual system. This can be very costly. Also analytical analysis on the variables involved is difficult due to the high interdependency between them. This model will help analyzing the system without disturbing or destroying it and predict its performance for any change.

\subsection{Computer simulation}

Computer simulation refers to methods for studying a wide variety of models of real-world systems by numerical evaluation using software designed to imitate the system's operation or characteristics, often over time. Practically, simulation is the process of designing and creating a computer model of a real or proposed system for the purpose of conducting numerical experiments to give us better understanding of the behavior of that system for a given set of conditions. Simulation models can be used to model quite complex systems and thus are often the choice for modeling [25].

\subsubsection{Different types of simulations}

1. Static vs. Dynamic: time is an important element in the dynamic model while it doesn't play an important role in the static simulations.

2. Continuous vs. Discrete: in case of continuous simulation the state of the system can change continuously over time. But in case of discrete simulation the change can occur only at separated points in time. You can combine the elements of both in the model to form mixed-models.

3. Deterministic vs. Stochastic: for deterministic there is no random input on the other hand stochastic models have random input. A model can have variables that are both deterministic and stochastic.

\subsubsection{Advantages of simulation}

1. Inferences can be drawn about the system without building, disturbing or destroying it.

2. Simulation can be used to design and calibrate a system or for performance determination. 
3. Once constructed, the model can be used to analyze different situations.

4. This model can also be used in cases where input parameters are not very clear or are unknown.

5. Results are much cheaper to obtain than experimenting with the actual system.

6. Easier to apply than analytical (mathematical) methods.

7. Easy to explain to management.

\subsubsection{Disadvantages of simulation}

1. It may hide some critical assumptions.

2. Simulation is not precise. Degree of imprecision cannot be measured.

3. Simulation can be subject to misuse.

4. Complex systems will lead to complex models.

\subsection{General simulation procedure}

Simulation results from the perception that it can help resolve one or more issues associated with the design of a new system or the modification of an existing system. There are no strict rules for developing a simulation model, but the general recommended guidelines are presented below. This is an iterative process in which each step may not be complete before moving to the next step. The advantage of adapting to this procedure is to ensure that the project is conducted in an organized and timely fashion.

\subsubsection{Plan the study}

In planning the study, we have to define our objectives as to which are the variables of study, the relationship between the variables, what the sensitivity analyses are and what sort of decision making is required. Here we also identify the constraints that are to be considered for the model. Also, the level of detail, degree of accuracy and the form of the results may be planned. Thus, this step identifies the scope of the study and gives us the purpose and the intended use of the model. 


\subsubsection{Define the system}

With a proper plan, this step will define a conceptual model on which the simulation model will be based. The work of gathering and validating the system information is carried out here. Several factors must be considered while gathering the data. For example identify the cause-and-effect relationship or the conditions under which the data is collected, or deciding for the key important factors, etc. determine the data requirements from appropriate sources and convert this data in useful form for the use by the model.

\subsubsection{Building the model}

Once the data is collected, model building can be started. The goal here is the valid representation of the system and also to provide a statistical or graphical representation needed to satisfy the objectives. This is a progressive step in which detail is added to the model in stages rather than all at once. Similarly, complexity is also added in stages.

\section{Verification}

Once it is defined using the software tool, the model is checked for its correctness. This process of demonstrating that a model works as intended is referred as verification.

\section{Validation}

Another check is how closely the model the model reflects the system definition. The process of determining how closely the model corresponds to the real system is referred to as validation.

\subsubsection{Conducting experiments}

The next step is conducting experiments. Here the designer sets some hypothesis and tests it through simulation. Based upon the results of the simulation the designer draws conclusions for the set hypothesis. The model can be run with different scenarios and the results can be observed for analysis. This can be also used for comparing alternative decisions or for investment analysis. 


\subsubsection{Analyzing the output}

This concerns drawing inferences about the actual system based on the simulation output. The simulation output never identifies the problems, but reports the symptomatic behavior of problems. Extreme caution must be taken when interpreting the simulation results.

\subsubsection{Reporting the results}

This is the last step where recommendations are made for the improvement in the actual system based on the results of the simulated model. Animation and output charts are extremely useful aids for communication.

\subsection{Research Objectives}

A large amount of data is collected in industries for performance monitoring or for generating a database. This raw data must be converted into meaningful information and must be presented in a proper format to generate knowledge about the system. This information and knowledge will help the companies to analyze their systems and investment decisions as well as carry out sensitivity analyses for the system. The objective of this research is to convert such raw data into knowledge. The aim of this research is to design and develop a model for the utility energy supply chain in the steel industry with the help of collected data, validate the model, perform some first-level evaluations of different control strategies and evaluate the usefulness of the model in making control and operating strategy decisions. The specific objectives of this research are listed as follows:

1. Gather data from appropriate sources and convert data into useful form for the use by a simulation model.

2. Design and develop a simulation model that is a valid representation of the system and provide graphical representation of the results.

3. Verify and validate the model.

4. Execute the model using varying inputs and analyze the output to develop an operating procedure for the system so as to reduce the loss of energy. 


\section{Chapter 2 \\ Literature Review}

\subsection{Energy conservation measures in steel industry}

The US steel industry has reduced its energy consumption over the past few decades. The historical perspective of the energy use in steel industry and how energy consumption was reduced is discussed by Stubbles [1]. It compares average energy consumption figures with good practices. It projects new technologies and further restructuring of the industry to reduce the energy consumption per ton and estimates potential energy savings. The report also estimates the energy consumption in terms of carbon equivalent and carbon dioxide emissions. The report gives a good insight of the energy use and potential energy savings in steel industry.

The actual energies that are consumed in practice for producing liquid steel form scrap and ore are larger than the theoretical minimum energies required to produce it. Fruehan, Fortini, Paxton, Brindle [2] present the absolute minimum energy to produce steel from ore and mixtures of scrap. This gives an insight in to the differences in the theoretical and actual energy consumptions and the factors causing the increase in the energy consumption. The energy consumption is also calculated in terms of carbon equivalent. The study does not focus on actual energy consumed but just compares the industry averages with the theoretical minimum.

Most of the iron production in United States is done by smelting iron ore in the Blast Furnaces. The problem with blast furnace iron making is that the furnaces are relatively small as compared to the new ones and thus inefficient. Also, the availability of high grade metallurgical coke is dropping. Thus the iron making is becoming costly. A summary report prepared by Lockwood Greene Technologies [3], is aimed at evaluating alternate iron making process is carried out. An approach for evaluating the processes was designed so as to have a relative comparison of energy consumptions for each process and find out those alternatives which were lowest in cost and environmentally friendly.

The US Department of Energy's (DOE), Office of Industrial Technologies (OIT) also has a "Best Practices" program that works with industries to identify plant-wide 
energy conservation opportunities and efficiency improvements. Some of these case studies have shown good energy savings in the steel industry. Few of the "Best Practices" projects are mentioned below.

A project carried out at a steel mill for improving the steam turbine performance [4] shows that by rebuilding the turbine to incorporate the latest steam path technology and using warmer water instead of cold water for boilers feed water make-up the company significantly increased the capacity and the efficiency of the steam turbine system. The project resulted in large annual savings in terms of electricity and natural gas.

An "Energy Optimization Business Team" is formed at a steel plant [5], which identifies and implements projects that save energy and thus improve performance of plant operation. This energy team has implemented a variety of projects for energy savings in areas such as pilots for boilers, insulating steam lines, repairing steam leaks and repairing leaks in compressed air system.

Steelmaking is an energy intensive process. To reduce the high energy costs a large integrated steel plant carried out a project to replace the plants old utility equipment with modern computer controlled system from a central control center. The project focused on upgrading the control system and instrumentation for the utility system [6]. Thus instead of controlling from different locations a central control center was designed which gathered all the information and helped in making optimal decisions with the changes in energy demand patterns. The modernization of controls and central monitoring facility resulted in large energy and cost savings. The project represents the application of new technology by the management and the ability to reduce the energy [7].

\subsection{Mathematical programming applications in integrated steel plants}

Integrated steel manufacturing is a complex process. Mathematical programming techniques were used in this industry from a long time. There are a number of variables which interact with each other thus decision making is crucial in this case. Thus mathematical programming applications are found in areas of production planning, scheduling, inventory planning, etc. 


\subsubsection{National steel planning models}

A model for analyzing the steel production for United States is presented by Tsao, and Day [8]. Here a process model is developed for national planning of steel production. Using the engineering and metallurgical information a technology matrix is developed, which represents the technology structure. A linear programming model is then developed using this technology matrix, detailed costs and the sales and revenue Figures. The model estimates of intermediate production and input utilization are compared with the industrial statistics for each year from 1955 to 1968. The model gives fairly good results, but has an error in the coking coal production. A correction of this error is presented by Nelson [9].

Anandalingam [10] addresses the issues of investments in environments where the demand is uncertain by defining a stochastic programming process model. The model also considers uncertainty in technology. To incorporate the parameters and the demand uncertainty, the usual process model is extended by modeling it as stochastic linear program. The model is used for strategic planning rather than operational planning and is applied to steel planning in India.

\subsubsection{Product-mix optimization models}

Determining optimal production level in an integrated steel plant is of prime importance as the profit is not only sensitive to total volume of production but also the product mix. This optimum product mix changes from month to month and is dependent on the mill, furnace availability and the demand. Suboptimal solutions can be developed by experience but do not achieve the level of profit. Thus mathematical programming has a number of applications in this area.

A cost minimization linear programming model was developed by Fabian [11, 12], in which the blast furnace production process is expressed as a set of constraints of a linear programming model. The model optimizes the cost by changing the input selection. The model has four sub-models; one for iron making, one for steel making and one each for rolling and finishing. All the models are then combined to form a master model of 
integrated steel plant. All the technological constraints are considered including the capacity balance, material balance, thermal energy balance, etc.

A large scale database model was developed by Fourer with support of American Iron and Steel institute [13]. As this project was not related to any specific company the model developed is a generic model and any steel company could use it by using its own data. The users will only enter and maintain the data with reporting of optimal results. An associated linear program is automatically generated and is solved to obtain the results. As the model is generic it can be also applied to similar industries like coal mining and oil refineries.

\subsubsection{Mathematical models for energy in integrated steel plants}

The efficient use of energy in iron and steel plants is important as it contributes to $20 \%$ of the total operational cost for the plant. Mathematical models have been developed to have an energy efficient operation.

In case of steel plants, some of the processes require a fixed amount of power and this cannot be switched off even in case of a power crisis. So optimal allocation of electrical energy is important for a steel plant. A mathematical model for optimal allocation of the electrical power was developed and implemented in a steel company in India by Sinha, Chandrasekaran, Mitter, Dutta, Singh, Roy, Choudhury, and Roy, P. [14]. A mixed integer linear programming model has been developed which has a profit maximization objective, with energy as a limiting constraint. The model considers marketing constraints, capacities, yield, profitability, routes, energy and oxygen balances. It models an integrated steel plant with blast furnaces, steel melting shops, and primary and finishing mills. The model considers optimal allocation of capacities, optimal allocation of available power and material flow.

In the iron and the steel manufacturing process a lot of by-product gases are generated and they are used as an energy source. Thus these energy sources are free and do not pay additional cost for purchasing them. But because of unbalance between the generation and the consumption of the by-product gases, at time scale, temporal excess of shortage of the gases happen. Not much research work has been reported on optimization of these by-product gas supply and distribution. A mathematical model is formulated by 
Jeong, Heui-Seok and Chonghun [15] in which the objective is to minimize the total cost over the planning horizon subject to constraints for using the by-products gases over the purchased fuels. Other constraints are the material balance, the time varying relationship between the generation and the consumption of the byproduct gases, minimum input, energy balance, etc. The cost consists of the fuel cost, various penalty costs and the steam generation benefit.

An optimal energy distribution control method for steel works is proposed by Fukuda, Makino, Suzuki, and Ishida, [16]. Energy demand forecasting and optimization approach is used. ARMAX (Auto Regressive Moving Average and Exogenous variable) is used for the forecasting of energy and gradient descent method is used for the optimization of energy.

\subsubsection{Other areas where mathematical programming is used in a steel industry}

Different models have been constructed such as blending models which are basically a cost minimizing models with the thermo chemical metallurgical process in the blast furnace, coke ovens iron and steel foundries are expressed as linear constraints for the problem. The solution indicates a minimum cost related input materials.

Similarly mathematical models have been developed for scheduling, inventory and distribution models. Models for optimal ingot sizes, assignment of semi-finished slabs to order, cutting stock optimization models have also been developed. Dutta and Fourer [17], summarize published applications in large steel plants have a record for all the above mentioned models.

\subsection{Simulation approach for developing models}

A process model of iron and steel industry was developed by Anandalingam [18] and has a particular focus on energy use and conservation possibilities. Monte-Carlo simulation is used where the model parameters are assumed to be stochastic and distributed normally. It considers steel manufacturing with variables and parameters as coal input, iron ore fines, electricity, heat, sinter, etc. It has random variable inputs with known probability distribution. The analysis is carried out by estimating numerically the 
probability distribution of the output variables of process model. The process model is made for Indian iron and steel industry.

Another process model used to study the energy use and conservation in the steel industry in India is developed by Anandalingam and Bhattacharya [19]. It simulates the production process by policy simulation. The production process is modeled by a set of interconnected process activities, each of which defines unique relationships between process output and a number of inputs. It analyzes the impact of energy and material use of a combination of different technologies and evaluates the production cost of each technology.

\subsection{Utility system management and operational optimization}

For many industrial companies the energy and the utilities cost represent a large portion of their operating costs. Thus large companies are now focusing on reducing the energy cost. Also, optimal operation of site utility systems is becoming an important part of any successful business strategy.

An overview of utility system optimization and management is discussed by Dhole, Seillier, Garza [20] from Aspen Utilities. Aspen Utilities is a single tool that allows economic integration of all business processes associated with purchasing, supply and the use of the utilities. The software has a non-linear mixed integer linear optimization capability. The paper discusses the capabilities and the aspects that are supported by Aspen Utilities software. The software is capable of forecasting, production planning, optimization, performance monitoring and investment planning.

A structured approach for steam system improvement is discussed by Eastwood [21]. The reasons and benefits of building a steam system model are presented here. It gives a spreadsheet based system models with a built-in physical properties database, which helps in reducing the operating costs of steam generation and distribution. Two types of models are considered; planning model and optimizer. The planning model evaluates the projects, what if scenarios, while the optimizer automatically switches the equipment on or off to arrive at an optimum.

CHP (Combined Heat and Power) is a term used to describe energy utilities generation and distribution systems in industrial plants. It is all inclusive of - boilers, fire 
heaters, steam turbines, gas turbines, expanders etc. To understand the interactions between them, a simulation model of CHP is useful. The development of such CHP model using electronic spread sheet an illustration of its application using a detailed example is given by Kumana [22]. Thus the CHP models can be one of the tools for energy and cost accounting and improving energy efficiency.

\subsection{Conclusion}

The above literature gives an idea about the work carried out in the area of energy conservation in steel industry and the measures taken towards reducing the energy cost and optimizing the utility resources in steel industry. It can be seen that a lot of research has been carried out in the area of energy conservation in the steel manufacturing process. New technology and use of mathematical models for optimization has helped the iron and steel manufacturing process to be energy efficient. Similarly, various steps have been taken to optimize the utility energy usage. Simulation in this area is restricted to use of mathematical models and spreadsheet. Higher level simulation software is rarely used. No literature was found on the use of simulation as a tool for analyzing and enhancing the utility energy supply chain for steel industry. The higher level simulation software operates by intuitive graphical user interfaces, menu and dialogues. The model is run with a dynamic graphical animation of system components as they move around and change. The advantage of using such software is that, we can get a better understanding of the system in whole without building, disturbing or destroying it. Also, these are easier to explain to the management as well as easier to apply then mathematical models. Such models can then be used for sensitivity analysis, investment decisions and measuring the performance of the system. Thus research in this area will be of immense help to the steel industry for analyzing and improving on their energy efficiency. 


\section{Chapter 3 \\ Research Approach}

\subsection{Steam Distribution Diagram}

Integrated Steel industries generate many by-products while producing steel. They generate blast furnace gas and waste heat as by-products during steel production. They have a co-generation plant, which uses the produced blast furnace gas for production of steam. This high pressure steam is used for the following purposes

1. Direct work generation in blast furnace turbo blowers and boiler auxiliary systems.

2. Electric generation in turbines

3. Conversion to distribution pressure steam in a throttling/desuperheater station.

The data was collected from an integrated steel plant. The data collection and corresponding analysis gives a better understanding of the process as well as the current operating practice of the plant.

The system distribution diagram is shown in the Figure 3.1. Most of the steam is distributed at 200 psig to the Users. This steam comes from several sources. The majority of the steam is produced by the high pressure boilers as shown in the diagram. There are five boilers and they produce steam at about 800 psig and $820^{\circ} \mathrm{F}$. Boilers \#3, \#4 and \#5 are located near the blast furnace. The units are water tube boilers made by Babcock and Wilcox $(B \& W)$. These are older boilers and they have a capacity of 300,000 lbs to $350,000 \mathrm{lbs}$ per hour of steam. These units can run on various fuels including fuel oil, natural gas, and blast furnace gas (BFG). The other two boilers (\#101 and \# 102) are new and are Foster-wheeler (FW) units. Each of these boilers can produce about 320,000 lbs per hour of high pressure steam. They can run on natural gas and blast furnace gas. All the boilers have a pilot which uses natural gas when burning BFG. Table 3.1 summarizes the boiler data. 


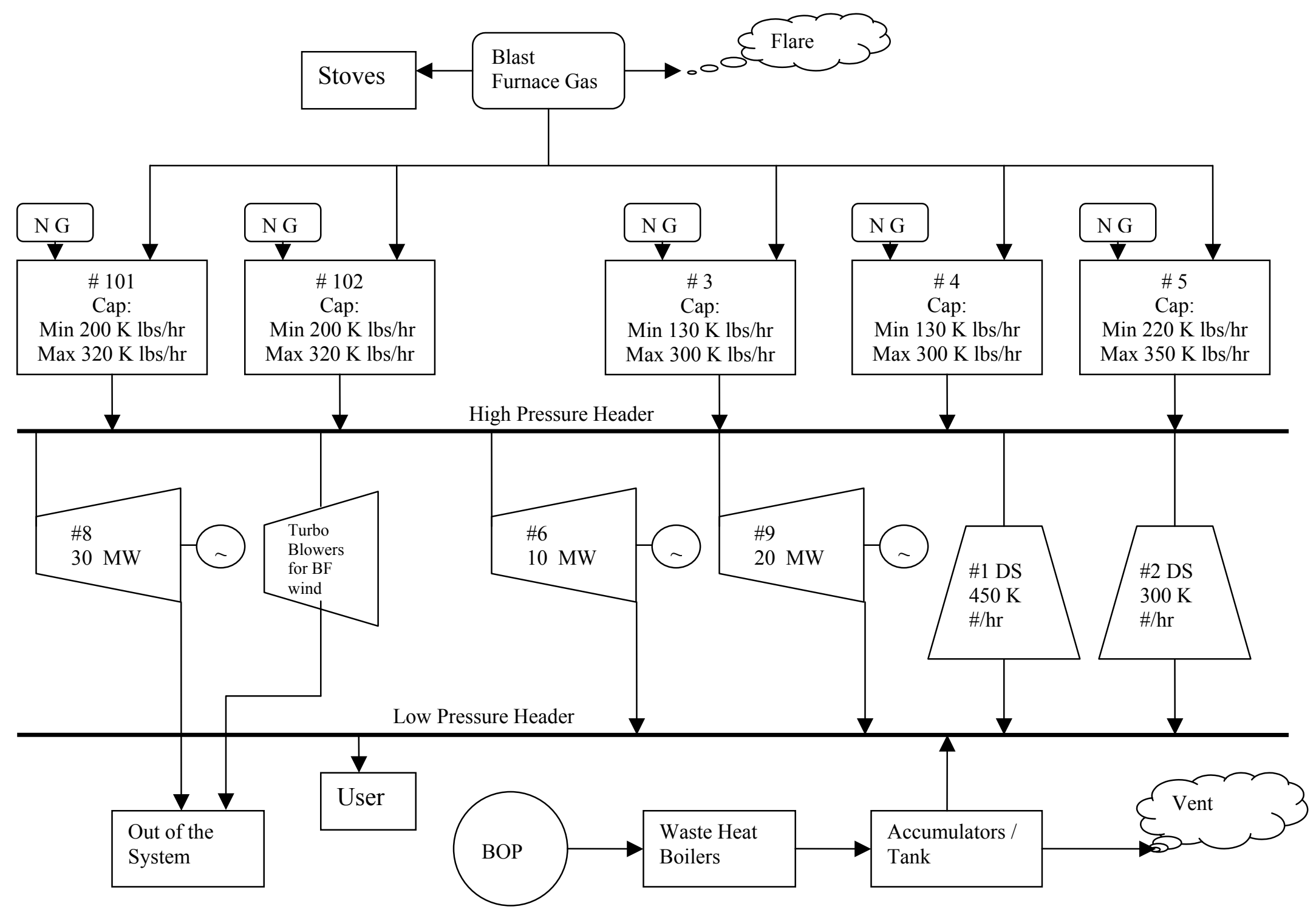

Figure 3.1: Steam system diagram 


\begin{tabular}{|c|c|c|c|}
\hline \multirow{2}{*}{ Boiler \# } & \multicolumn{2}{|c|}{ Capacity $(\mathrm{KPPH})$} & \multirow{2}{*}{$\begin{array}{c}\text { Efficiency } \\
(\%)\end{array}$} \\
\cline { 2 - 3 } & Minimum & Maximum & 68 \\
\hline 3 & 130 & 300 & 73 \\
\hline 4 & 130 & 300 & 72 \\
\hline 5 & 220 & 350 & 76 \\
\hline 101 & 200 & 320 & 80 \\
\hline 102 & 200 & 320 & \\
\hline
\end{tabular}

Table 3.1: Boiler Data

In addition to these boilers, there are waste heat boilers at the basic oxygen plant (BOP). These boilers produce steam from the waste heat released during the steel making process. Steam production at these boilers is cyclical and occurs for roughly half of the 45-minute BOP cycle. This can be seen from the Figure 3.2. This steam is fed to an accumulator at pressures ranging from 200 psig to 600 psig. The accumulator consists of two pipes 10 feet in diameter and 120 feet in length. From the accumulators, the steam is fed through a regulator at 200 psig to the low pressure header. This BOP steam accounts for $17 \%$ of the total distribution level steam consumption. This can be observed from Figure 3.3.

There are three turbines viz. \#8, \#6 and \#9. The maximum and minimum steam flow rates and their corresponding electric power outputs are shown in the Table 3.2. The \#8 turbine is used to relieve pressure from the high pressure header without charging more steam to the low pressure header and generating electricity in the process. The other two turbines are used to feed the low pressure header at $200 \mathrm{psig}$. The desuperheaters are used only in cases where the turbines \#6 and \#9 are insufficient to satisfy the demand at the low pressure header.

\begin{tabular}{|c|c|c|c|c|}
\hline \multirow{2}{*}{ Turbine } & \multicolumn{2}{|c|}{ Minimum } & \multicolumn{2}{c|}{ Maximum } \\
\cline { 2 - 5 } & Steam Flow & Generation & Steam Flow & Generation \\
\cline { 2 - 5 } & $(\mathrm{KPPH})$ & $(\mathrm{MW})$ & $(\mathrm{KPPH})$ & $(\mathrm{MW})$ \\
\hline 6 & 70 & 2.5 & $360-400$ & $12.2-12.6$ \\
\hline 8 & 25 & 2.5 & 300 & 28 \\
\hline 9 & 70 & 1.9 & $580-600$ & $18-19$ \\
\hline
\end{tabular}

Table 3.2: Turbine data 


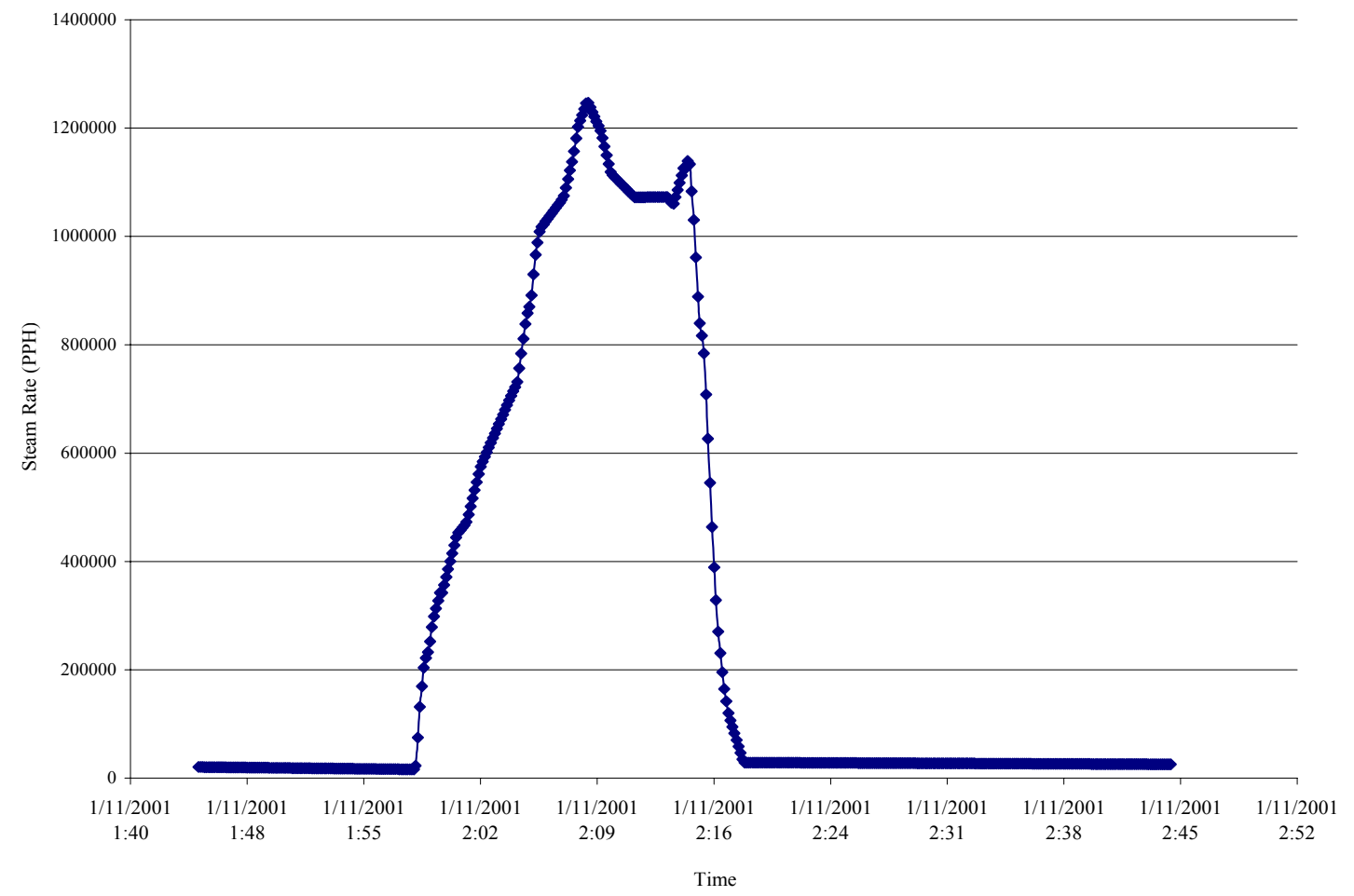

Figure 3.2: BOP steam cycle

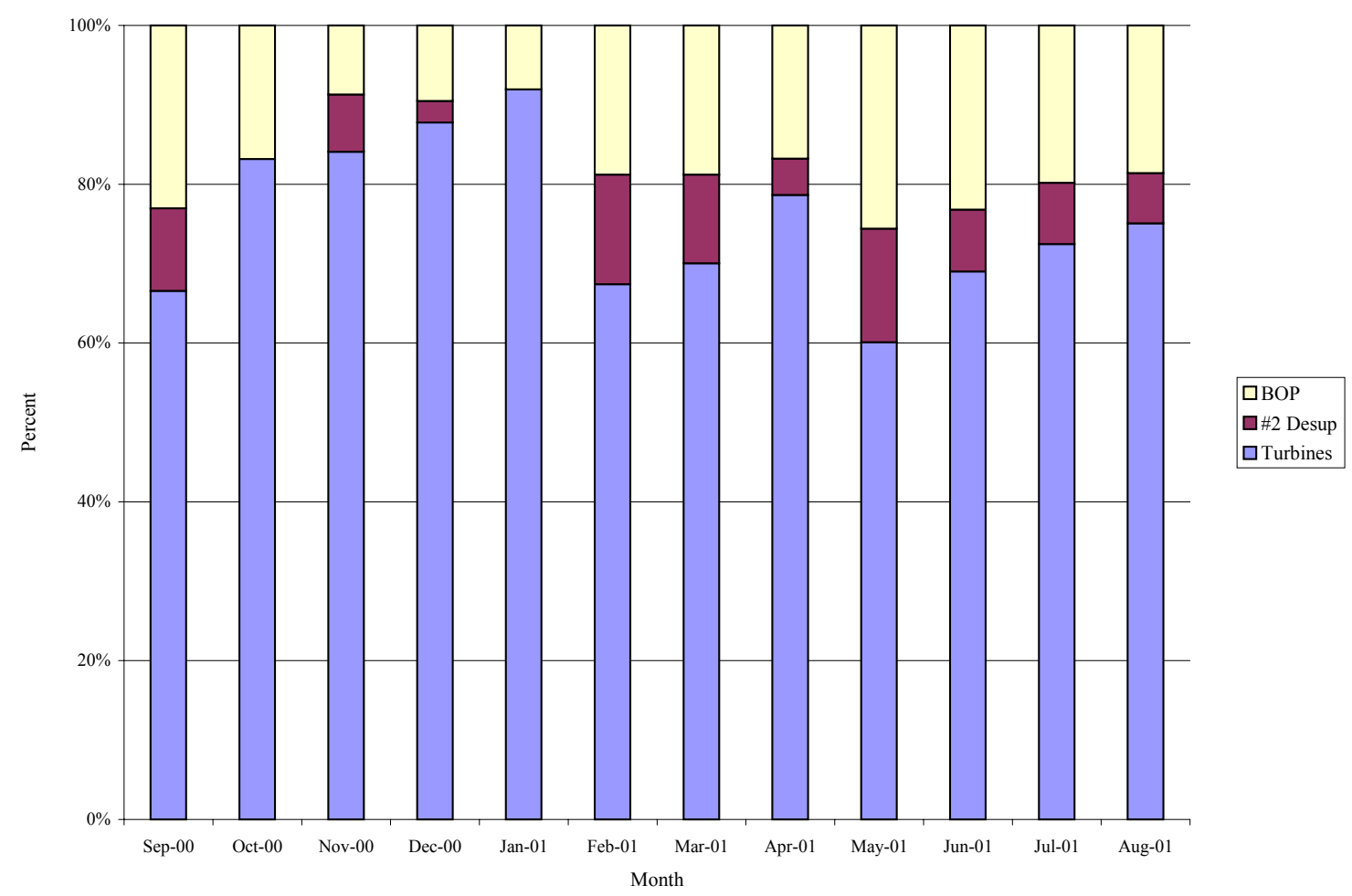

Figure 3.3: Percentage LP Steam Available through different sources 
The ramp rates for the boilers and the turbines are as in Table 3.3.

\begin{tabular}{|c|c|}
\hline & $\begin{array}{c}\text { Ramp rates from Min to } \\
\text { Max }\end{array}$ \\
\hline$\# 3$ and $\# 4$ & $2.5-5$ minutes \\
\hline$\# 5$ & $1.5-3$ minutes \\
\hline$\# 101$ and $\# 102$ & 2 minutes \\
\hline All turbines & $10-20$ seconds \\
\hline
\end{tabular}

Table 3.3: Ramp rates for boilers and turbines

\subsubsection{Fuel Use}

All the boilers can burn either blast furnace gas $(\mathrm{BFG})$ which is a free fuel (byproduct of producing iron) or purchased fuel (natural gas). The boilers have pilots which consume only natural gas. The pilots consume large amount of natural gas because they are really incinerators for the BFG, which doesn't burn well by itself. Presently the amount of steam required (user demand) is higher than what the boilers can produce with the available BFG. Thus the required deficit is filled by the use of natural gas. The consumption of BFG and natural gas is shown in Figure 3.4. It is desired to minimize the amount of purchased fuel used by the boilers. The monthly BFG use is shown in Figure 3.5. It is also observed that there are times when more BFG is produced than can be consumed by the boilers, thus the BFG must be flared. Most of the flaring occurs during the summer months, when the total demand is low, but even when the steam demand is high some BFG is flared. 


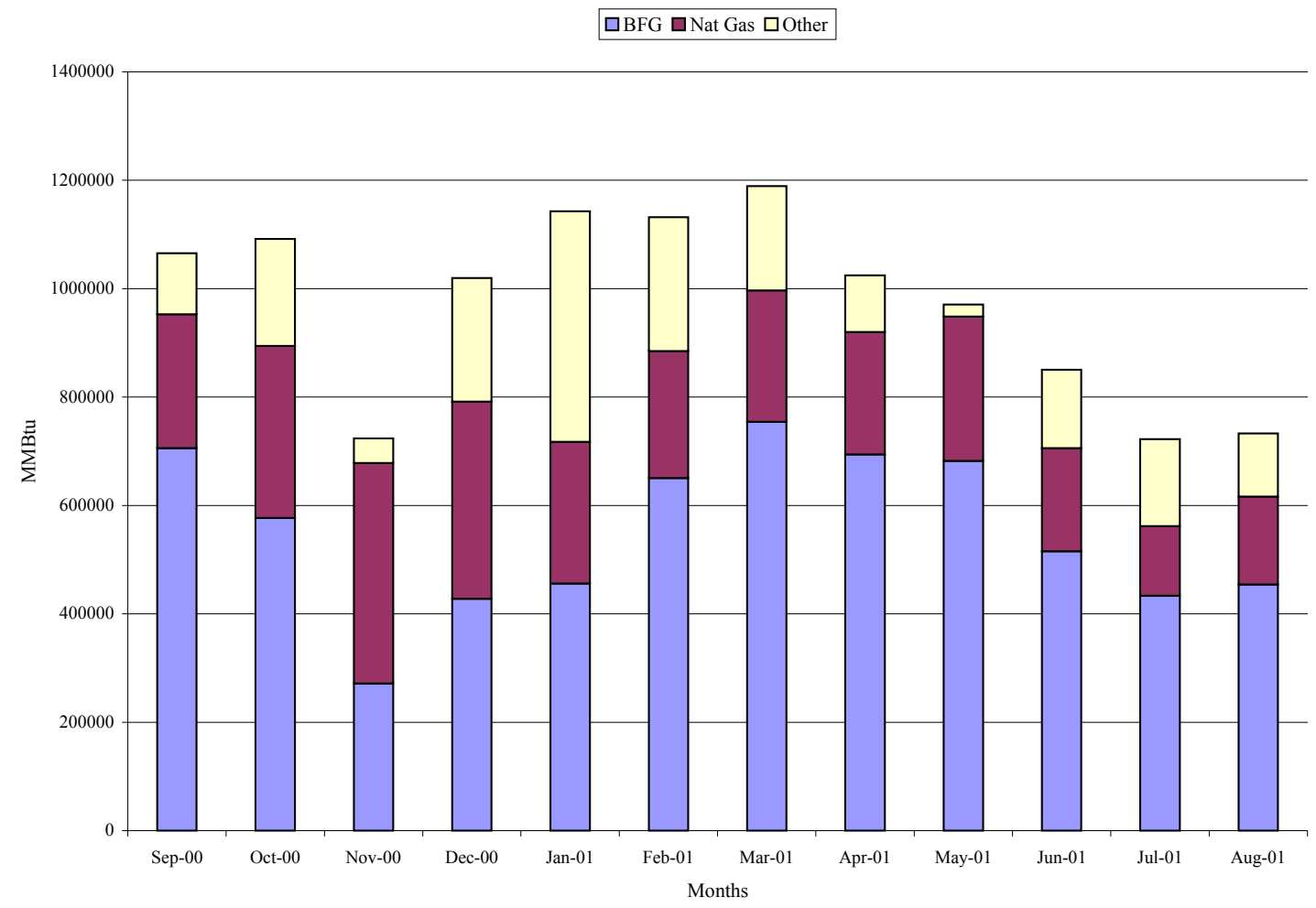

Figure 3.4: Boiler fuel use by month

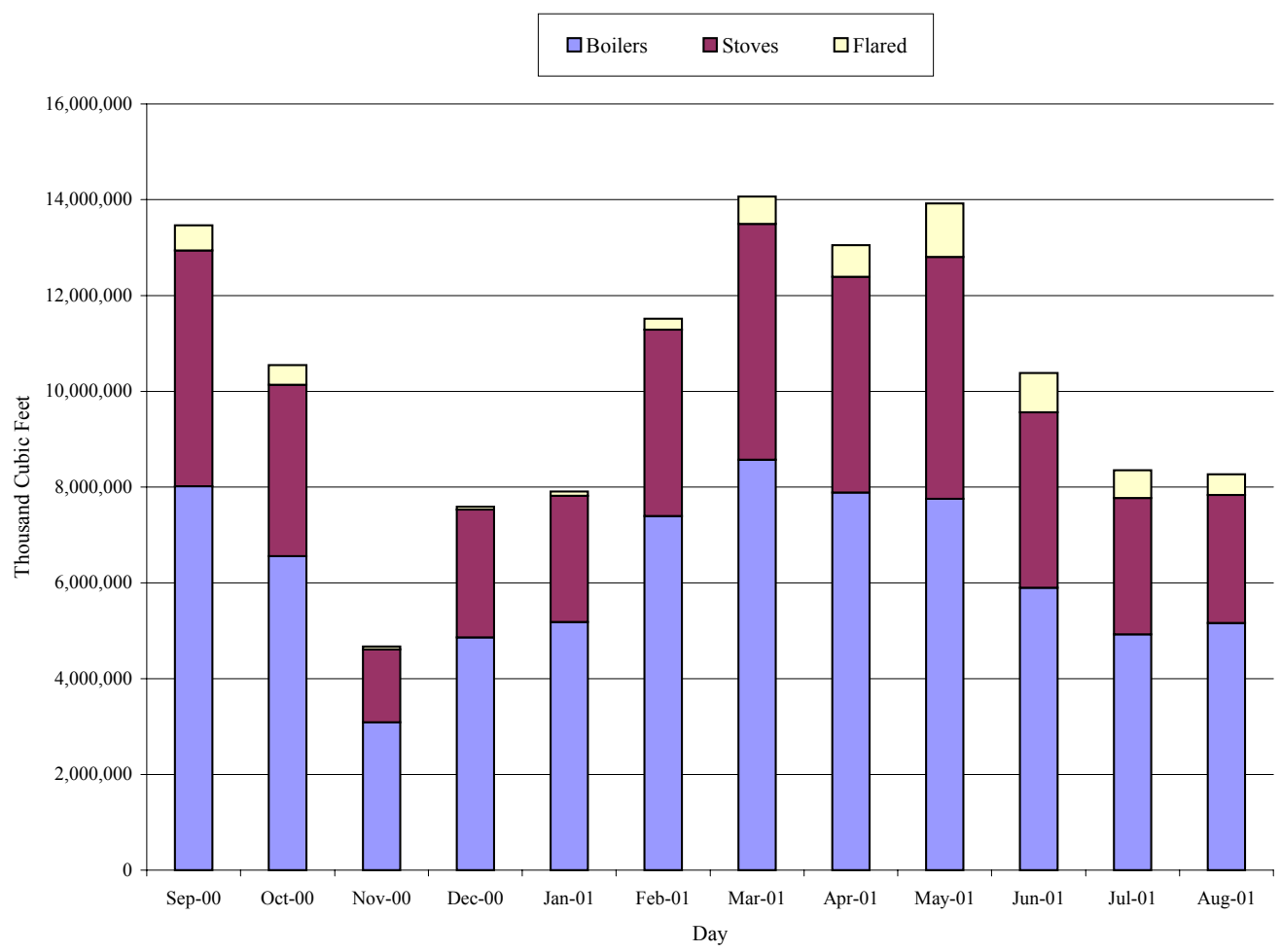

Figure 3.5: Monthly BFG use 


\subsubsection{Existing conditions}

The optimal management of the boilers and the steam distribution is difficult because of the interaction between the variables. The most important variable is the BOP steam production from the waste heat. Figure 3.6 shows the production of BOP steam in kilo-pounds per hour as a function of time (Drum Flow). The steam production is cyclical and it can be observed from the graph that within a span of 22 minutes the steam production goes from zero to well above 1,200,000 $\mathrm{lbs} / \mathrm{hr}$ and back to zero. The same cycle repeats itself after a span of about 23 minutes.

As stated earlier, the steam from the waste heat boilers is transferred to the accumulator. The accumulator is rated at 1000 psig. The steam is released to the low pressure header at 200 psig through a regulator. The steam flow from the accumulator is shown in the Figure 3.6 (Process Flow). The operating practice is that the accumulator is charged up to $600 \mathrm{psig}$ and the steam is vented to the atmosphere if the pressure increases above 600 psig. Some steam is vented periodically to prevent the overcharging of the accumulator. This can be observed from Figure 3.6 (Vented Steam). The amount of steam production is more than the capacity of the vent. Thus even though the venting starts at 600 psig the steam pressure builds up to about 800 psig in the accumulator.

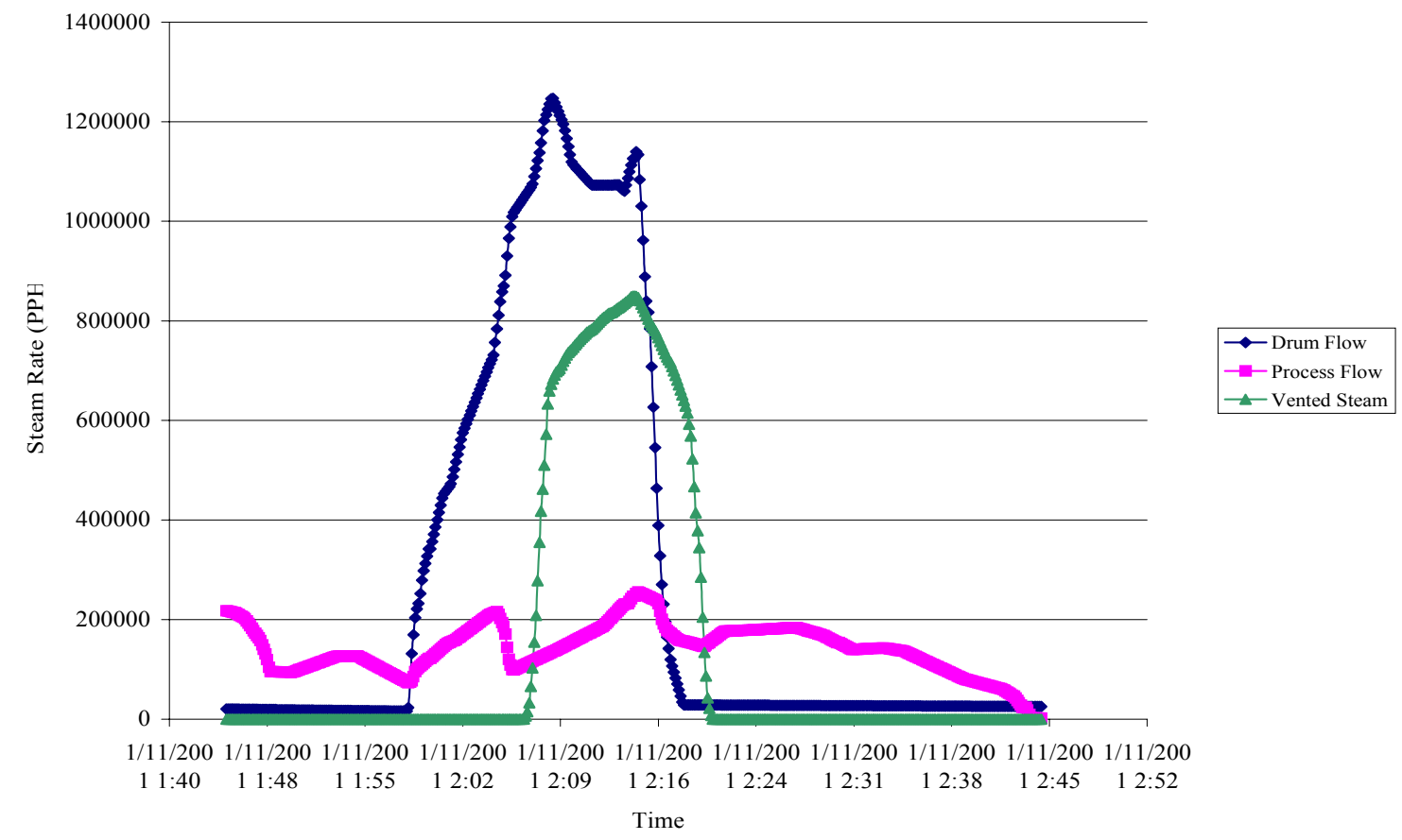

Figure 3.6: Steam flow rate 
As this steam flows into the low pressure header, the steam incoming from the boilers must be reduced. As the pressure in the low pressure header increases, the \#6 and \#9 turbines generators are backed down. The firing rates of the boilers are simultaneously reduced, but the steam production in the boilers cannot be reduced as fast as the steam flow rate through the turbines; this can be seen from the ramp rates of the boilers and turbines specified earlier. Thus the pressure in the high pressure header increases. The \#8 turbine generator acts as a relief valve. This turbine generator is ramped up pulling the excess steam from the high pressure header generating electricity in the process. This turbine takes the steam out of the system that is considered for analysis.

In cases where the steam demand is high and this demand cannot be satisfied by the \#6 and the \#9 turbine, the desuperheaters are used, which drop the steam pressure from the high pressure conditions to the low pressure conditions. There are several other small condensing turbines available to further smooth out the imbalances, which are not considered in the designed system.

This low pressure steam system serves many users scattered over the plant. Thus this system is also subjected to many load swings. The daily steam production from all the sources is as shown in Figure 3.7.

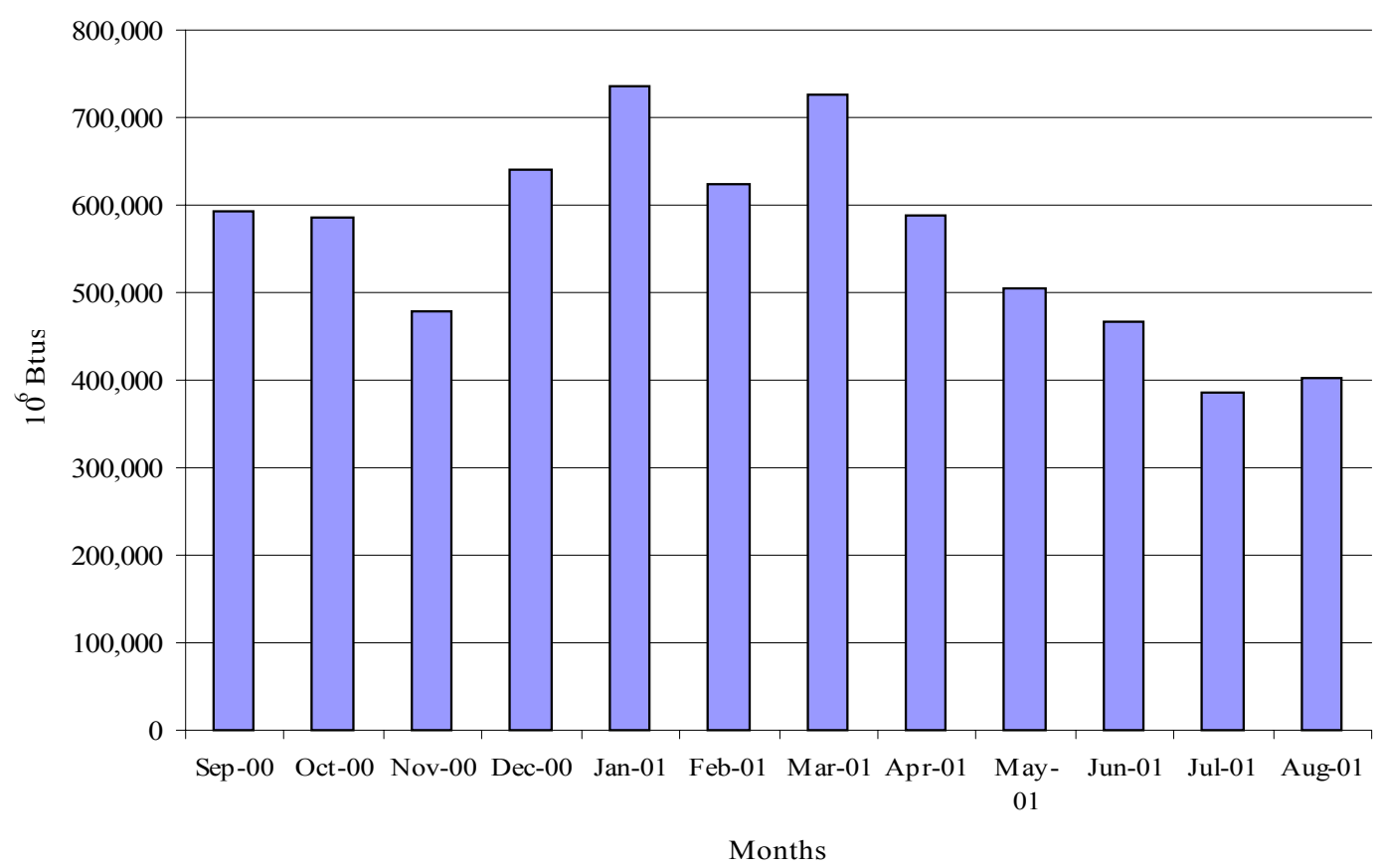

Figure 3.7: Low pressure steam generation 


\subsection{Simulation software}

A windows based simulation tool was used for developing the model. The simulation software has a "Build" menu with many modules in it. The models are created by completing the necessary build modules selected from this Build menu. Each module consists of various edit tables and dialogue boxes used to supply model information. Edit tables provide direct accesses to model data and consists of records, which consists of fields describing some aspect of the element. A layout window also appears with the graphical tools for placing the modules. A logic builder is also available which provides a quick and powerful way to create valid statements and expressions in logic fields.

Completed models are run using the "Simulation" menu. The model data is automatically checked for consistency and completeness before each simulation begins. The output generator for the software gathers statistics on each of the defined modules. These simulation results are presented in tabular format or graphic format, including histograms, pie charts, plots and bar graphs. Multiple output results can also be compared on the same charts.

\subsubsection{Model elements}

In building the model, we must define all of the basic modeling elements and a few of the optional ones. Different modeling elements of the software used are:

Locations: They represent fixed places in the system where the entities are routed for processing, storage, or some other activity or decision making. Locations are used to model elements like machines, waiting areas, work stations, queues, and conveyers.

Entities: Anything that the model processes is called an entity. Parts, products, people, paperwork should be modeled as entities. The movement of the entities triggers the model logic.

Arrivals: Anytime new entities are introduced in the system, it is called as arrival. An arrival record is defined by specifying number of entities per arrival, frequency of the arrival, location of their arrival, first time of their occurrence and total occurrences.

Processing: This defines the routing of the entities through the system and the operations that take place at each location they enter. Once the entities have entered the 
system, as defined in the arrivals, processing specifies everything that happens to them until they exit the system. It is this module where the model logic is defined.

Resource: This is a person, a piece of equipment, or some other device which is used for any of the following: transporting entities, assisting in performing operations on entities at locations, performing maintenance on entities or locations. Resources can be dynamic, i.e. they can move along a path.

Path Networks: When the resources are modeled as dynamic resources which travel between locations, they follow path networks. Entities moving by themselves between locations also move on a path network if referenced in the move logic of the routing (processing). Multiple entities and resources may share a common path network. The movement along the path network may be defined in terms of time or speed and distance. The path network can be passing or non-passing and consists of nodes connected by path segments. This segments can be unidirectional or bidirectional.

Variables: There two types of variables; global and local. Global variables are place holders defined by the users to represent changing numeric values. Local variables are available only within the logic in which they are defined, while global variables can be referenced anywhere where numeric expressions are allowed in the model. Variables can be either real numbers or integer values and are typically used for decision making or recording information.

To get a good understanding of the above modeling elements, we can relate the actual system element to these model elements. In relation to the model developed for the utility energy supply chain, the boilers, turbines, user, BFG gas generation, etc, are defined as locations as the entities are routed through them for changing the set variables. Steam, high pressure steam and low pressure steam, BFG gas, etc, are modeled as entities as these are the elements which trigger the logic. The user demand, the BFG, and the BOP steam generation are arrivals as these are the elements where new entities will be introduced in the model. Different path networks are defined so that these entities will move between locations, for example, between the boilers and the turbines. Variables are used for recording and observing the performance. For example, in the case of the steam pressure in the low pressure header, a variable is defined which increments or decrements 
as the process logic defined in processing. This incrementing or decrementing is triggered by the arrival of any entity in the location where this process logic is defined.

\subsection{Logic flow diagram of the model}

From the data collection and analysis, the whole system can be considered to be designed to supply low pressure steam to the users. The users are the Tin mill, Blooming mill, Strip Steel and Sheet mill, etc. They are the process steam end users. The whole system is a "User Driven System". For modeling purposes, this is considered as a "Pull System". The users will trigger the whole model.

As seen from the logic flow diagram, Figure 3.8, the cumulative User Demand is calculated and the required quantity is pulled from the low pressure header. This movement of steam from the low pressure header to the users will create a pressure drop in the low pressure header. The low pressure header is maintained at 200 psig, thus the turbines or the accumulator will send the steam to the header to maintain its pressure. This can be observed from the logic flow diagram; the model checks whether the steam pressure is below 200 psig. In case the pressure is below 200 psig the model calculates the amount of steam required, considered as "Error". Preference is given to the steam coming from the waste heat boilers (BOP steam). Thus the model checks the steam availability in accumulator. The steam arriving from the waste heat boiler is routed to the accumulator. The steam is then released to the low pressure header at $200 \mathrm{psig}$, if the steam in the accumulator is above a certain point, named here as the "charging point". This level is measured in terms of the quantity of steam in accumulator (KP). If the steam in accumulator is above the "charging point", which is input to the model, the steam from the accumulator is routed to the low pressure header. In the case when the steam is not available at the accumulator, the turbines are ramped up so as to pull the steam from the high pressure header.

If the "Error" is greater than the steam available in the accumulator, all the available steam is routed to the low pressure header. Again the model will calculate the "Error" and then this required steam will be supplied by ramping up the turbines, as it moves in the loop. 


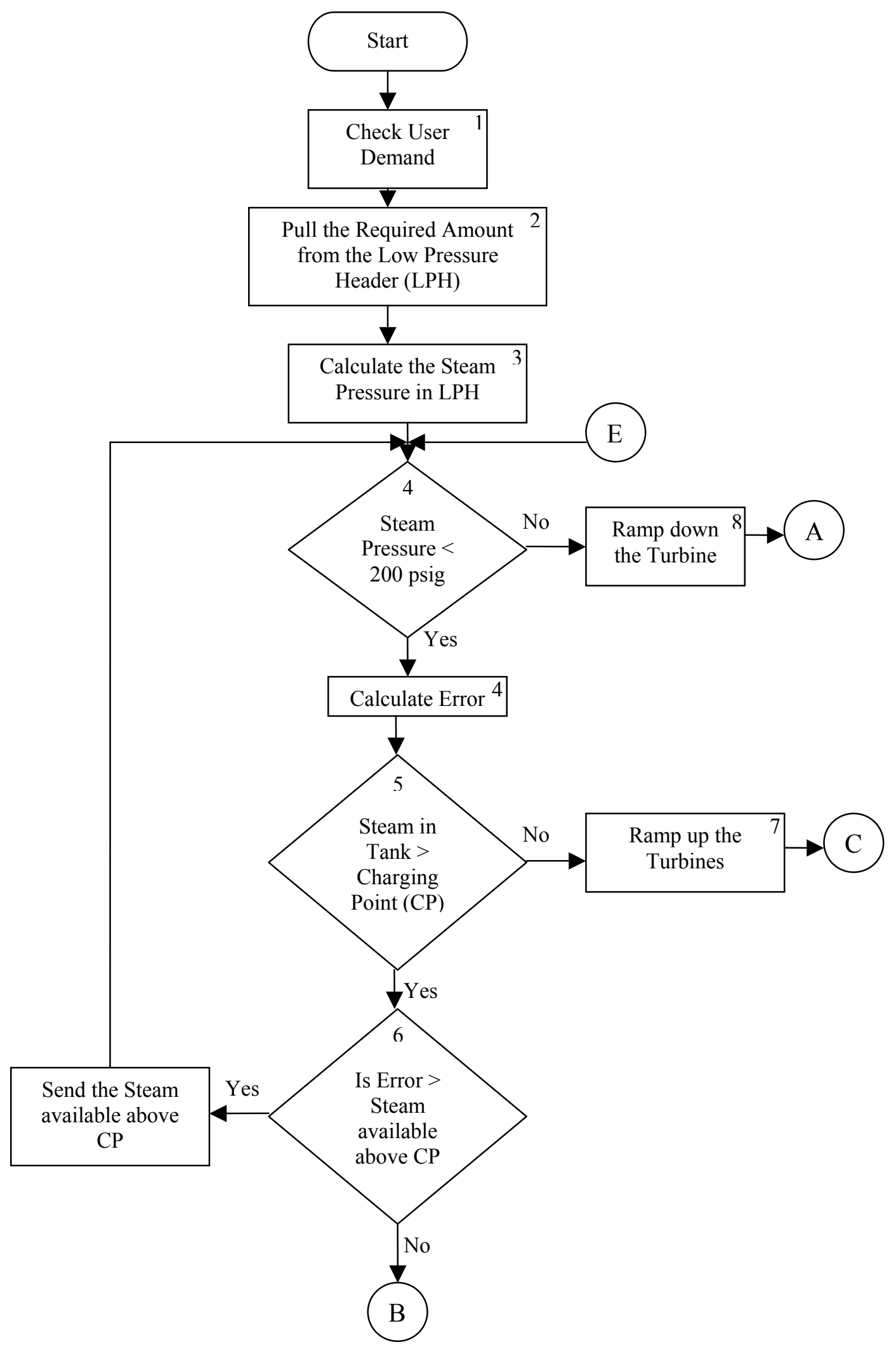

Figure 3.8: Logic Flow Diagram 


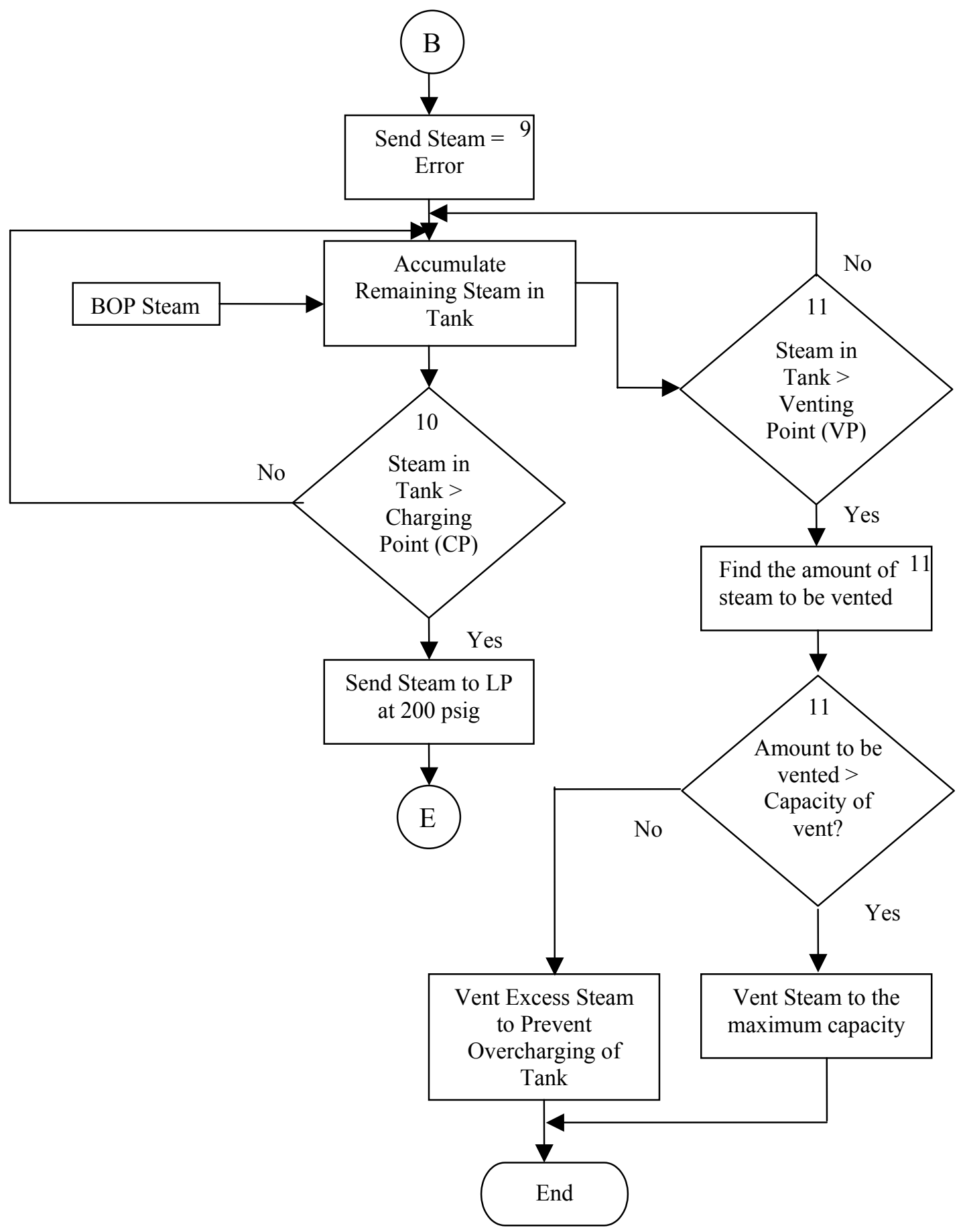

Figure 3.8: Logic Flow Diagram 


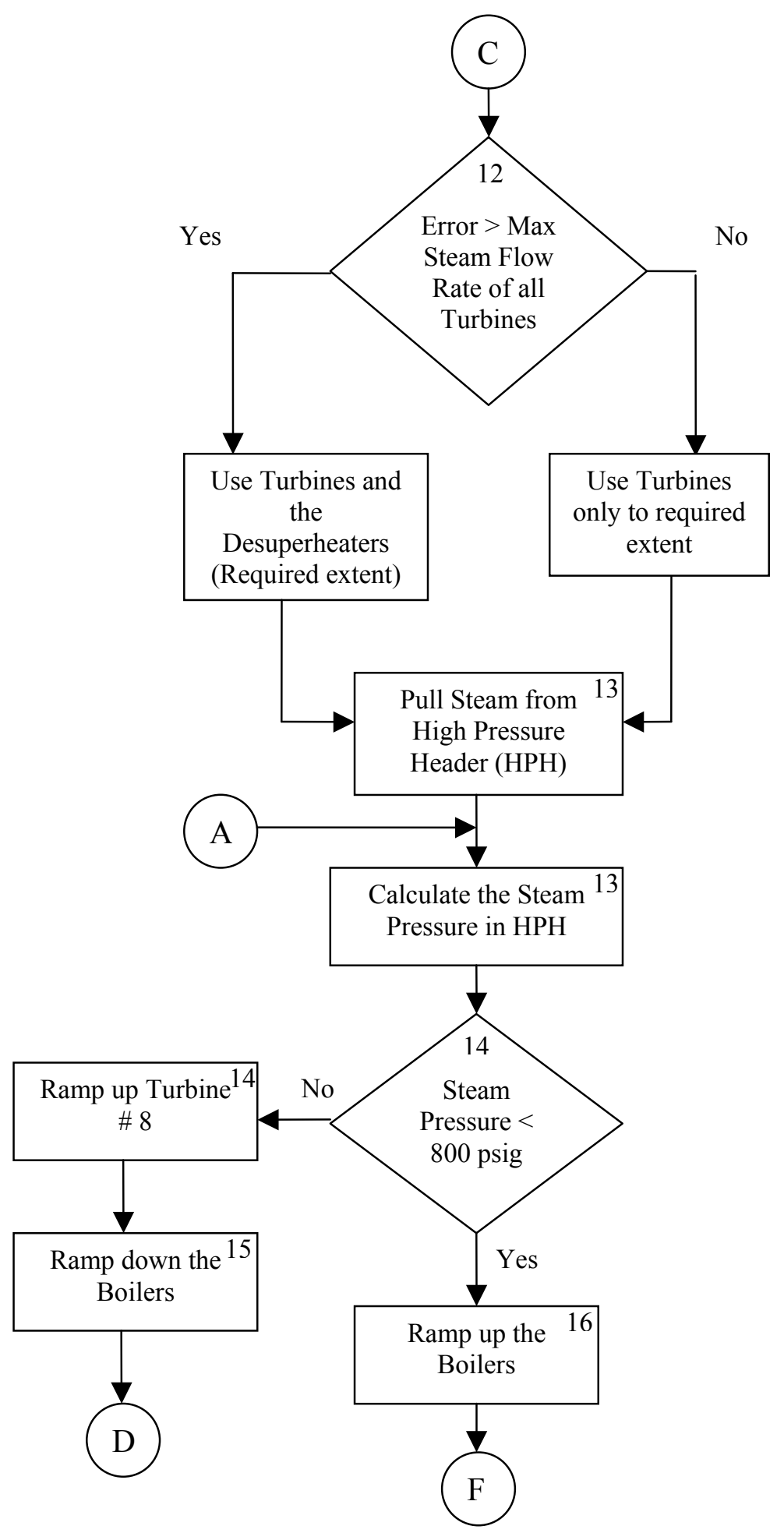

Figure 3.8: Logic Flow Diagram 


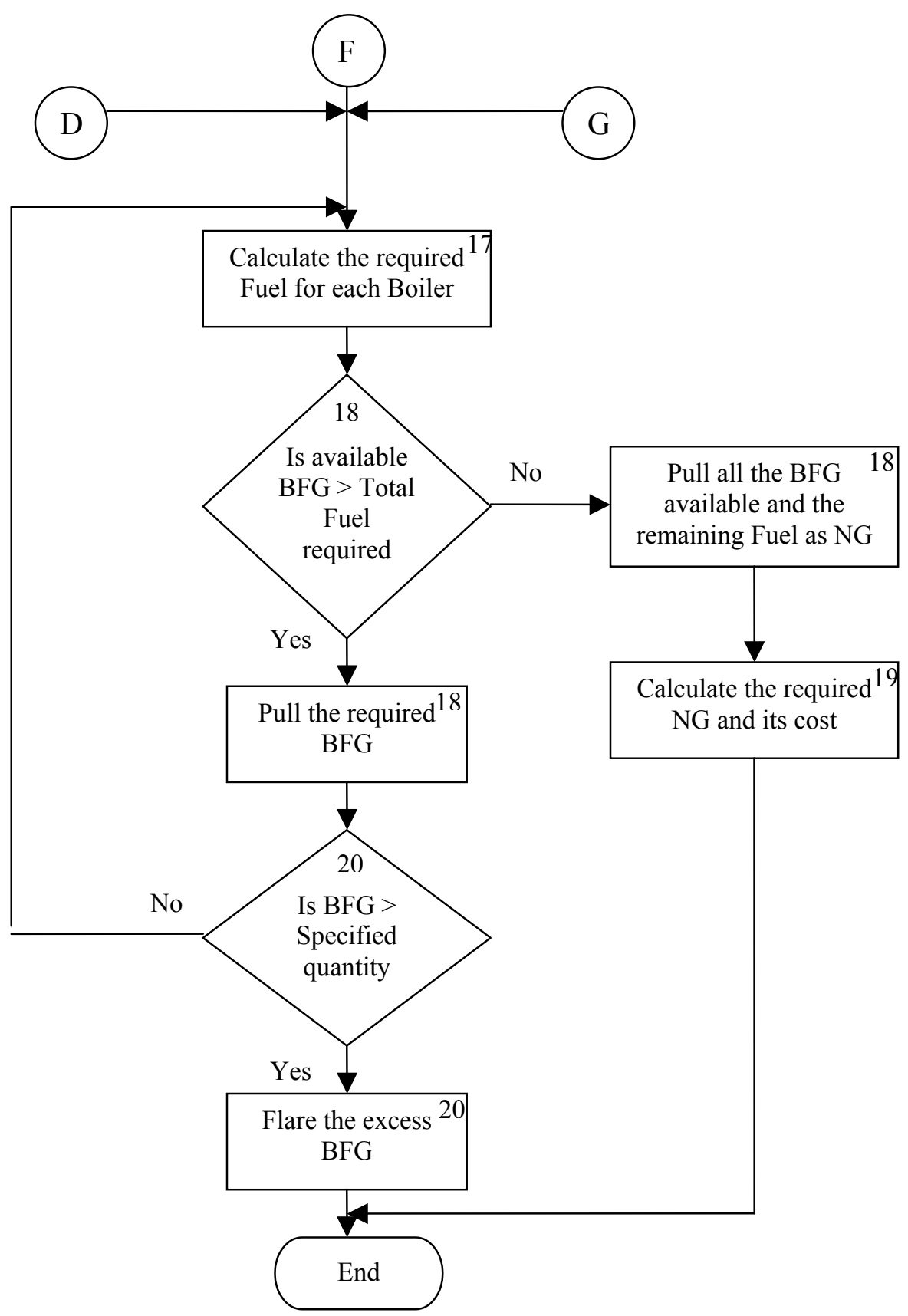

Figure 3.8: Logic Flow Diagram 


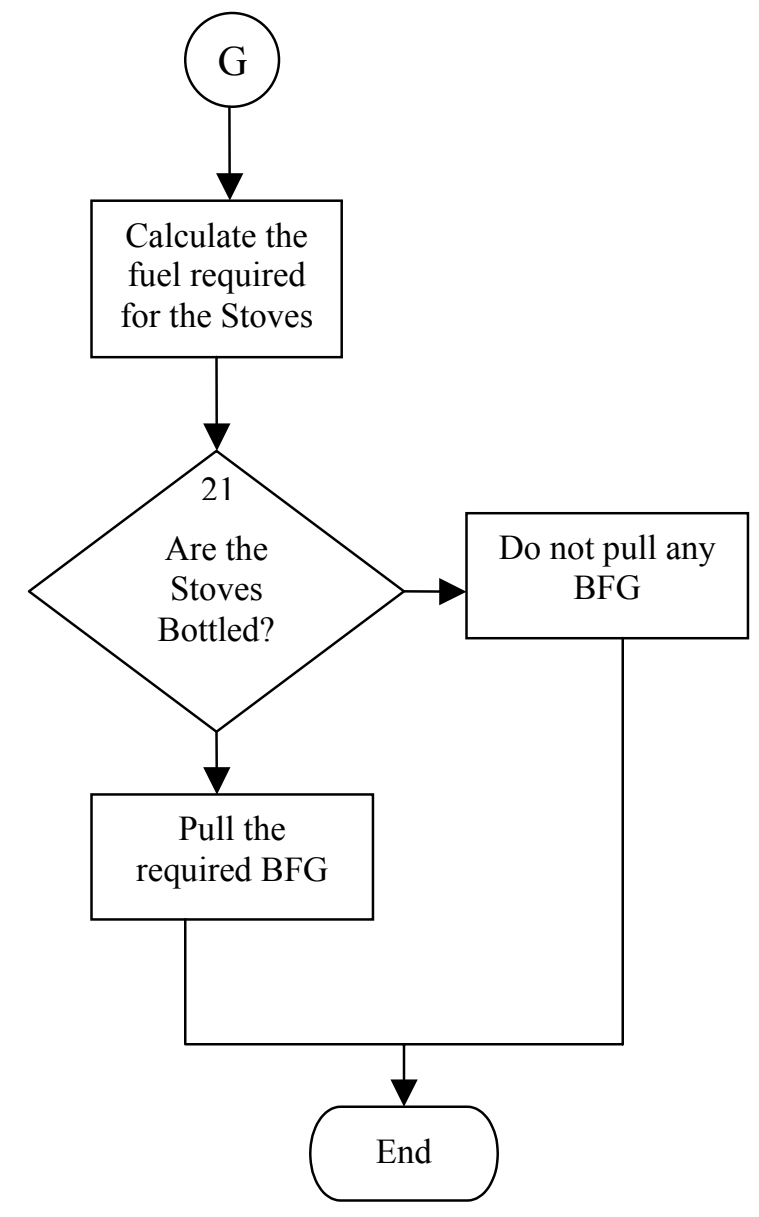

Figure 3.8: Logic Flow Diagram

Now if the "Error" is smaller than the available steam, only the required amount is routed to the header and the remaining is then accumulated in the accumulator. For the steam in the accumulator, two points are continuously checked, the "charging point" and the "venting point". As soon as the "charging point" is attained the steam is routed to the low pressure header at 200 psig and the model again checks the low pressure header pressure. In cases where the accumulator holds steam above the specified "venting point", it vents the low pressure steam to atmosphere. The BOP steam is directly routed to the accumulator as shown in the Figure 3.8.

Whenever the turbines are ramped up to supply the steam to the low pressure header, the model will check whether the "Error" is greater than what the turbines can supply. If it is greater, the desuperheaters will ramp up to supply the excess steam requirement. The turbines in turn will pull the steam from the high pressure header. As in 
the case of the low pressure header, the model will now calculate the steam pressure in the high pressure header. This high pressure header is maintained at 800 psig. If the steam pressure is less than the set limit of $800 \mathrm{psig}$, the boilers are ramped up, to produce more steam. In the case when the steam pressure is more than $800 \mathrm{psig}$, turbine $\# 8$ is ramped up pulling the excess steam form the high pressure header and putting it out of the system under consideration. Thus, turbine $\# 8$ acts as a pressure relief valve. At the same time when the turbine $\# 8$ is ramped up, the boilers are ramped down so that they put less steam in the high pressure header.

As the turbines ramp down sensing the steam pressure in the low pressure header, the model will calculate the pressure in the high pressure header, check against its set point. And it will react in the same fashion as said earlier.

For the level of the steam generation by the boiler the model calculates the Btu's required for firing at the required level. Due to the ramping up and down of the boilers the fuel requirement is dynamic. The model will continuously calculate the fuel requirement and check whether the available BFG can satisfy the requirement. While modeling, the total amount of fuel required by all the boilers is calculated and compared to the total available BFG. If the requirement is less than the available BFG, the required quantity is routed to the boilers. In cases where the requirement cannot be satisfied by the $\mathrm{BFG}$, natural gas is pulled by the boilers. A separate natural gas location is available for each boiler from which it will pull the required gas. The model will then calculate the total amount of natural gas required. The pilots for the boilers are continuously pulling the required amount of natural gas. When the available BFG is more than the requirement of the fuel, the BFG is flared.

The last part of the logic flow diagram shows the logic for bottling of stoves. The stoves continuously pull BFG. When they are bottled, all the valves of the stoves are closed, and thus the BFG is not consumed. The stoves thus do not pull any BFG if they are bottled. The times when the stoves can be bottled can be specified by the user. This in turn affects the available BFG for the boilers. With each of the process blocks and decision box, a number is associated. This number is used in the Appendix V where the calculations related to the process block or the decision box is shown. 


\subsection{Developing the Simulation Model}

The whole system is designed to supply low pressure steam to the user. Therefore, the user is an important factor in the system. We can consider this as a "User Driven System". The users will pull the required amount of steam from the low pressure header. In turn the low pressure header will demand steam from the turbines as required. The steam from the waste heat boiler is sent to the low pressure header. The turbines will ramp up or down depending upon the amount of steam required by the low pressure header. In turn, the boilers will ramp up or down depending upon the high pressure header. As the pressure goes above a set limit in the high pressure header, the boilers will ramp down and simultaneously the \#8 turbine can ramp up, sending the excess steam in the high pressure header out of the system.

The simulation uses discrete simulation software. The process of steam is a continuous process. To design a continuous process, two major elements are used in the model:

1. The "Pull system": The simulation software has a "Pull system". The software describes "Pull system" as a system in which locations produce parts only on down stream demand. There are 2 types of pull systems

a. Based on limited buffer or queue sizes

b. Based on more distant down stream demand

The first system will send the parts to the location until capacity is available at the location. While the second method requires us to trigger part movement based on down-stream demand.

2. Global variables: Global variables are the place holders defined by the user to represent changing numeric values. These variables can either contain real numbers or integers, including element index values, and are typically used for decision -making and recording information. A global variable can be referenced anywhere in the model.

The entities are integers and most of the variables involved are real. Thus, as the model runs, the software will truncate the real quantities in integer numbers. To overcome this problem, global variables are defined to keep a track 
of the dynamics of the system. Thus the entities will move from location to location updating the global variables.

In our model, we say that it is a user driven system, thus the users are the down stream demand and we design it as a "demand pull" system. The arrival (the user steam requirement) at the user will trigger the whole model. This arrival will pull the steam from the low pressure header, which will in turn trigger the turbines. Then, depending up on the steam pulled by the turbine, the pressure in the high pressure header will change and this will trigger the boilers to ramp up or down. The user can be set as random or a deterministic load with some noise. Figure 3.9 shows these concepts.

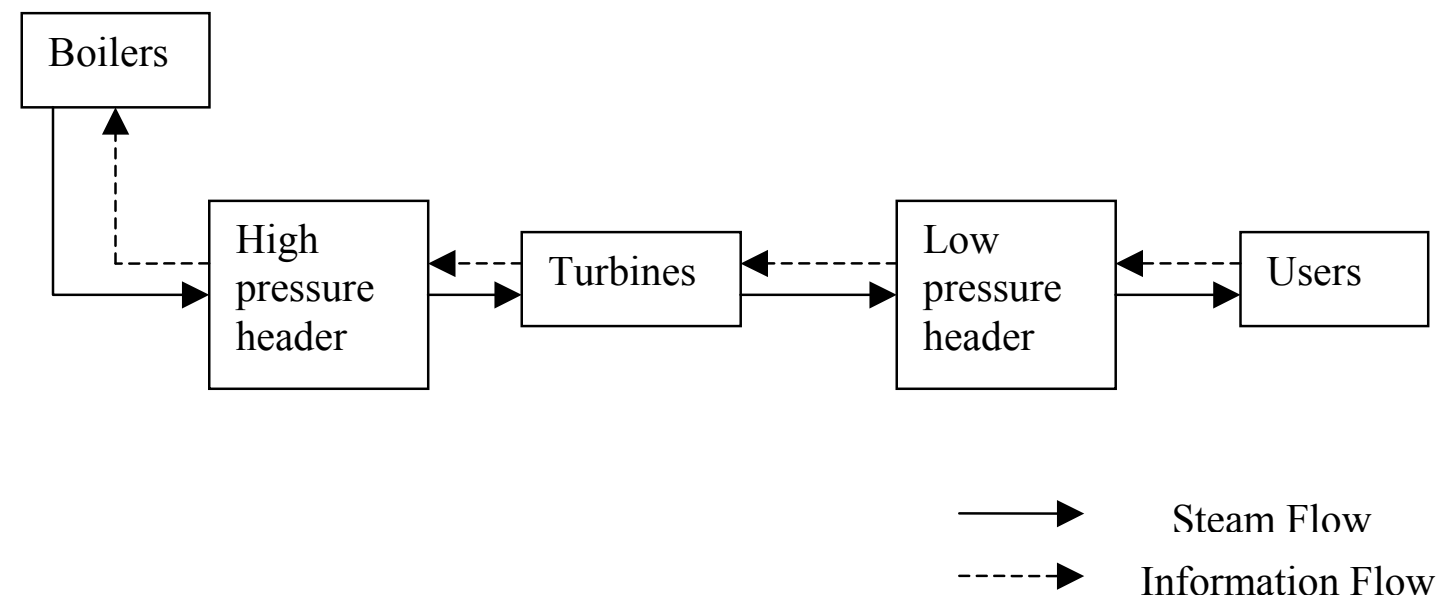

Figure 3.9: The "Pull System"

From Figure 3.1, it can be seen that the steam arriving from the waste heat boiler is routed to the accumulator and the steam is then released to the low pressure header at 200 psig. This steam will affect the low pressure header and is cyclic in nature. Thus the pressure maintained in the low pressure header is a function of steam from the turbines and steam from the waste heat boilers; with preference for the steam from the waste heat boilers. Thus the amount of steam flowing from the turbine is dependent upon the waste heat steam.

This is accommodated in the model as a "supply push" mechanism. As the BOP goes on, a huge amount of steam is generated independent of user demand at that time. For this event, a separate arrival of the waste heat steam is designed. This arrival cycle is 
the same as observed in the normal case. The data collected for the BOP steam is input in the model through arrays. And these array values are the arrivals for the waste heat steam.

This steam arrival is then linked to the accumulator. The accumulator has two set points viz. the charging point and the venting point. The charging point is the set point up to which the steam is accumulated in the accumulator, before it is sent to the low pressure header. And the venting point is the set point above which the accumulator cannot hold any more steam and the steam is vented to the atmosphere. The accumulator is charged until the charging point and then the steam is passed to the low pressure header at 200 psig. When the accumulator has steam above its venting point it will vent the steam to atmosphere.

A variable is defined as the capacity of the accumulator. The capacity is defined in terms of $1000 \mathrm{lbs}$ of steam. The variable is updated as the waste heat steam comes into the accumulator. When it goes above the charging point, the steam is routed to the low pressure header. The relationship between the amount of steam in the accumulator and corresponding pressure is shown in Appendix IV. Similarly a variable is defined for the low pressure header capacity (in terms of $1000 \mathrm{lbs}$ of steam). This variable is continuously maintained so as to have a pressure of 200 psig in the low pressure header. This is a dynamic variable and it gets decremented when the user pulls the required steam and gets incremented when the steam enters the low pressure header (either through turbines or through the accumulator). These concepts are shown in Figure 3.10.

Another variable is assigned which calculates the "error" between the low pressure header variable and set point of 200 psig. Only this error is sent to the header, first preference being to waste heat steam. Thus, if the waste heat steam is more than the "error" the only the "error" is sent and the remaining is accumulated in the accumulator, thus increasing the accumulator related variable. When this accumulator variable moves above the venting point, the steam is vented. Similarly, the venting variable is incremented by the amount more than the venting point and corresponding accumulator variable is decremented by the same amount. 


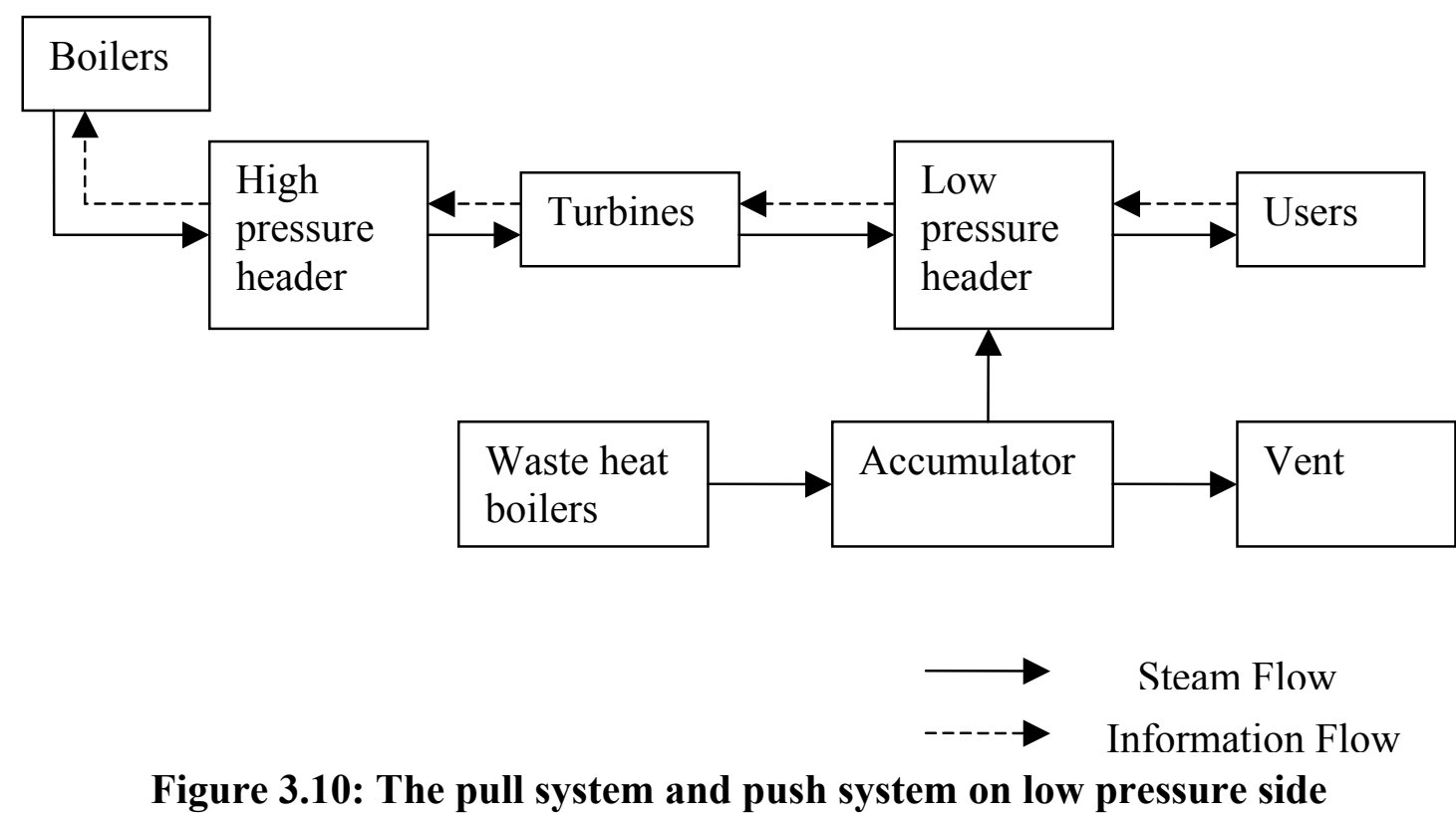

For the high pressure side, see Figure 3.11, a variable is defined for the amount of steam in the high pressure header. The variable is similar to the one defined in the low pressure header. The variable is incremented as the steam from any of the five boilers is added to it and is decremented as the steam is pulled by the turbines or the desuperheaters. This variable is continuously adjusted to have pressure of $800 \mathrm{psig}$ in the high pressure header. The relationship between the amount of steam in the high pressure header and corresponding pressure is shown in Appendix IV. Whenever the value is exceeded, the steam is pushed through the $\# 8$ turbine, incrementing the variable associated with it. Similarly variables are assigned to the $\# 6$ and $\# 9$ turbines as well as the desuperheaters. These increment and decrement as the steam passes through them and they represent the steam flow rate through them. Low and high set points are induced for these variables; this accommodates the maximum and minimum steam flow through the turbines. Also for each turbine a variable associated with its steam flow is defined, which is a relation between the power generated for a level of steam flow. This accommodates the electric generation for these turbines.

In the case of the boilers, we have two variables associated with each. One indicates the amount of steam generated and the other gives the amount of Btu's required for that level of steam generation. The variable for steam generation is linked to the amount of steam in the high pressure header. A linear relationship is developed such that the boilers 
fire at maximum when the pressure moves below the set point and at minimum when the pressure is at the set point. The Btu variable is used for the amount of blast furnace gas (BFG) required. The boilers will pull the BFG as per their requirement from a common location. Limits are put on the variables denoting the steam generation, accommodating the maximum and the minimum firing rates for the boilers.

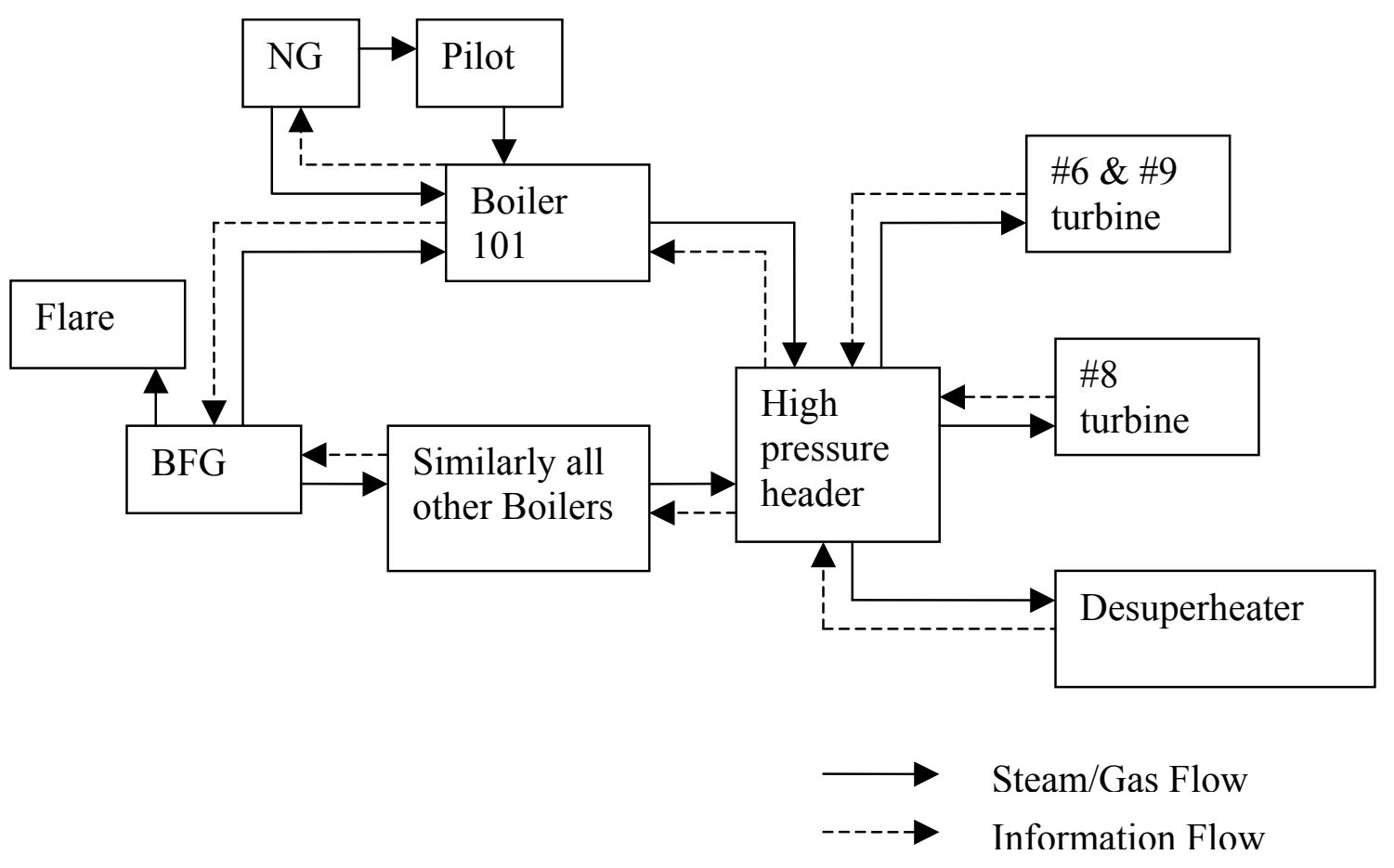

Figure 3.11: The high pressure side

For the blast furnace gas, data is collected and the amount of blast furnace gas produced is found and is converted into Btu equivalent. This is modeled as a separate location with its arrival. This gas is then routed to the boilers and the stoves. The stoves are given the preference over the boilers, i.e. they are continuously supplied with the $\mathrm{BFG}$ and the remaining amount is distributed to the boilers. The BFG is sent to the boilers with the following preference; first to the boiler 101, then 102, then 3 and 4 and 5 . If the blast furnace gas is insufficient to satisfy the fuel requirement, natural gas is used. Due to this, boilers 4 and 5 may seem to use more natural gas. 
Each boiler has a pilot that uses natural gas. Thus to model the use of natural gas, each boiler is supplied with a separate location denoting a pilot and the pilot is supplied with a separate natural gas reserve. The same gas reserve supplies the boiler with natural gas in cases where the firing levels need more fuel than available BFG. For the arrivals of the natural gas, data is collected and converted to Btu's. Thus the required Btu's for the boilers are satisfied by the Btu's of BFG and the natural gas (if required).

For the case where the level of the BFG is more than required, the BFG is flared. As designed earlier, a variable is defined for the BFG production. If the gas is not utilized completely, the entities are routed to a location 'flaring'. Here the variable is incremented, thus denoting the flaring of BFG, see Figure 3.11.

Another variable is defined for the efficiency of the boilers. The efficiency of a boiler changes as the load changes. It is defined as a step change and a linear relation is obtained for the efficiency. The linear relationship is defined in Table 3.4.

\begin{tabular}{|c|c|c|c|}
\hline Boiler & $\begin{array}{c}\text { Load } \\
\text { (KPPM) }\end{array}$ & efficiency & Relation \\
\hline \multirow{3}{*}{101} & 4.3 & $65 \%$ & \multirow{3}{*}{$y=9.375 x+40$} \\
\hline & 4.8 & $75 \%$ & \\
\hline & 5.3 & $80 \%$ & \\
\hline \multirow{3}{*}{102} & 4.3 & $65 \%$ & \multirow{3}{*}{$y=9.375 x+40$} \\
\hline & 4.8 & $75 \%$ & \\
\hline & 5.3 & $80 \%$ & \\
\hline \multirow{3}{*}{3} & 4 & $65 \%$ & \multirow{3}{*}{$y=10 x+40$} \\
\hline & 4.5 & $70 \%$ & \\
\hline & 5 & $75 \%$ & \\
\hline \multirow{3}{*}{4} & 4 & $65 \%$ & \multirow{3}{*}{$y=10 x+40$} \\
\hline & 4.5 & $70 \%$ & \\
\hline & 5 & $75 \%$ & \\
\hline \multirow{3}{*}{5} & 4.8 & $65 \%$ & \multirow{3}{*}{$\mathrm{y}=8.3333 \mathrm{x}+40$} \\
\hline & 5.4 & $70 \%$ & \\
\hline & 6 & $75 \%$ & \\
\hline
\end{tabular}

$\mathrm{y}=$ efficiency of boiler $(\%), \mathrm{x}=$ load (KPPM)

Table 3.4: Relationship for the boiler efficiency

In case of the stoves, they are bottled after every 45 minutes. Two stoves are considered here for modeling purposes. When the stoves are bottled, they do not consume any BFG and thus the available BFG for the boilers is more than the normal. This is accommodated in the model, as the stoves pulling the required BFG from the BFG 
location and after every 45 minutes this pulling of BFG is set to zero, thus modeling as the stoves are being bottled. This bottling time is set to be three minutes.

For the overall model, the set limits such as the maximum and the minimum firing rates for boilers, the steam flow rates of turbines, the set points for the accumulator, low pressure header, high pressure header, etc. are input into the model through arrays. The arrays input their values from an Excel sheet (initializing, before running the model), thus changing these values is easy. The arrays and the input values for the variables are shown in Appendix III. A relationship was obtained between the steam flow and the power generated for the turbines and this is used for the electric generation. Similarly, a linear relationship was developed for the boilers which simulate their ramping up and down, and for the turbines which pull the required steam depending upon the error in the low pressure header. The calculations are as shown in Table 3.5 and 3.6.

From the Table 3.4 it can be seen that the boilers operate in sequence. This is done as boilers 101 and 102 are more efficient than the others. Thus, if the steam pressure in the high pressure header goes below 800 psig boilers 101, 102 will fire at full blast, while the \#3 boiler will fire at the required level indicated by the relation.

\begin{tabular}{|c|c|c|c|c|}
\hline Boiler & & $\begin{array}{l}\text { Pounds of } \\
\text { steam in } \\
\text { HP } \\
(1000 \text { lbs })\end{array}$ & $\begin{array}{c}\text { Boiler } \\
\text { steam } \\
\text { generation } \\
(\mathbf{1 0 0 0} \text { lbs })\end{array}$ & Relation \\
\hline \multirow{2}{*}{ \#101 } & Min & 20 & 3.3 & \multirow{2}{*}{$y=-x+23.333$} \\
\hline & Max & 18 & 5.3 & \\
\hline \multirow{2}{*}{ \#102 } & Min & 18 & 3.3 & \multirow{2}{*}{$y=-x+21.333$} \\
\hline & Max & 16 & 5.3 & \\
\hline \multirow{2}{*}{ \#3 } & Min & 16 & 2.2 & \multirow{2}{*}{$\begin{array}{c}\mathrm{y}=-1.4167 \mathrm{x}+ \\
24.833\end{array}$} \\
\hline & Max & 14 & 5 & \\
\hline \multirow{2}{*}{ \#4 } & Min & 14 & 2.2 & \multirow{2}{*}{$y=-1.4167 x+22$} \\
\hline & Max & 12 & 5 & \\
\hline \multirow{2}{*}{$\# 5$} & Min & 12 & 3.7 & \multirow{2}{*}{$\begin{array}{c}y=-1.1667 x+ \\
17.667\end{array}$} \\
\hline & Max & 10 & 6 & \\
\hline
\end{tabular}

$\mathrm{y}=$ Boiler Steam generation $(1000 \mathrm{lbs}), \mathrm{x}=$ Steam in HP header $(1000 \mathrm{lbs})$

Table 3.5: Relationship for the boiler ramping 


\begin{tabular}{|c|c|c|c|c|}
\hline Turbine & & $\begin{array}{l}\text { Pounds of } \\
\text { steam in } \\
\text { LP/HP } \\
(1000 \text { lbs })\end{array}$ & $\begin{array}{c}\text { Steam } \\
\text { Flow rate } \\
(1000 \\
\text { lbs/min }) \\
\end{array}$ & Relation \\
\hline \multirow{2}{*}{ T6 } & Min & 200 & 1.2 & \multirow{2}{*}{$y=-0.9167 x+184.5$} \\
\hline & Max & 194 & 6.7 & \\
\hline \multirow{2}{*}{ T9 } & Min & 205 & 1.2 & \multirow{2}{*}{$\begin{array}{c}y=-1.7667 x+ \\
363.33\end{array}$} \\
\hline & Max & 200 & 10 & \\
\hline \multirow{2}{*}{ Desuperheater } & Min & 194 & 0 & \multirow{2}{*}{$\begin{array}{c}\mathrm{y}=-0.9514 \mathrm{x}+ \\
184.58\end{array}$} \\
\hline & Max & 180 & 13.32 & \\
\hline \multirow{2}{*}{$\mathrm{T} 8$} & Min & 20 & 0.4 & \multirow{2}{*}{$y=2.2917 x-45.417$} \\
\hline & Max & 22 & 5 & \\
\hline
\end{tabular}

Table 3.6: Relationship for the turbine steam flow rate

As in the case of boilers, turbine \#9 is given preference over turbine \#6. But turbine \#6 always operates at its minimum level. For the turbine \#8, as it acts as a pressure relief valve for high pressure header, steam pressure in high pressure header is considered while calculating the relationship.

In all cases, bounds are put on the minimum and the maximum values in the model code, thus keeping level with the maximum and the minimum level of firing rates for the boilers and the minimum and the maximum steam flow rate for the turbines.

For the model, one entity represents $1000 \mathrm{lbs}$ per minute of steam flow rate. Thus as one entity moves from boiler to turbine; $1000 \mathrm{lbs}$ of steam flows from the boiler to the turbine. This time increment is selected from the fact that as the number of entities in the model at any instance increase the model runs slower. As the final objective is integrating the system equipment to understand the process better and to analyze the system for operations management, running the model in minutes instead of seconds satisfies the objectives with faster running speed.

The model is run with some specific level of steam in the high pressure header, low pressure header and some low pressure steam in the accumulator. The boilers already are producing the minimum amount of steam they produce. The turbines are also operating at their lowest steam flow rate. This is done so as to stabilize the system quickly. If the model is run empty at the start, then time will be wasted to reach 
equilibrium and it will run erratic until equilibrium is attained. So some set specified levels are fixed and set before the model starts, which helps it stabilize quickly.

The structure of the model via its graphical representation as it appears on the computer screen is shown in Appendix I. Also the color code for the variables is shown in the table AI in Appendix I. The list of variables and their initial values are shown in Appendix II. 


\section{Chapter 4 \\ Model Execution}

\subsection{Model Assumptions}

The following assumptions are made while designing and executing the simulation model.

1. The plant has many low pressure steam users. In the model, a single user is considered which is equivalent to the total steam consumed by all the users.

2. It is assumed that the users will consume a minimum amount of low pressure steam which is nearly equal to the total amount of steam produced by the boilers at their lowest firing rate.

3. The pressure in the high pressure header is maintained at 800 psig.

4. The volume of the high pressure header is assumed to be same as the accumulator volume. This is done because no data exists for the high pressure header volume, while we have an exact volume of the accumulator.

5. The pressure in the low pressure header is maintained at $200 \mathrm{psig}$.

6. As the low pressure header supplies low pressure steam throughout the plant the volume of the low pressure header is very high and cannot be determined. In the model the volume is assumed to be such that 200,000 lbs of steam in the header correspond to 200 psig steam pressure.

7. For modeling purposes only two stoves are considered which consume the same amount of blast furnace gas as all the stoves in the plant.

\subsection{Model Validation}

Data was collected from the plant on various variables. This data is plotted so as to obtain an idea about the process. The model is then run with the set input variables. The output generator collects the data for all the variables. This data is exported to an Excel sheet and then plotted. These graphs are compared with each other for validation purposes. Three variables are considered here, viz. the BOP steam flow, vented steam and the pressure in the low pressure header. 
From the following graphs, Figure 4.1 to 4.4 , it can be seen that the model closely represents the actual system. The dynamics of the system are very well reflected by the simulation model. Thus the model is now ready for conducting experiments and analyzing the results.

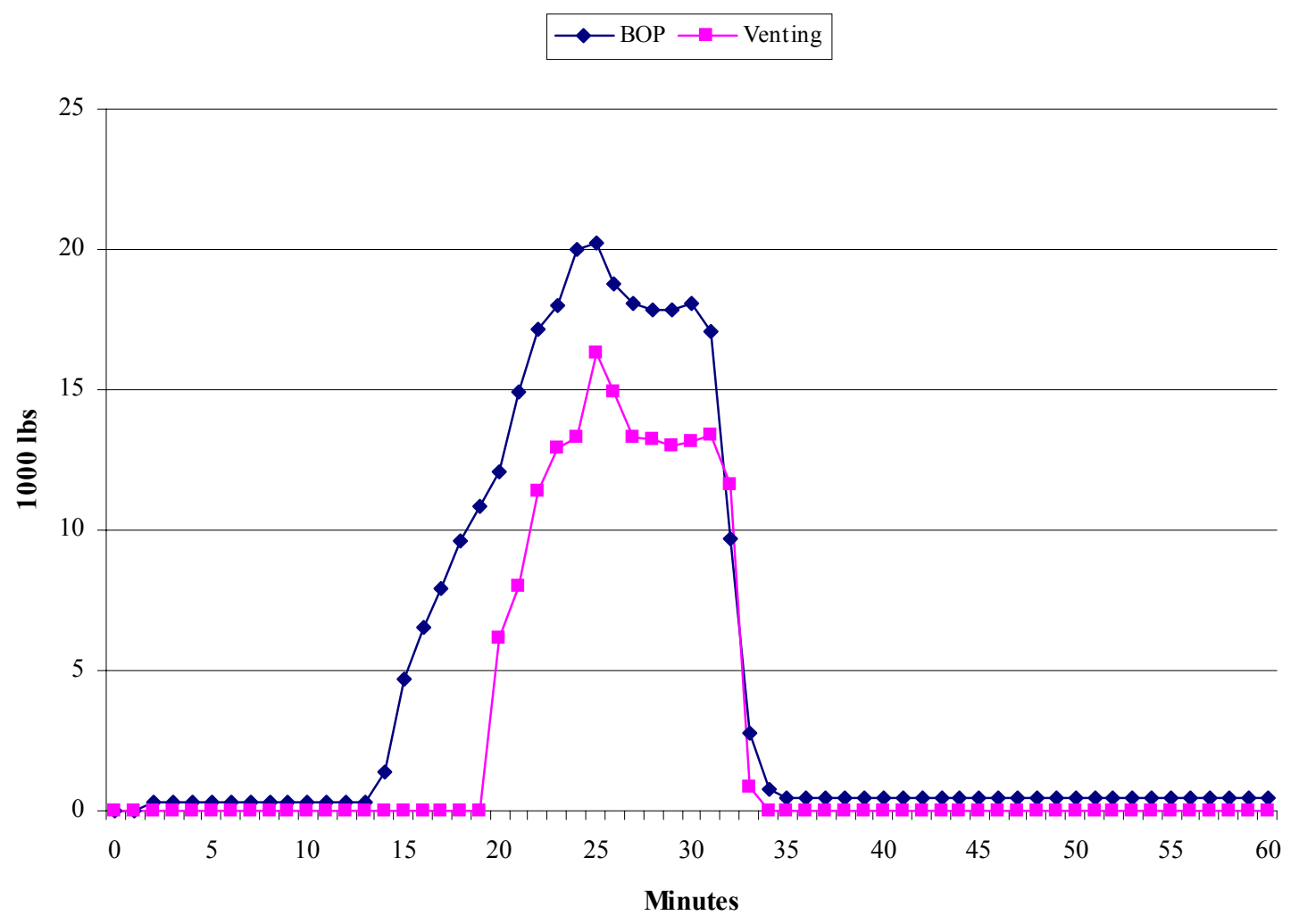

Figure 4.1: BOP and Venting (Data Exported from the software) 


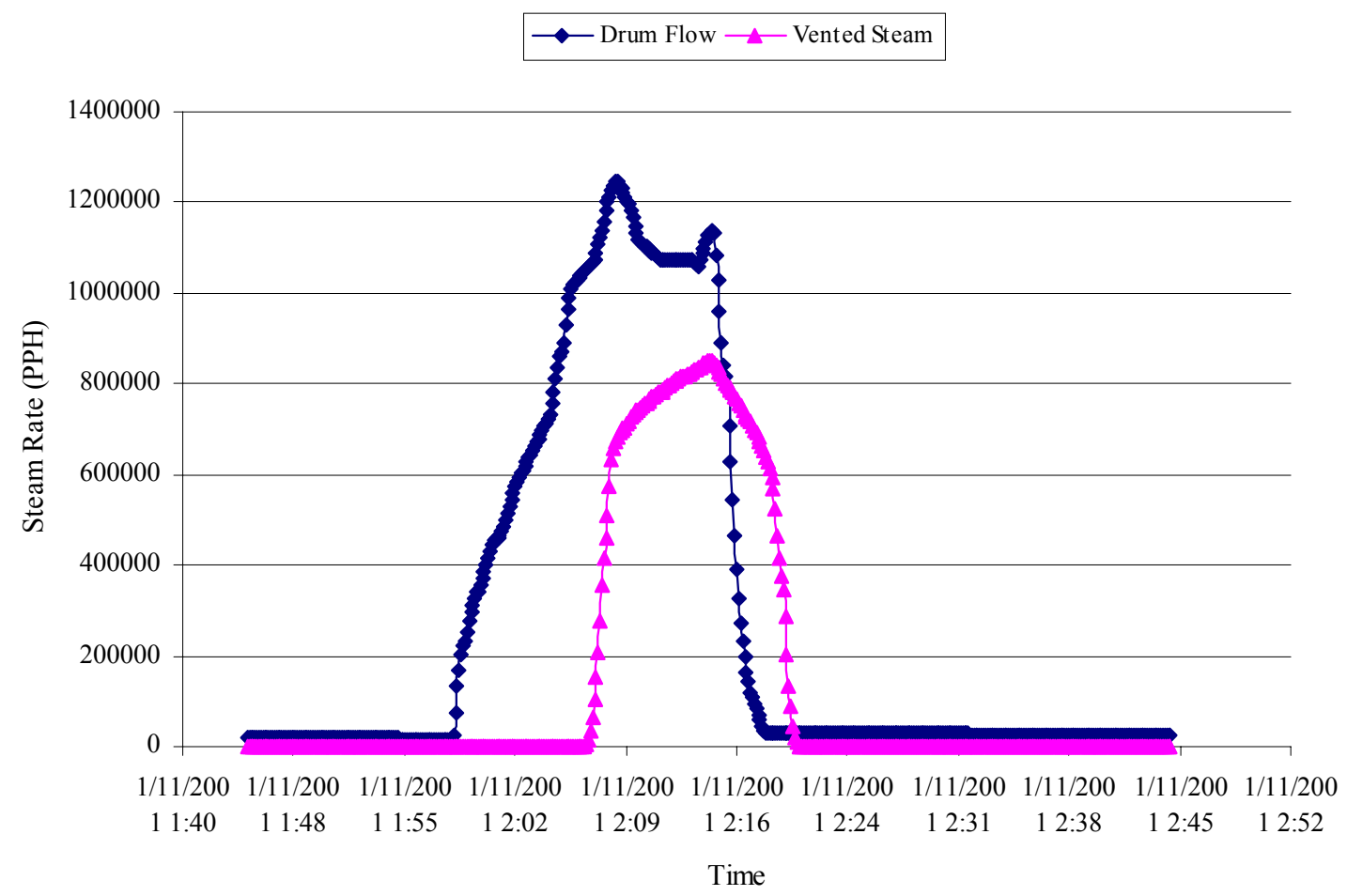

Figure 4.2: BOP and Venting (From the collected data)

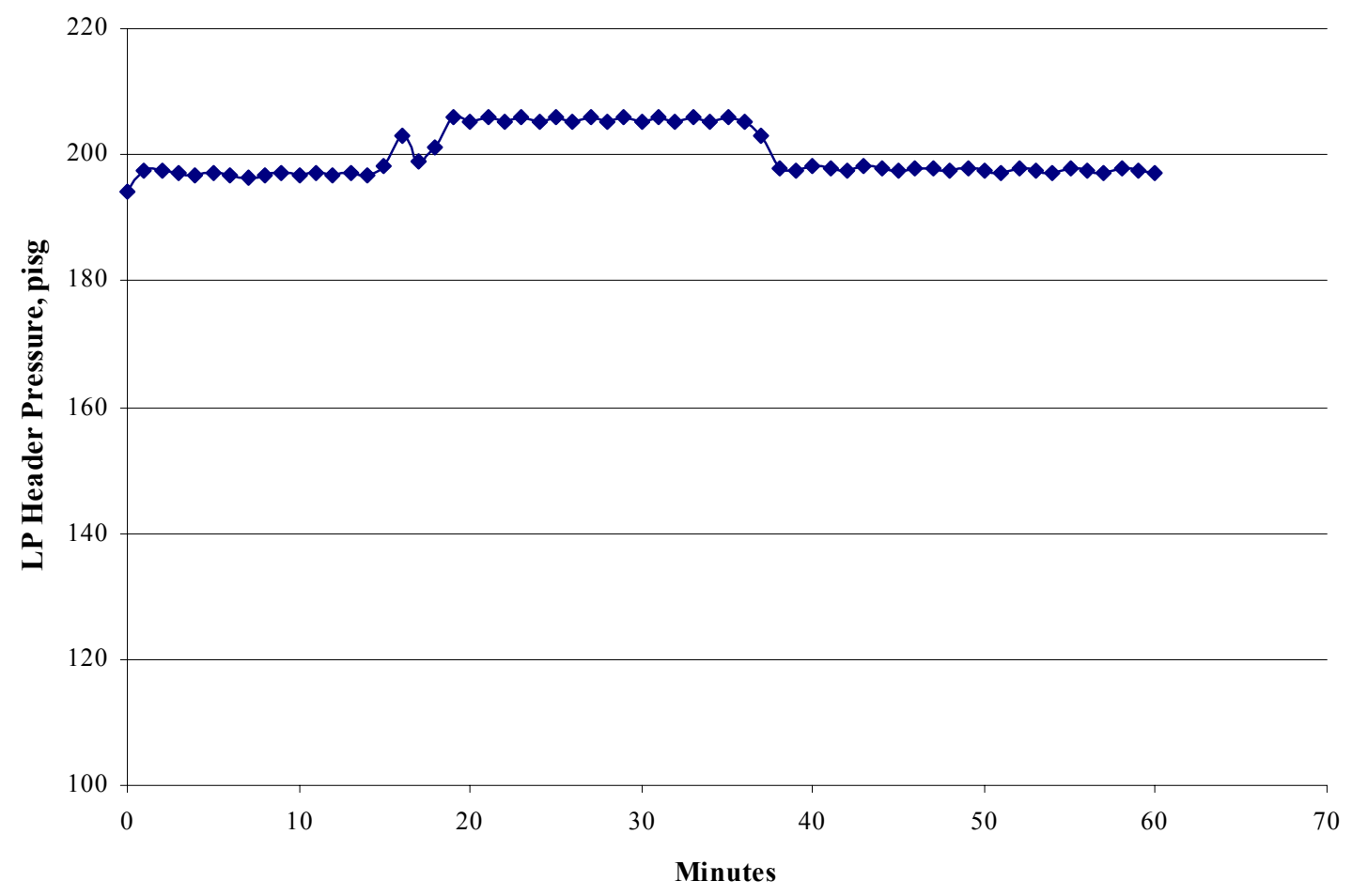

Figure 4.3: LP Header Pressure (From the data exported from software) 


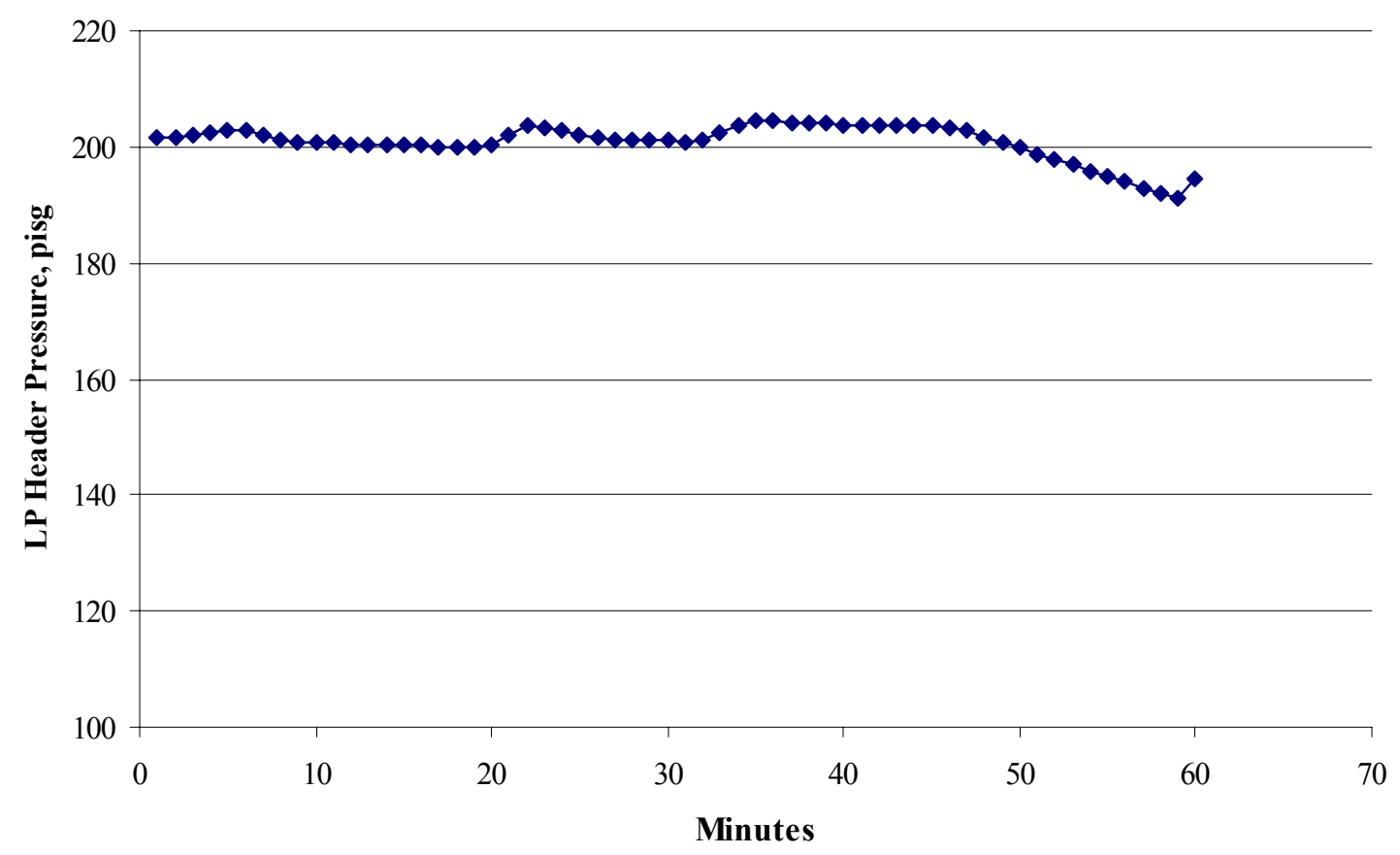

Figure 4.4: LP Header Pressures (From the collected data)

\subsection{Conducting Experiments with the simulation model}

The simulation model was run with different inputs and the output was analyzed. Two cases are considered here; the time at which the stoves are bottled and running the system with less boilers.

\subsubsection{Time for bottling of stoves}

The hot air that is blown in the blast furnace is preheated in the stoves. The stove is said to be bottled when the brick work is heated to the required temperature and is now ready to go 'on-blast'. In this case, the valves on the stoves are shut and thus no gas or air is passed through the stove. Thus during the bottling of the stoves, the blast furnace gas available for the boilers is more than normal availability. The simulation model is now run with the following data input -

1. The tank charging point is set at $200 \mathrm{psig}$ and the venting pressure is assumed to be 600 psig.

2. The user demand was considered to be $828,000 \mathrm{lbs}$ per hour. 
3. All the five boilers are working.

4. The BFG arrival is considered to be constant at $235 \mathrm{Mcf} / \mathrm{min}$ or $20.7 \mathrm{MMBtus}$.

5. The stoves are bottled when the BOP is on-blow (the steam from the waste heat boiler is at its maximum).

6. The bottling time for the stoves is three minutes.

After the model is run the output generator collects the data and can be analyzed for decision making. The data obtained after running the simulation is plotted in Figure 4.5. It is observed that there is flaring during the time the stoves are bottled.

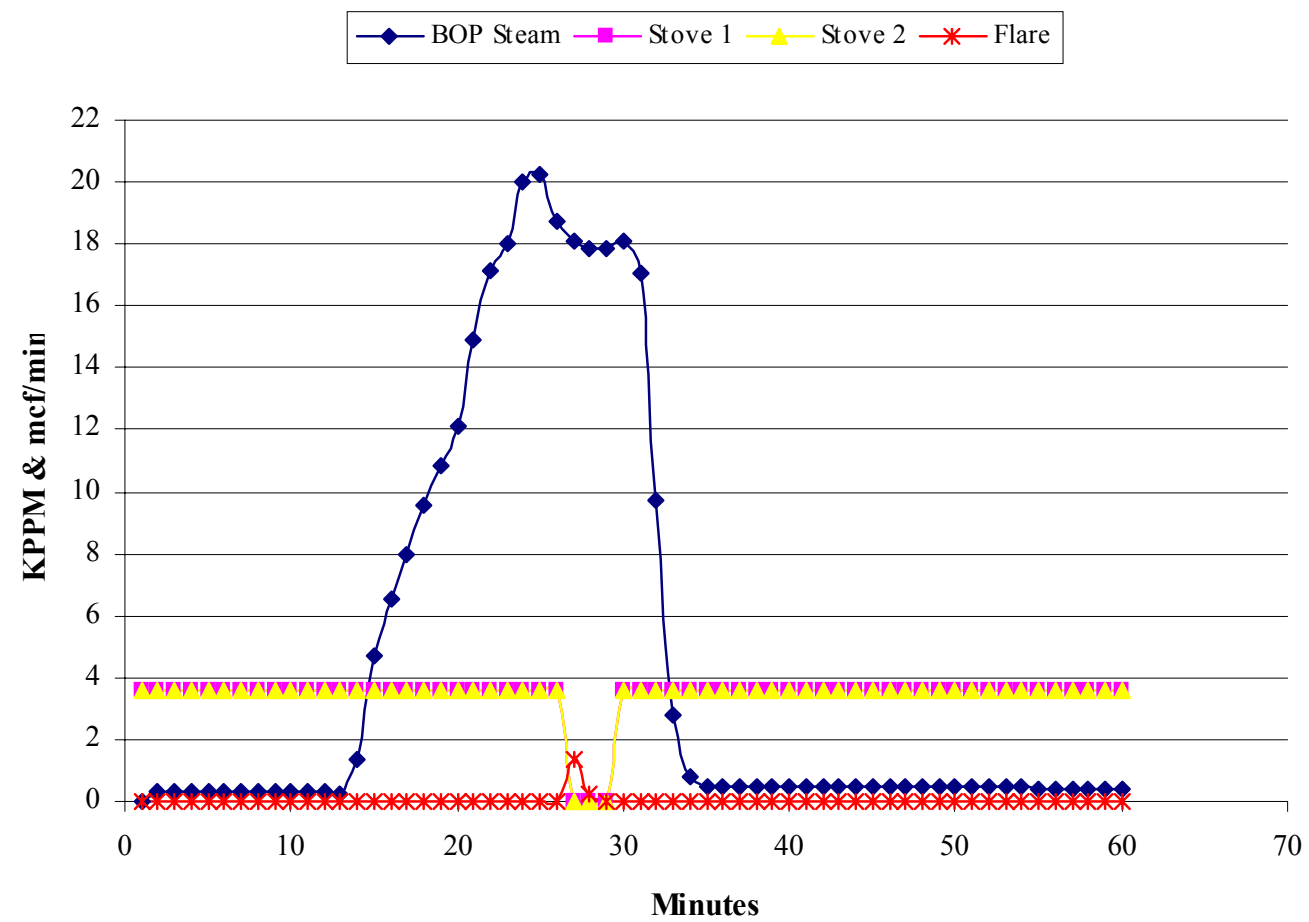

Figure 4.5: Flaring when stoves are bottled while BOP is on-blow

From the steam diagram and the logic flow chart, it can be seen that when the BOP steam is on-blow the pressure in the low pressure header increases and that puts the turbines down. As the turbines ramp down the pressure in the high pressure header increases, thus the boilers are also ramped down. In such a case, the boilers will start consuming less BFG as they ramp down and if the stoves are bottled during this time then there is an excess of BFG and that cannot be consumed, thus the BFG is flared. 
From the data the model generated, the amount of BFG flared is $1.55 \mathrm{MMbtu}$ in the one hour simulation run. Assuming that this is the amount that will fall short for the boilers in the long run, they will consume natural gas. The average cost of natural gas is about $\$ 5.5$ /MMbtu. Thus the company may experience $\$ 8.55$ per hour extra cost. If this is integrated over a years span, then considering 50 weeks of operation and 7 days a week the company incurs additional cost of $\$ 71,820$ annually.

The solution of this problem is to bottle the stoves when the BOP is off-blow. There is a 45 minutes gap before the stove is again bottled. Thus this operation can be performed before the BOP goes on-blow.

The model is now run again with the same input data but the bottling is done when the BOP is off-blow. After the model is run the output generator collects the data and it can be analyzed. The data obtained after running the simulation is plotted in Figure 4.6. It is observed that there is no flaring of BFG.

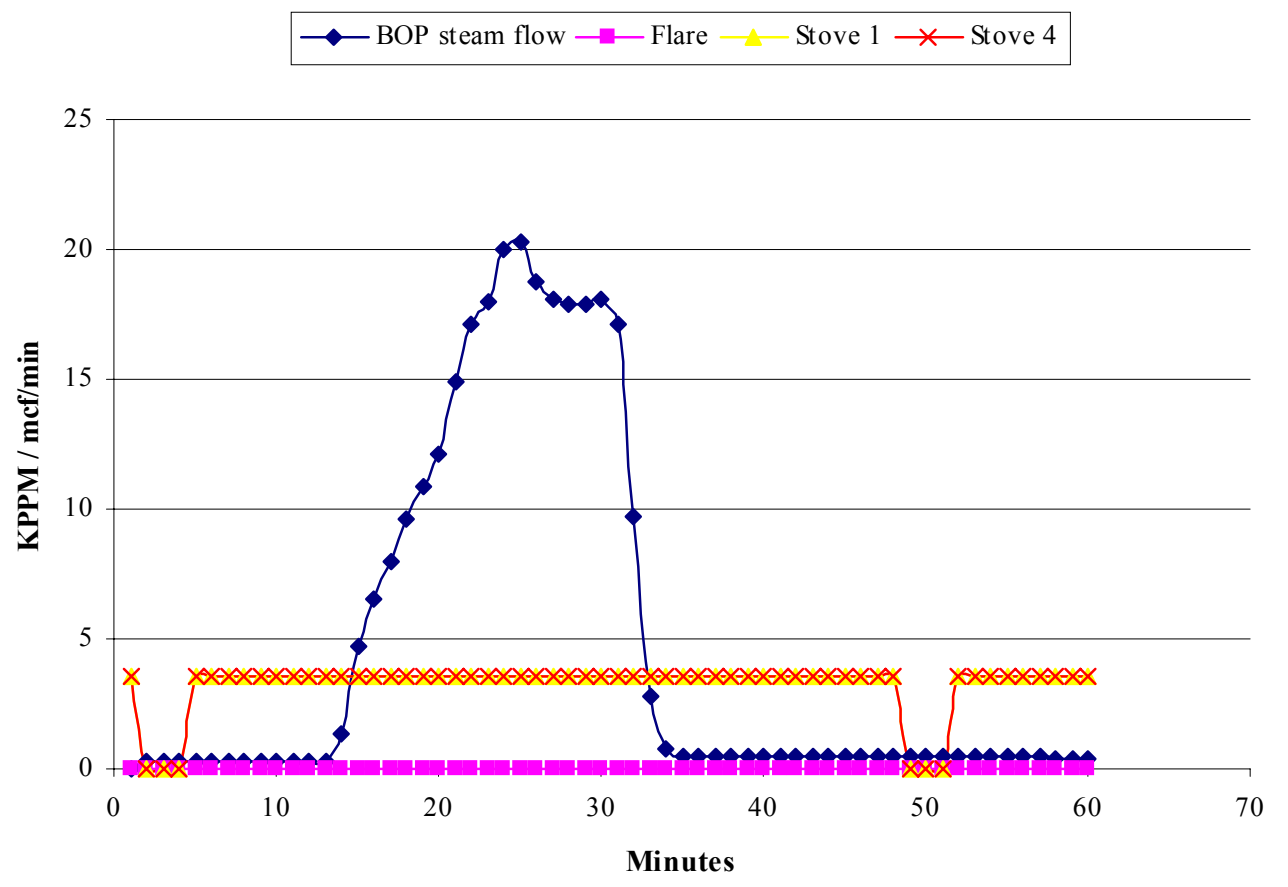

Figure 4.6: Flaring when stoves are bottled while BOP is off-blow 
As seen from the Figure 4.6, the strategy of bottling the stoves when the BOP is offblow works. Thus the energy is utilized completely and this will reduce the extra cost to the plant.

\subsubsection{Shutting down of boilers}

Consider the above case; all the five boilers are working and the stoves are bottled when the BOP is off-blow. From the data gathered by the output generator of the simulation model, we can find out the total amount of natural gas consumed. Assuming the natural gas cost to be $\$ 5.5$ / MMbtu the natural gas cost can also be plotted with the natural gas consumption. Figure 4.7 shows the natural gas consumption and the cost associated with it.

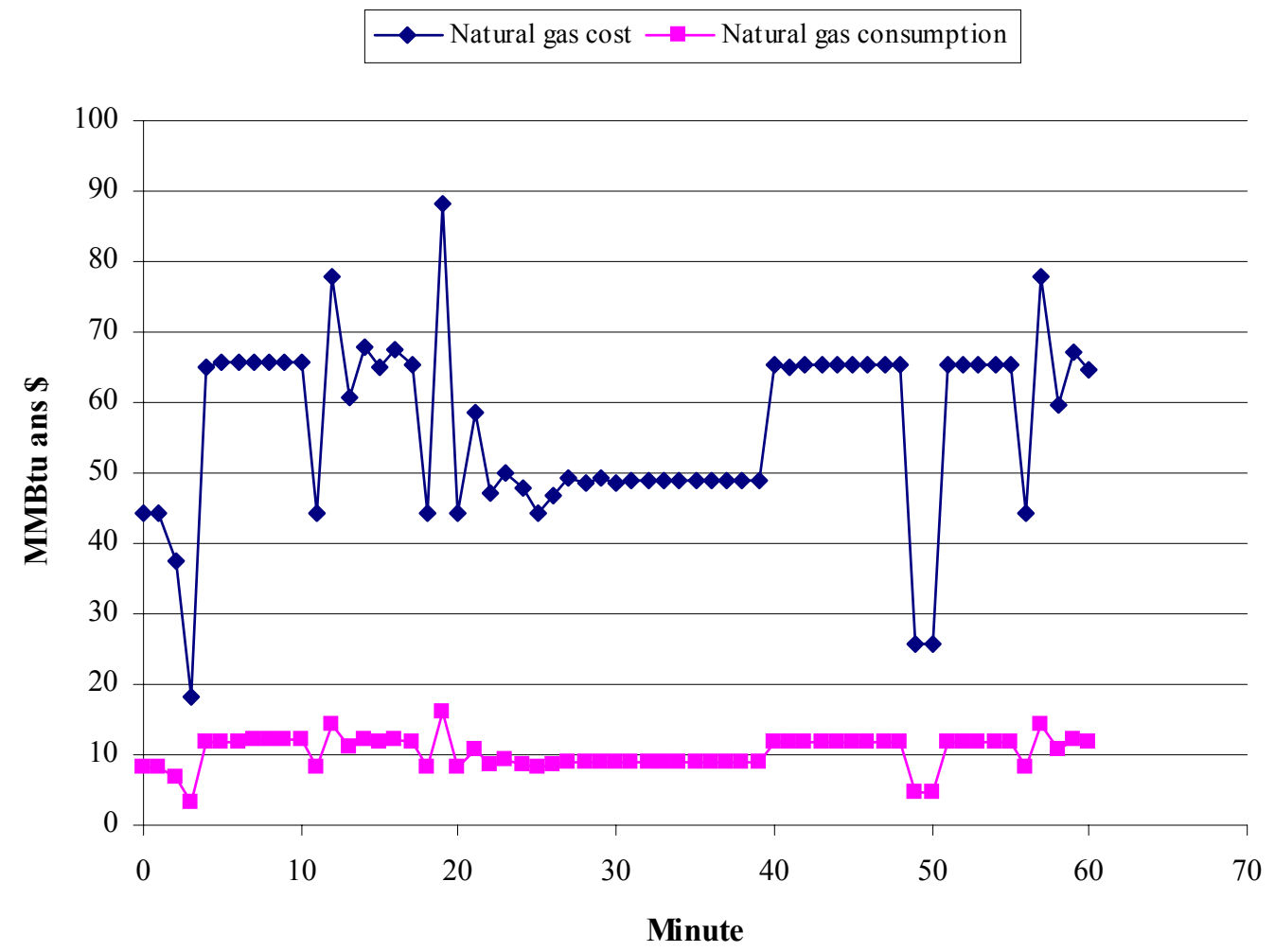

Figure 4.7: Natural gas consumption and cost 
From the data generated by the model and the plot above, it can be seen that the average consumption of natural gas is about $10 \mathrm{MMbtu}$ for the one hour run. The average cost of natural gas is then about $\$ 55$ per hour.

The user demand is constant and can be well satisfied by four boilers. Thus to check a new operating strategy, one of the five boilers is shut down. Say, boiler \#4 is now shut down and the model is run. The input data remains the same but the only change is that we now run four boilers instead of five. The data is generated for the natural gas consumption and cost. Figure 4.8 shows a plot for the generated data.

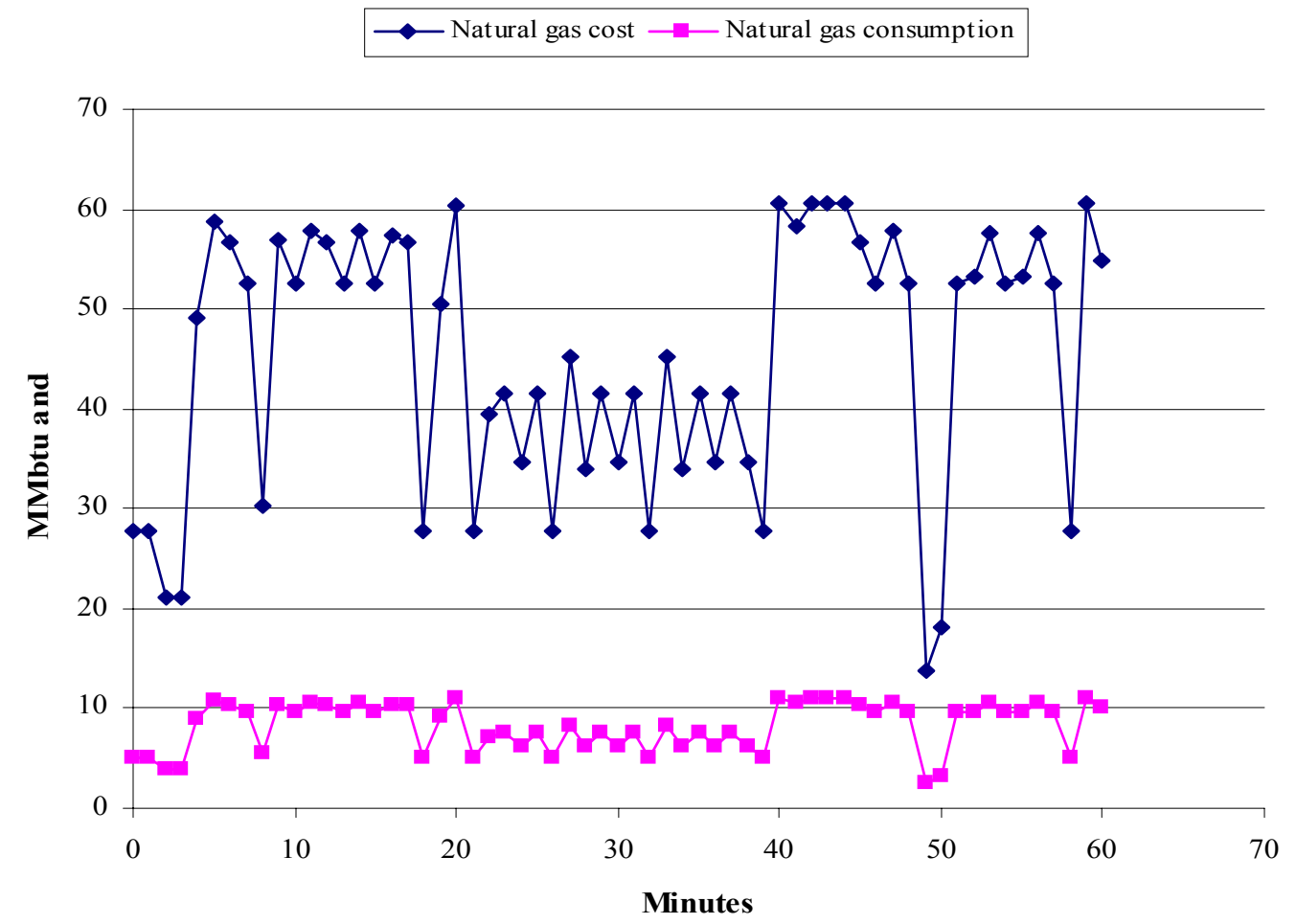

Figure 4.8: Natural gas consumption and cost

From the graph it can be observed that the average consumption of natural gas is reduced from $10 \mathrm{MMbtu} / \mathrm{hr}$ to about $8 \mathrm{MMbtu} / \mathrm{hr}$. Thus the cost of natural gas also reduces to about $\$ 45$ per hour. This is $\$ 10$ savings per hour by just shutting down one boiler. If this is integrated over one year span, then considering 50 weeks of operation and 7 days a week the company saves about $\$ 84,000$ annually. Due to shutting of one boiler, boilers \#101, \#102 and \#3 are mostly run at full loads and the fourth boiler, boiler \#5 is run at partial load. Also, a small pressure drop is observed in the high pressure 
header. The pressure reduces from average $800 \mathrm{psig}$ to $760 \mathrm{psig}$. But this pressure drop is not significant and can be tolerated by the system components.

\subsection{Conclusion from above scenarios}

The plant currently uses a combination of base loading and parallel ramping to regulate the high pressure header conditions. Thus, all the boilers "hunt" up and down almost continuously. This type of operation leads to inefficient boiler usage. As designed in the model, the boilers should ramp up and down in sequence. This will help to operate the boilers at their most efficient levels.

From the above experiments, it can be seen that through the operating strategy of timing the bottling of stoves as well as shutting down of one of the boilers, the company can save considerable amount money, nearly $\$ 150,000$ annually. This will also help to minimize energy loss, making the system energy efficient.

\subsection{Reducing the amount of steam vented from the accumulator}

Another scenario can be run for reducing the steam vented from the accumulator. Form Figure 3.5 it is seen that, the steam production is cyclical and within a span of 22 minutes the steam production goes from zero to well above $1,200,000 \mathrm{lbs} / \mathrm{hr}$ and back to zero. The same cycle repeats itself after a span of about 23 minutes. Thus it is a 45 minute cycle. A strategy can be analyzed which may help in reducing the amount of steam vented. The boilers should be set in such a way that as the BOP steam sets in the boilers will ramp down by themselves. This is integrating the BOP steam production (waste heat boilers) to the other boilers.

To set up the model for running the above scenario, some modification is required in the operation code for the boilers. The model is run for one hour. In that hour from the BOP cycle it is seen that the BOP sets in after 13 minutes. A code needs to be added to the existing operation code for the boilers, which will set the steam generation variable (Boiler_var) for all the boilers, to minimum at the $13^{\text {th }}$ minute. And at the end of the BOP, the $34^{\text {th }}$ minute set the variables back to normal, so that they operate according to the steam pressure in the high pressure header. 
After making the modification to the operation code and running the model, following things must be analyzed:

1. Amount of steam vented as compared to normal operation.

2. The pressure in the high and the low pressure header.

3. The working of the turbines.

4. Whether the user is properly satisfied with low pressure steam.

The analysis of the above scenario may result into saving on the amount of steam vented from the accumulator. As the steam production in waste heat boilers increases, the normal boilers will be put at their lowest. Thus less steam will be added by the turbines to the low pressure header because they will also ramp down to maintain the high pressure header pressure. This will help to consume more amount of steam from the accumulator because the required steam for the low pressure header will be provided by the accumulator. Due to this, the steam pressure in the accumulator will lower, reducing the amount of steam vented. 


\section{Chapter 5}

\section{Conclusion and Future work}

\subsection{Conclusion}

The iron and steel making is a complex process. Large amount of energy is consumed in this process. The major sources of energy consumed are coal, natural gas and electricity. On-site electricity generation is carried out by most of the integrated steel industries. This contributes to $10 \%$ of the total electric use in the steel industry. Large amounts of by-product gases are also generated during the production. This is a free source of energy and must be used instantaneously. To capture this energy the steel industries have computerized control on system equipment. But still some energy is vented to atmosphere. This leads to buying of natural gas. The venting of free energy can be avoided by linking different equipments so that they anticipate the dynamic energy fluctuations and use real time data communication for decision-making.

A simulation model is developed to mimic existing situation. The goal of understanding the process and integrating the system equipments can be achieved by developing this model. Data is collected from appropriate sources and then analyzed. The simulation model is designed and is then validated. This model can be used to perform some first-level evaluations of different control strategies in making control and operating strategy decisions. Different scenarios are run by varying the inputs in the model and the effects of changes are analyzed.

As a result of this work it is learnt that developing an operating strategy that allows using the absolute minimum number of boilers necessary to supply the load is of paramount importance. The rewards are so compelling that they will easily justify some investment in demand side load management capability and research into optimization of boiler combinations and risk management.

Secondly, it is also learnt that simulation can be used as a tool for management of extremely complex systems of boilers, fuel supplies and steam users. This simulation model has tremendous value in generating "risk or reward" analyses.

Another use of the model would be analysis of various boiler staging and control schemes under realistic loading conditions. At present, the plant uses a combination of base 
loading and parallel ramping to regulate high pressure header conditions. This leads the boilers to "hunt" up and down almost continuously and further to inefficient boiler performance. The model is designed to ramp up the boilers in sequence. This will lead to run the boilers at their most efficient level. Similar strategies can be analyzed by the simulation model.

Finally, the model is ideal for studying the effects of changes prior to implementation thus avoiding the risks of implementation. The model can also be used as a training simulator for improving the proficiency of boiler operators and other personnel associated with the power house. This gives an opportunity to train the operators to handle unusual or even emergency situations without disrupting normal operations.

\subsection{Future work}

This research work has covered the basic objective of performing some first-level evaluations of different control strategies and to evaluate the usefulness of the simulation model in making control and operating strategy decisions. Secondly, the simulation model can be used for analysis of various control schemes under realistic loading conditions. The model is ideal for studying the effects of a change, prior to implementation thus avoiding the risks of implementation. To further refine the model used for these simulations, a good deal of effort would be required to gather adequate input data so as to generate realistic scenarios. Following future work is suggested for this research -

1. Accurate data must be collected for the control algorithms of different equipment. Similarly, accurate data must be collected related to system capacities, for e.g. the exact volume of the high pressure header.

2. Instead of using one minute time interval as present, use one second time interval. This would help to analyze the dynamics of the equipment as their response times are in seconds. But to consider the second time interval again accurate data of system is necessary.

3. Analyzing various boiler staging and control schemes for the boiler operations under realistic loading conditions. 
4. Allowing the header pressures to float over a wider range instead of maintaining a specific pressure. 


\section{Bibliography}

1. J Stubbles, "Energy use in the US Steel Industry: An Historical Perspective and Future Opportunities”, Office of Industrial Technologies, 2000

2. R J Fruehan, O Fortini, H W Paxton, R Brindle, “Theoretical Minimum Energies to Produce Steel for Selected Condition”, Office of Industrial Technologies, 2000

3. Summary Report, "Ironmaking Process Alternatives Screening Study", vol 1, Lockwood Greene, 2000.

4. Best Practices, Steam System Publications, "The Challenge: Improving Steam Turbine Performance at a Steel Mill”, Office of Industrial Technologies, April 1998

5. Best Practices, A Management Success Story, "Energy Team Pursues a Wide Range of Projects to Improve Operations at Steel Plant", Office of Industrial Technologies, April 2000

6. Best Practices, Technical Case Study, "Modernization of Controls Improves Productivity and Reduces Energy Costs at a Large Steel Plant", Office of Industrial Technologies, November 2000

7. Best Practices, Management Case Study, "Ongoing Control System Modernization Project at a Steel Plant Improves Operations", Office of Industrial Technologies, December 2000

8. Tsao, C. S. Day, R. H., "A Process Analysis Model for the U.S Steel Industry," Management Science 17, B588 -B608, 1971

9. Nelson, J. P, "A Note on Economics of Metallurgical Coke Production," Management Science 18, B237-B239, 1971

10. Anandalingam, G., "A Stochastic Programming Model for Investment Planning," Computers and Operations Research 14, 521-536, 1987

11. Fabian, T., "A Linear Programming Model of Integrated Iron and Steel Production," Management Science 4, 415-449, 1958

12. Fabian, T., "Blast Furnace Production Planning - A Linear Programming Example," Management Science 14, B1-B27, 1967 
13. Fourer, R., "Database Structures for Mathematical Programming Models," Decision Support Systems 20, 317-344, 1997

14. Sinha, G. P.; Chandrasekaran, B. S.; Mitter, N.; Dutta, G.; Singh, S.B.; Roy, Choudhury, A. R.; and Roy, P. N., "Strategic and Operational Management with Optimization at Tata Steel," Interfaces $25: 1,1995$

15. Jeong Hwan Kim, Heui-Seok Yi and Chonghun Han, "Optimal Byproduct Gas Distribution in the Iron and Steel Making Process Using Mixed Integer Linear Programming", International Symposium on Advanced Control of Industrial Processes, , Kumamoto, Japan, pp.581-586, 2002

16. Fukuda, K., Makino, H., Suzuki, Y. and Ishida, S., "Optimal energy distribution control at the steel works", IFAC simulation of control systems, Vienna, Austria, pp. 337-342, 1986

17. Dutta, G. and Fourer, R., "A Survey of Mathematical Programming Applications in Integrated Steel Plants." Manufacturing \& Service Operations Management, 3, pp. 387-400, 2001

18. G. Anandalingam, "Process Modelling Under Uncertainty: Simulation Analysis of Indian Steel", Journal of the Operational Research Society, vol. 38, no. 2, pp 115125,1987

19. G. Anandalingam and D. Bhattacharya, "Process Modelling and Industrial Energy Use in Developing Countries", Omega: The International Journal of Management Science, vol. 13, no. 4, pp 295-306, 1985

20. V Dhole, D Seillier, K Garza, "Utility System Management and Operational Optimization", 24 ${ }^{\text {th }}$ National Industrial Energy Technology Conference Proceedings, pp 73-83, 2002

21. A Eastwood, "ProSteam - A Structured Approach to Steam System Improvement", $24^{\text {th }}$ National Industrial Energy Technology Conference Proceedings, pp 113-122, 2002

22. JD Kumana, "Use Spreadsheet-Based CHP Models to Identify and Evaluate Energy Cost Reduction Opportunities in Industrial Plants", 23 ${ }^{\text {rd }}$ National Industrial Energy Technology Conference Proceedings, 2001. 
23. Russell C, Vaughan W, "Steel Production: Process, Products and Residuals", John Hopkins University Press, 1976

24. Steel Industry Analysis Brief, http://www.eia.doe.gov/emeu/mecs/iab/steel/ index.html

25. Kelton W, Sadowski R, Sadowski D, "Simulation With Arena", Second edition, Mc Graw Hill

26. http://www.atsiinc.com/BF/The_Stove.htm

27. Cengel Y, Boles M, "Thermodynamics: An Engineering Approach", Third edition, Mc Graw Hill, pp 956-961

28. Ganeshan, R. \& Harrison, T. P. "An Introduction to Supply Chain Management. “, [Internet], 2000, http://silmaril.smeal.psu.edu/misc/supply_chain_intro.html 


\section{Appendix I}

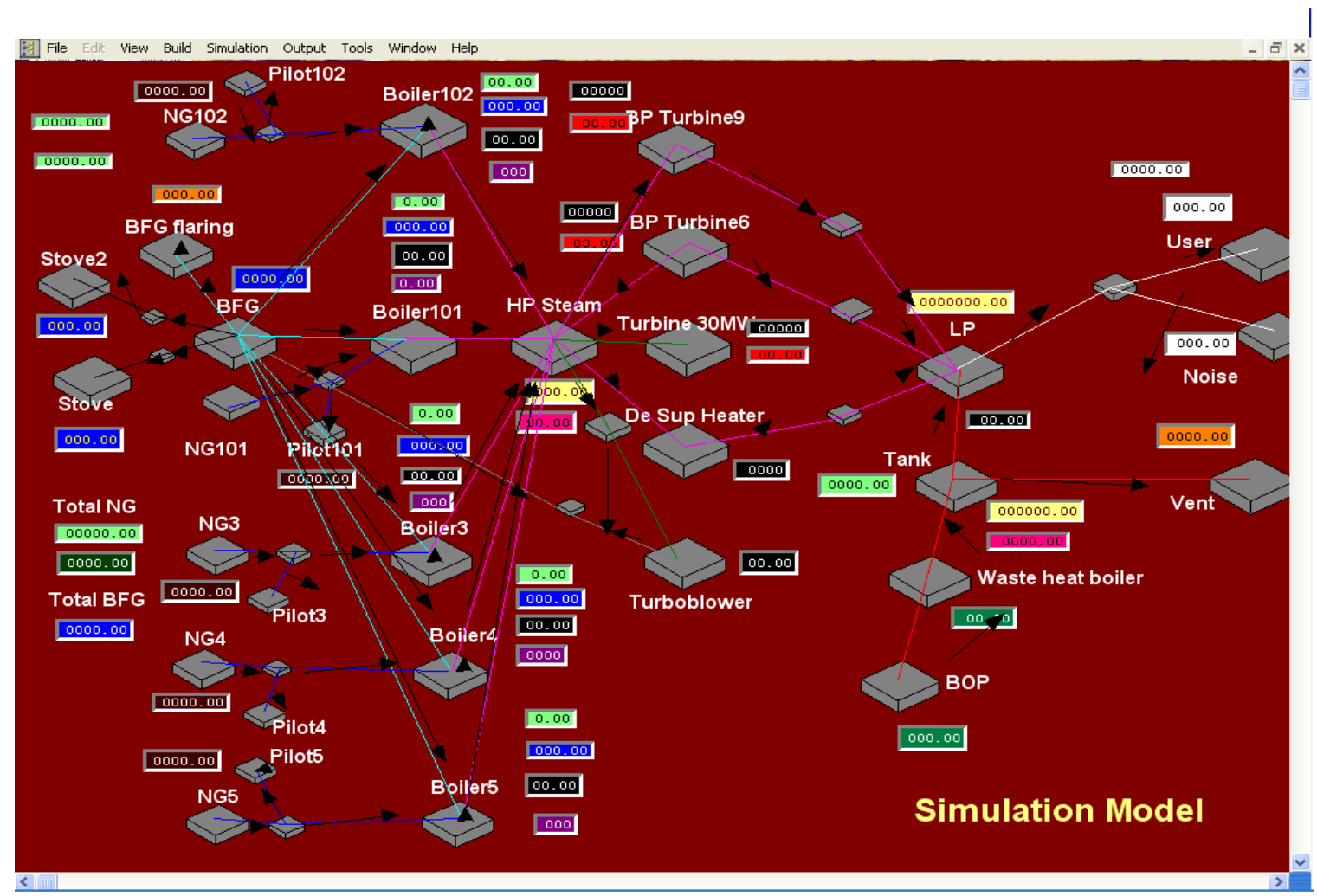

Figure A1.1: Screenshot of the model

\begin{tabular}{|l|l|}
\hline Color & Variable \\
\hline Blue & Blast furnace gas (BFG) \\
\hline Light green & Natural gas (NG) \\
\hline Black & Steam flow rate / Firing rate for boilers \\
\hline Purple & Efficiency of the boilers \\
\hline Yellow & KP of steam in HP or LP \\
\hline Pink & Pressure of steam corresponding to KP of steam \\
\hline Red & Electricity generated by the turbines \\
\hline White & User requirement \\
\hline Dark green & BOP cycle \\
\hline Orange & $\begin{array}{l}\text { Represents the loss of energy } \\
\text { (BFG flaring and Steam venting) }\end{array}$ \\
\hline
\end{tabular}

Table A1.1: Color Coding Scheme 


\section{Appendix II}

Table A2.1: List of variables

\begin{tabular}{|c|c|c|c|c|}
\hline Sr. No & Variable & Type & \begin{tabular}{|l} 
Initial \\
Value
\end{tabular} & Used For \\
\hline 1 & User_req_counter & Real & 0 & User demand \\
\hline 2 & User_cumm & Real & 0 & Cumulative user demand \\
\hline 3 & Dummy_arrival_counter & Real & 0 & Arrival at user \\
\hline 4 & HP_Steam_Arrival & Real & 0 & Arrival at High Pressure (HP) header \\
\hline 5 & BOP_Steam_arrival & Real & 1 & Arrival at BOP \\
\hline 6 & LP_Steam_arrival_var & Real & 0 & Arrival at Low Pressure (LP) header \\
\hline 7 & Total_LP_steam & Real & 0 & Amount of steam in LP \\
\hline 8 & desuperheater & Real & 0 & Steam flow through desuperheater \\
\hline 9 & Boiler_var101 & Real & 3.33 & Steam generation in boiler 101 \\
\hline 10 & Boiler_var101cumm & Real & 0 & Graph for the steam generation in 101 \\
\hline 11 & HP_Steam_var & Real & 20 & Amount of steam in HP header \\
\hline 12 & turbo_blower & Real & 0 & Steam flow through Turbo blower \\
\hline 13 & $\mathrm{~m} 1$ & Real & 0 & Steam in Waste heat boilers \\
\hline 14 & bol & Real & 0 & Counter \\
\hline 15 & Boiler_var102 & Real & 3.33 & Steam generation in boiler 102 \\
\hline 16 & Boiler_var102cumm & Real & 0 & Graph for the steam generation in 102 \\
\hline 17 & Boiler_var3 & Real & 2.17 & Steam generation in boiler 3 \\
\hline 18 & Boiler_var3cumm & Real & 0 & Graph for the steam generation in 3 \\
\hline 19 & Boiler_var4 & Real & 2.17 & Steam generation in boiler 4 \\
\hline 20 & Boiler_var4cumm & Real & 0 & Graph for the steam generation in 4 \\
\hline 21 & Boiler_var5 & Real & 3.67 & Steam generation in boiler 5 \\
\hline 22 & Boiler_var5cumm & Real & 0 & Graph for the steam generation in 5 \\
\hline 23 & NG_101 & Real & 0 & Natural gas consumption for boiler 101 \\
\hline 24 & NG_102 & Real & 0 & Natural gas consumption for boiler 102 \\
\hline 25 & NG_3 & Real & 0 & Natural gas consumption for boiler 3 \\
\hline 26 & NG_4 & Real & 0 & Natural gas consumption for boiler 4 \\
\hline 27 & $\mathrm{NG}_{-}^{-} 5$ & Real & 0 & Natural gas consumption for boiler 5 \\
\hline 28 & flaregraph & Real & 0 & Graph of the Flared BFG \\
\hline 29 & Flare & Real & 0 & Flaring of BFG \\
\hline 30 & MW30tur & Real & 0 & Power Generation in turbine $\# 8$ \\
\hline 31 & MW6tur & Real & 0 & Power Generation in turbine \#6 \\
\hline 32 & MW9tur & Real & 0 & Power Generation in turbine $\# 9$ \\
\hline 33 & Total & Real & 200 & Amount of Steam in LP \\
\hline 34 & $\mathrm{~m}$ & Real & 8 & Amount of steam in accumulator \\
\hline 35 & $\mathrm{~m} 2$ & Real & 0 & Steam Flow from accumulator to LP \\
\hline
\end{tabular}




\begin{tabular}{|c|c|c|c|c|}
\hline 36 & LP_Pressure & Real & 0 & Pressure in LP \\
\hline 37 & HP_Pressure & Real & 0 & Pressure in HP \\
\hline 38 & NG_cumm & Real & 0 & Cummulative natural gas consumption \\
\hline 39 & NG_tot & Real & 0 & Total natural gas consumption \\
\hline 40 & Stove_var & Real & 3.59 & BFG consumed by stove 1 \\
\hline 41 & Stove_var2 & Real & 3.59 & BFG consumed by stove 2 \\
\hline 42 & arr_value & Real & 1 & Pointer in array \\
\hline 43 & $\mathrm{i}$ & Real & 0 & Counter \\
\hline 44 & $\mathrm{k}$ & Real & 0 & Counter \\
\hline 45 & Noise_var & Real & 0 & Noise for the user \\
\hline 46 & Tot_BFGgraph & Real & 0 & Graph for total BFG consumed \\
\hline 47 & Tot_BFG & Real & 0 & Total BFG consumed \\
\hline 48 & btu101 & Real & 0 & $\begin{array}{l}\text { Fuel requirement for boiler } 101 \text { in } \\
\text { terms of btu's }\end{array}$ \\
\hline 49 & btu102 & Real & 0 & $\begin{array}{l}\text { Fuel requirement for boiler } 102 \text { in } \\
\text { terms of btu's }\end{array}$ \\
\hline 50 & btu3 & Real & 0 & $\begin{array}{l}\text { Fuel requirement for boiler } 3 \text { in terms } \\
\text { of btu's }\end{array}$ \\
\hline 51 & btu4 & Real & 0 & $\begin{array}{l}\text { Fuel requirement for boiler } 4 \text { in terms } \\
\text { of btu's }\end{array}$ \\
\hline 52 & btu5 & Real & 0 & $\begin{array}{l}\text { Fuel requirement for boiler } 5 \text { in terms } \\
\text { of btu's }\end{array}$ \\
\hline 53 & Totalbtu & Real & 0 & $\begin{array}{l}\text { Total requirement of fuel for all boilers } \\
\text { in terms of btu's }\end{array}$ \\
\hline 54 & pi101 & Real & 0 & $\begin{array}{l}\text { Natural gas consumed by pilot for } \\
\text { boiler } 101\end{array}$ \\
\hline 55 & pi102 & Real & 0 & $\begin{array}{l}\text { Natural gas consumed by pilot for } \\
\text { boiler } 102\end{array}$ \\
\hline 56 & pi3 & Real & 0 & $\begin{array}{l}\text { Natural gas consumed by pilot for } \\
\text { boiler } 3\end{array}$ \\
\hline 57 & pi4 & Real & 0 & $\begin{array}{l}\text { Natural gas consumed by pilot for } \\
\text { boiler } 4\end{array}$ \\
\hline 58 & pi5 & Real & 0 & $\begin{array}{l}\text { Natural gas consumed by pilot for } \\
\text { boiler } 5\end{array}$ \\
\hline 59 & watervar & Real & 0 & For water addition in desuperheater \\
\hline 60 & Vent_var & Real & 0 & Amount of steam vented \\
\hline 61 & s1 & Real & 3.59 & BFG consumed by Stove 1 \\
\hline 62 & $\mathrm{~s} 2$ & Real & 3.59 & BFG consumed by Stove 2 \\
\hline 63 & sc1 & Integer & 2 & $\begin{array}{l}\text { For timing of first stove's bottling (in } \\
\text { terms of the minute it is bottled) }\end{array}$ \\
\hline
\end{tabular}




\begin{tabular}{|c|l|c|c|l|}
\hline 64 & sc2 & Integer & 2 & $\begin{array}{l}\text { For timing of second stove's bottling (in } \\
\text { terms of the minute it is bottled) }\end{array}$ \\
\hline 65 & error & Real & 0 & $\begin{array}{l}\text { Calculating the amonut of steam } \\
\text { required in LP header }\end{array}$ \\
\hline 66 & MW9 & Real & 5.58 & Steam flow through turbine \#9 \\
\hline 67 & MW9graph & Real & 0 & Graph of steam flow through turbine \#9 \\
\hline 68 & MW6tur & Real & 3.92 & Steam flow through turbine \#6 \\
\hline 69 & MW6graph & Real & 0 & Graph of steam flow through turbine \#6 \\
\hline 70 & desuper & Real & 6.67 & Steam flow through desuperheater \\
\hline 71 & desupergraph & Real & 0 & $\begin{array}{l}\text { Graph of steam flow through } \\
\text { desuperheater }\end{array}$ \\
\hline 72 & count1 & Real & 0 & Counter \\
\hline 73 & tur30 & Real & 0 & Graph of steam flow through turbine \#8 \\
\hline 74 & MW30 & Real & 2.71 & Steam flow through turbine \#8 \\
\hline 75 & BOPgraphvar & Real & 0 & Graph of the BOP steam \\
\hline 76 & bol1 & Real & 0 & Counter \\
\hline 77 & bol2 & Real & 0 & Counter \\
\hline 78 & bol3 & Real & 0 & Counter \\
\hline 79 & Total1 & Real & 0 & Graph of amount of steam in LP \\
\hline 80 & HP_Steam_var1 & Real & 0 & Graph of amount of steam in HP \\
\hline 81 & bol4 & Integer & 0 & Counter \\
\hline 82 & eff101 & Real & 0 & Efficiency for boiler 101 \\
\hline 83 & eff102 & Real & 0 & Efficiency for boiler 102 \\
\hline 84 & eff3 & Real & 0 & Efficiency for boiler 3 \\
\hline 85 & eff4 & Real & 0 & Efficiency for boiler 4 \\
\hline 86 & eff5 & Real & 0 & Efficiency for boiler 5 \\
\hline 87 & bol5 & Integer & 0 & Counter \\
\hline 88 & bol6 & Integer & 0 & Counter \\
\hline 89 & bol7 & Integer & 0 & Counter \\
\hline 90 & bol8 & Integer & 0 & Counter \\
\hline 91 & bol9 & Integer & 0 & Counter \\
\hline 92 & bol10 & Integer & 0 & Counter \\
\hline 93 & bol11 & Integer & 0 & Counter \\
\hline 94 & mgraph & Real & 0 & $\begin{array}{l}\text { Graph of amount of steam in } \\
\text { accumulator }\end{array}$ \\
\hline 95 & Ventgraph & Real & 0 & Graph of amount of steam vented \\
\hline 96 & m2graph & 0 & $\begin{array}{l}\text { Graph of amount of steam flowing } \\
\text { from accumulator to LP }\end{array}$ \\
\hline 97 & count2 & Counter \\
\hline
\end{tabular}




\begin{tabular}{|c|l|c|c|l|}
\hline 98 & sv & Real & 0 & $\begin{array}{l}\text { Specific Volume of steam in } \\
\text { accumulator }\end{array}$ \\
\hline 99 & tp & Real & 0 & Steam Pressure in accumulator \\
\hline 100 & bfgcon101 & Real & 0 & BFG consumed by boiler 101 \\
\hline 101 & bfgcon102 & Real & 0 & BFG consumed by boiler 102 \\
\hline 102 & bfgcon3 & Real & 0 & BFG consumed by boiler 3 \\
\hline 103 & bfgcon4 & Real & 0 & BFG consumed by boiler 4 \\
\hline 104 & bfgcon5 & Real & 0 & BFG consumed by boiler 5 \\
\hline 105 & bfgcontot & Real & 0 & Total BFG consumed \\
\hline 106 & Ngcost & Real & 0 & Total natural gas cost \\
\hline 107 & g1 & Real & 0 & Counter \\
\hline
\end{tabular}




\section{Appendix III}

Input values / Arrays

\begin{tabular}{|c|c|c|c|}
\hline Sr. No & Equipment No. & & KPPM \\
\hline 1 & 101 & Min & 3.33 \\
\hline 2 & & Max & 5.33 \\
\hline 3 & 102 & Min & 3.33 \\
\hline 4 & & Max & 5.33 \\
\hline 5 & 3 & Min & 2.17 \\
\hline 6 & & Max & 5.00 \\
\hline 7 & 4 & Min & 2.17 \\
\hline 8 & & Max & 5.00 \\
\hline 9 & 5 & Min & 3.67 \\
\hline 10 & & Max & 6.00 \\
\hline 11 & T6 & Min & 1.17 \\
\hline 12 & & Max & 6.67 \\
\hline 13 & T9 & Min & 1.17 \\
\hline 14 & & Max & 10.00 \\
\hline 15 & T8 & Min & 0.42 \\
\hline 16 & & Max & 5.00 \\
\hline 17 & Ramp rates & 101 & 0.02 \\
\hline 18 & & 102 & 0.02 \\
\hline 19 & & 3 & 0.01 \\
\hline 20 & & 4 & 0.01 \\
\hline 21 & & 5 & 0.01 \\
\hline 22 & & T6 & 0.20 \\
\hline 23 & & T9 & 0.20 \\
\hline 24 & & Trg & 0.24 \\
\hline 25 & Desuper & Ramp rate & 1.00 \\
\hline 26 & & Min & 0.00 \\
\hline 27 & & Max & 13.32 \\
\hline 28 & & 3.58 \\
\hline 29 & & & \\
\hline 30 & & & Avg \\
\hline
\end{tabular}

Table A3.1: Array Name - arrboltur[] (Array for boilers, turbine and desuperheater data) 


\begin{tabular}{|c|c|c|c|}
\hline $\begin{array}{l}\text { Sr. } \\
\text { No }\end{array}$ & Set Points & $\begin{array}{c}\begin{array}{c}\text { Values in } \\
\text { model }\end{array} \\
\end{array}$ & Unit \\
\hline 1 & HP set pt & 22 & $\mathrm{KP}$ \\
\hline 2 & LP set pt & 17.5 & KP \\
\hline 3 & Vent set pt & 30 & KP \\
\hline 4 & Tank to LP & 4.8 & KPPM \\
\hline 5 & Tank set pt & 8 & $\mathrm{KP}$ \\
\hline 6 & User & 13.8 & KPPM \\
\hline 7 & TB & 6.51 & KPPM \\
\hline 8 & Vent capacity & 17.04 & $\mathrm{KP}$ \\
\hline 9 & Desuperheater & 13.32 & KPPM \\
\hline 10 & $\begin{array}{l}\text { rate of flow (tank to } \\
\text { LP) }\end{array}$ & 1 & КРPM \\
\hline 11 & $\begin{array}{l}\text { rate of flow (tank to } \\
\text { Vent) }\end{array}$ & 1 & KPPM \\
\hline 12 & BFG arrival & 20.72 & MMBtu's \\
\hline 13 & Stove arrival1 & 3.59 & MMBtu's \\
\hline 14 & Stove arrival2 & 3.59 & MMBtu's \\
\hline 15 & Pilotarival101 & 0.33 & MMBtu's \\
\hline 16 & Pilotarival102 & 0.33 & MMBtu's \\
\hline 17 & Pilotarival3 & 0.42 & MMBtu's \\
\hline 18 & Pilotarival4 & 0.42 & MMBtu's \\
\hline 19 & Pilotarival5 & 0.87 & MMBtu's \\
\hline 20 & NGarrival101 & 1.00 & MMBtu's \\
\hline 21 & NGarrival102 & 1.00 & MMBtu's \\
\hline 22 & NGarrival3 & 1.25 & MMBtu's \\
\hline 23 & NGarrival4 & 1.25 & MMBtu's \\
\hline 24 & NGarrival5 & 2.60 & MMBtu's \\
\hline
\end{tabular}

Table A3.2: Array Name - arrsetpt[] (Array for various set points and initial values) 


\begin{tabular}{|c|c|}
\hline Cummsec[] & boparr[] \\
\hline Minute & $\begin{array}{c}\text { Value } \\
(\mathrm{KP})\end{array}$ \\
\hline 1 & 0.341 \\
\hline 2 & 0.335 \\
\hline 3 & 0.330 \\
\hline 4 & 0.324 \\
\hline 5 & 0.319 \\
\hline 6 & 0.313 \\
\hline 7 & 0.308 \\
\hline 8 & 0.302 \\
\hline 9 & 0.296 \\
\hline 10 & 0.291 \\
\hline 11 & 0.285 \\
\hline 12 & 0.280 \\
\hline 13 & 0.274 \\
\hline 14 & 1.357 \\
\hline 15 & 4.723 \\
\hline 16 & 6.553 \\
\hline 17 & 7.956 \\
\hline 18 & 9.592 \\
\hline 19 & 10.827 \\
\hline 20 & 12.084 \\
\hline 21 & 14.905 \\
\hline 22 & 17.163 \\
\hline 23 & 17.987 \\
\hline 24 & 19.997 \\
\hline 25 & 20.269 \\
\hline 26 & 18.748 \\
\hline 27 & 18.082 \\
\hline 28 & 17.875 \\
\hline 29 & 17.880 \\
\hline 30 & 18.102 \\
\hline & \\
\hline
\end{tabular}

\begin{tabular}{|c|c|}
\hline Cummsec[] & boparr[] \\
\hline Minute & $\begin{array}{c}\text { Value } \\
\text { (KP) }\end{array}$ \\
\hline 31 & 17.089 \\
\hline 32 & 9.715 \\
\hline 33 & 2.759 \\
\hline 34 & 0.791 \\
\hline 35 & 0.479 \\
\hline 36 & 0.477 \\
\hline 37 & 0.475 \\
\hline 38 & 0.473 \\
\hline 39 & 0.471 \\
\hline 40 & 0.469 \\
\hline 41 & 0.466 \\
\hline 42 & 0.464 \\
\hline 43 & 0.462 \\
\hline 44 & 0.460 \\
\hline 45 & 0.458 \\
\hline 46 & 0.456 \\
\hline 47 & 0.454 \\
\hline 48 & 0.452 \\
\hline 49 & 0.450 \\
\hline 50 & 0.448 \\
\hline 51 & 0.446 \\
\hline 52 & 0.444 \\
\hline 53 & 0.442 \\
\hline 54 & 0.440 \\
\hline 55 & 0.438 \\
\hline 56 & 0.436 \\
\hline 57 & 0.433 \\
\hline 58 & 0.431 \\
\hline 59 & 0.429 \\
\hline 60 & 0.427 \\
\hline & \\
\hline 5
\end{tabular}

Table A3.3: Array Name: Cummsec[] and boparr[] (Arrays for BOP arrivals, one is for the minute and other for the value ) 


\section{Appendix IV}

\section{I] Relationship between volume of steam in accumulator and corresponding pressure}

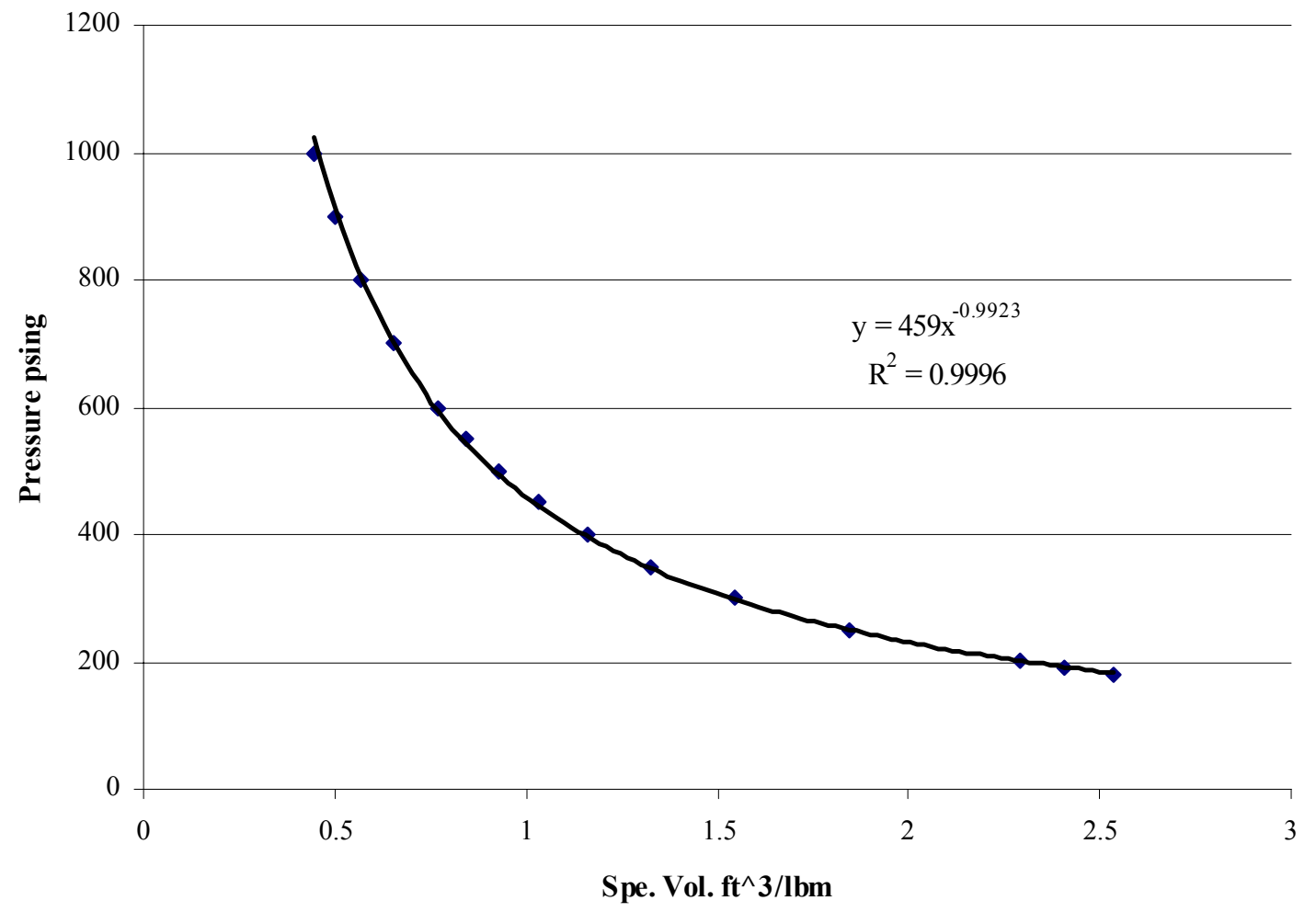

Figure A4.1: Graph of Pressure vs. Specific Volume

Using the saturated water - pressure table [27], for the range of pressure from 180 psig to $1000 \mathrm{psig}$, the specific volume of steam is found out at each level pressure level and is plot as shown in figure. An exponential relationship is obtained which is:

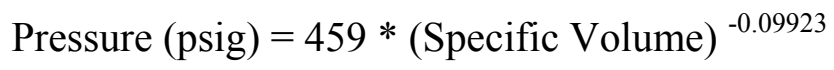

As the volume of the tank is known, consists of two pipes 10 feet in diameter and 120 feet in length, we can calculate the amount of steam in tank at a given pressure or vice versa. Finally the relationship is as under:

$$
\text { Pressure }(\mathrm{psig})=459 *(18852 /(\mathrm{m} * 1000))^{-0.09923}
$$

where, $\mathrm{m}=$ amount of steam in tank in $1000 \mathrm{lbs}$. 


\section{II] Relationship between volume of steam in high pressure header and corresponding pressure}

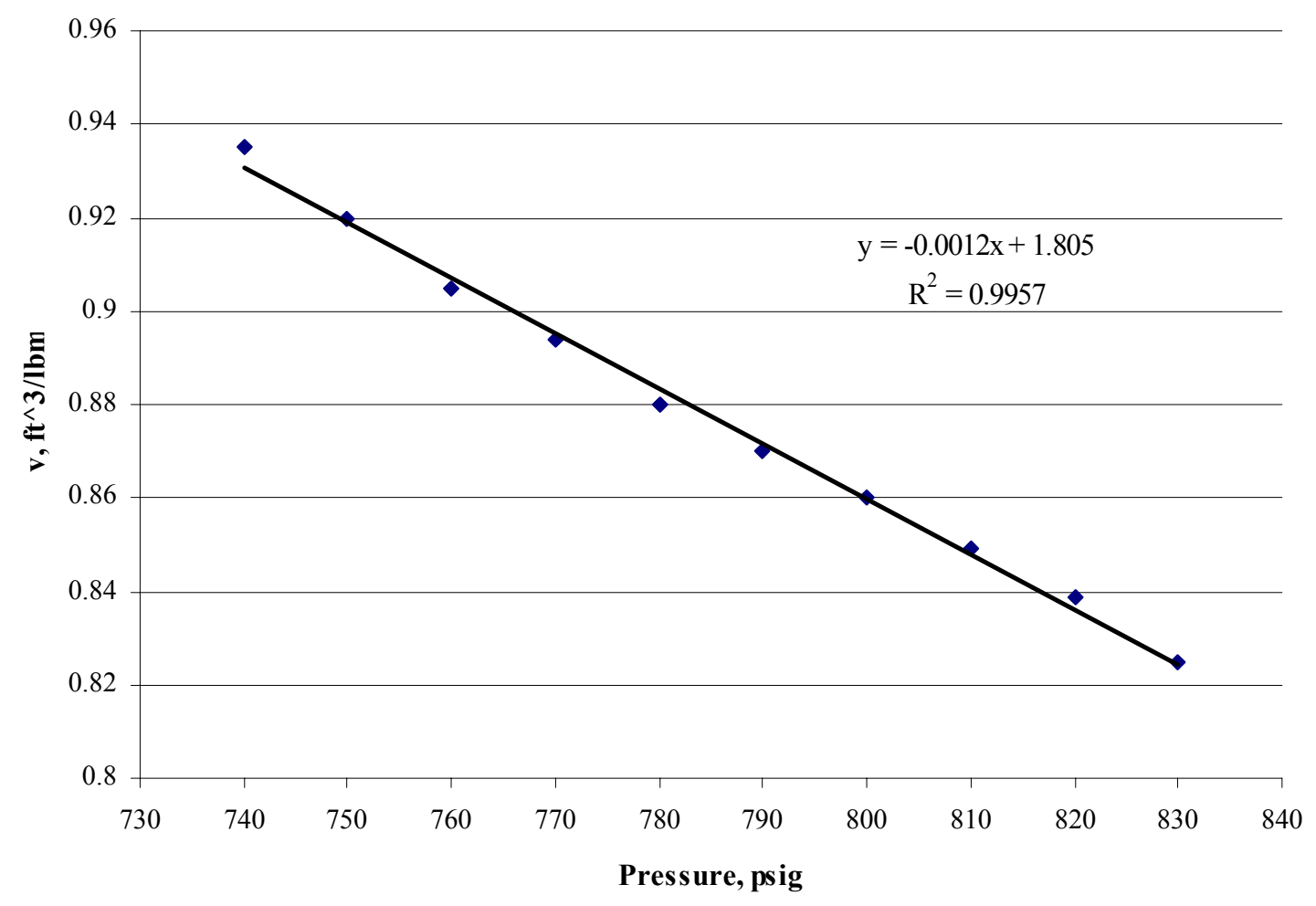

Figure A4.2: Graph of Specific Volume vs. Pressure

Using the superheated water table [27], for the range of pressure from 740 psig to $830 \mathrm{psig}$, the specific volume of steam is found out at each level pressure level and is plot as shown in figure. The linear relationship is obtained over the given range which is:

$$
\text { Specific Volume }=-0.0012 * \text { Pressure }+1.805
$$

The volume of the high pressure header is assumed to be same as that of the tank (18852 cubic feet), we can calculate the amount of steam in the high pressure header at any given pressure or vice versa. Finally the relationship is as under:

$$
\text { Pressure }(\text { psig })=1504.08-\left(833.33 *\left(18852 /\left(\mathrm{m}^{*} 1000\right)\right)\right)
$$

where, $\mathrm{m}=$ amount of steam in high pressure header in $1000 \mathrm{lbs}$. 


\section{Appendix V}

The following shows calculations performed in the operation code for the software. The numbers here are related to the logic flow chart in the previous section, as shown in Figure 3.8. Each number is related to a process block or a decision box in the logic flow process chart.

1. Initialize the variable for user (User_req counter) to the user demand at that minute. This demand is addition of the normal demand plus the noise, if any noise is put into the model. The variable related to noise is Noise_var. thus,

$$
\text { User demand }=\text { User_req_counter }+ \text { Noise_var }
$$

2. This user demand is then pulled from the low pressure header. Thus the amount of steam in the low pressure header (Total) will reduce.

$$
\text { Total }=\text { Total }- \text { User_req_counter- Noise_var }
$$

3. The pulling of steam from the low pressure header will reduce the pressure in the header. As per the assumption for the low pressure header, the $1000 \mathrm{lbs}$ of steam correspond to 1 psig pressure. Thus the user pull will be the amount, which equals the reduction in steam pressure. The steam pressure should be maintained at 200 psig, thus here we check the steam pressure (Total) and depending on its value we either ramp down the turbines or pull steam from the accumulator.

4. If the steam pressure (Total) is less than $200 \mathrm{psig}$, we calculate the error. The variable is named as 'error' itself. This error is the amount of steam required to maintain the steam pressure at $200 \mathrm{psig}$. Thus

$$
\text { error }=200-\text { Total }
$$

If the error is less than zero it is set back to zero.

5. The accumulators are charged up to a point before they send steam to the low pressure header. This test box checks the steam level (m) in accumulator, also 
called as Tank. If the steam is more than $8000 \mathrm{lbs}$ (200 psig pressure) then the steam is routed to the low pressure header.

6. The next test box checks whether the steam in accumulator can satisfy the 'error'. If the error is greater than the available steam, all the steam is routed to the low pressure header ('Yes' for the test box). Again it checks the steam pressure and moves through the loop. In case, where no steam is available in the accumulator, the steam will be supplied by the turbines.

7. As the turbines ramp up new steam flow rate will be calculated with the updated amount of steam in the low pressure header (Total). Thus for the turbines -

$$
\begin{gathered}
\text { MW9 }=-1.7667 * \text { Total }+363.33 \\
\text { MW6 }=-0.9167 * \text { Total }+184.5
\end{gathered}
$$

For both the turbine variables the maximum and minimum bounds are checked. As this amount of steam is pulled by the turbines it is added to the low pressure header. Thus for the low pressure header -

$$
\begin{aligned}
& \text { Total }=\text { Total }+ \text { MW9 } \\
& \text { Total }=\text { Total }+ \text { MW6 }
\end{aligned}
$$

This same amount is then reduced from the high pressure header. And thus for the high pressure header -

$$
\begin{aligned}
& \text { HP_Steam_var }=\text { HP_Steam_var }- \text { MW9 } \\
& \text { HP_Steam_var }=\text { HP_Steam_var }- \text { MW6 }
\end{aligned}
$$

8. In case when the turbines are ramped down, again new steam flow rate is calculated using the same relations. But in this case due to the variable Total, which is greater than 200 will cause the steam flow rate to reduce (variables MW9 and MW6) and thus less steam is pulled from the high pressure header and added to the low pressure header. The pressure in the high pressure header is then checked for its set point. 
9. When the 'error' is smaller than, the amount of steam in accumulator, only the required steam is routed to the low pressure header. This will increase the amount of steam in the accumulator.

10. In the accumulator we check for two levels of steam. First the charging point (CP), as stated earlier is $8000 \mathrm{lbs}$ (200 psig). If the steam is less than the set point, then no steam is routed to the low pressure header and the steam is accumulated in the accumulator. As the accumulator is charged to the level of $8000 \mathrm{lbs}$ (200 psig) steam is routed to low pressure header. The variable $\mathrm{m} 2$, is the amount of steam passed by the accumulator to the low pressure header.

$\mathrm{m} 2=(\mathrm{m}-\mathrm{CP})^{*}$ Rate of transfer from accumulator to low pressure header

This steam is then added to the low pressure header -

$$
\text { Total }=\text { Total }+\mathrm{m} 2
$$

11. The steam from the waste heat boilers, the BOP steam (BOP_Steam_arrival), is directly added to the accumulator. Secondly, if the amount of steam is greater than $30,000 \mathrm{lbs}$ (600 psig), the venting point (VP), steam is vented. The vent has a maximum capacity of $17,040 \mathrm{lbs} / \mathrm{min}$, which is checked while venting the steam. Thus from the above description the amount of steam to be vented is -

$$
\text { Vent_var }=(800 /(200 * 60)) *(\text { tp-600 }) \text {, }
$$

where, tp is the pressure in the accumulator based on the amount of steam present. The pressure is calculated by finding the specific volume (sv) of the steam in the accumulator. The expressions for the steam specific volume and pressure are as given below -

$$
\begin{gathered}
\mathrm{sv}=(18852 /(\mathrm{m} * 1000)) \\
\operatorname{tp}=459 *(\mathrm{sv})^{-0.9923}
\end{gathered}
$$

The amount of steam in accumulator $(\mathrm{m})$ is given by - 


$$
\mathrm{m}=\mathrm{m}+\text { BOP_Steam_arrival-m2-Vent_var }
$$

12. When the turbines cannot suffice the need of steam in the low pressure header the desuperheaters are used along with the turbines. The steam flow rate for the turbines are calculated as specified earlier. For the desuperheaters, the steam flow rate is given by -

$$
\text { desuper }=-0.9514 * \text { Total }+184.58
$$

Similar to that of the turbines, desuperheaters will pull the required amount from the high pressure header and add it to the low pressure header. Thus the calculations of desuperheaters operation are similar to that of the turbines mentioned above.

$$
\begin{aligned}
\text { HP_Steam_var } & =\text { HP_Steam_var }- \text { desuper } \\
\text { Total } & =\text { Total }+ \text { desuper }
\end{aligned}
$$

13. As the turbines and the desuperheaters pull the steam from the high pressure header, the steam in the high pressure header reduces. Thus the pressure in the high pressure header reduces. We calculate the steam pressure in the high pressure header with the following expression -

$$
\text { HP_Pressure }=1504.08-(833.33 *(18852 /(\text { HP_Steam_var * 1000) }))
$$

14. The pressure in the high pressure header is maintained at $800 \mathrm{psig}$. If the pressure is more than $800 \mathrm{psig}$, the turbine \# 8 is ramped up pulling the excess steam from the header. This ramping up the turbine is similar to the one explained earlier. The steam flow rate for the turbine (MW30) is calculated by the expression -

$$
\mathrm{MW} 30=2.2917 * \text { HP_Steam_var }-45.417
$$

As this steam is pulled from the high pressure header, the steam in the high pressure header reduces. Thus

$$
\text { HP_Steam_var }=\text { HP_Steam_var }- \text { MW30 }
$$


15. Along with ramping of turbine, the boilers are ramped down so as to minimize the amount of steam put in the high pressure header. With the HP_Steam_var variable, the firing rates of the boilers are calculated for each of the boiler the firing rates are calculated as follows -

$$
\begin{gathered}
\text { Boiler_var101 }=- \text { HP_Steam_var }+23.33 \\
\text { Boiler_var102 }=- \text { HP_Steam_var }+21.33 \\
\text { Boiler_var3 }=-1.42 * \text { HP_Steam_var }+24.83 \\
\text { Boiler_var4 }=-1.42 * \text { HP_Steam_var }+22 \\
\text { Boiler_var5 }=-1.17 * \text { HP_Steam_var }+17.667
\end{gathered}
$$

For all the boiler variables the maximum and minimum bounds are checked.

16. In case when the pressure in the high pressure header is less than $800 \mathrm{psig}$, the boilers are ramped up so that they input more steam. As in the above case, new firing rates of the boilers are calculated using the same expressions. But in this case due to the variable HP_Steam_var, which is less than 800 will cause the firing rates to increase.

17. As we calculate the new firing rate for the boilers, the fuel requirement for each is also calculated by expressions -

$$
\begin{aligned}
\text { btu101 } & =(\text { Boiler_var/ }(\text { eff101/100))- pi101 } \\
\text { btu102 } & =(\text { Boiler_var/ }(\text { eff102/100))- pi102 } \\
\text { btu3 } & =(\text { Boiler_var/ }(\text { eff3/100))- pi3 } \\
\text { btu4 } & =(\text { Boiler_var/ }(\text { eff4/100))- pi4 } \\
\text { btu5 } & =(\text { Boiler_var/ }(\text { eff5/100))- pi5 }
\end{aligned}
$$

where,

all pi's are the fuel required by the boiler's pilots and all eff's are the efficiency of boilers given by the expressions -

$$
\begin{aligned}
\text { eff } 101 & =9.375 * \text { Boiler_var101+40 } \\
\text { eff1 } 102 & =9.375 * \text { Boiler_var102+40 } \\
\text { eff3 } & =10 * \text { Boiler_var3 }+40
\end{aligned}
$$




$$
\begin{gathered}
\text { eff4 }=10 * \text { Boiler_var } 4+40 \\
\text { eff5 }=8.33 * \text { Boiler_var } 5+40
\end{gathered}
$$

Total amount of btu's (Totalbtu) are calculated and then compared with the available BFG (Tot_BFG). The total fuel required is as per expression -

$$
\text { Totalbtu }=\text { btu101+btu102+btu3+btu4+btu5 }
$$

18. Each boiler will check if the BFG can suffice its fuel need. If it can, then that quantity of fuel is then absorbed from the Tot_BFG. Thus taking the case for boiler 101, if the available BFG is sufficient to keep the boiler at required firing level then,

$$
\text { Tot_BFG }=\text { Tot_BFG }- \text { btu101 }
$$

In case where the available BFG cannot satisfy the fuel requirement completely, the boiler will consume the available BFG and then for the remaining requirement, natural gas is used. Thus in case where boiler 101 requires more fuel than available BFG following calculations are performed -

$$
\text { btu101 = btu101 - Tot_BFG (Uses the available BFG) }
$$

NG_101 = btu101 (the remaining needs is sufficed by natural gas)

19. Here NG_101 is the variable which indicates the quantity of natural gas is consumed by boiler 101 . The same calculations are performed by all the boilers. We can now calculate the Total amount of natural (NG_tot) gas consumed by the expression -

$$
\mathrm{NG} \_ \text {tot }=\mathrm{NG} \_101+\mathrm{NG} \_102+\mathrm{NG} \_3+\mathrm{NG} \_4+\mathrm{NG} \_5+\mathrm{pi} 101+\mathrm{pi} 102+\mathrm{pi} 3+\mathrm{pi} 4+\mathrm{pi} 5
$$

And the natural gas cost can be calculated as -

$$
\text { NG_cost }=\text { NG_tot } * 5.5
$$


20. In case where the amount of BFG is more than consumed by the stoves and the boilers, the BFG is flared. This amount is vented to the atmosphere and thus lost. Thus to keep a track of it -

$$
\text { Tot_BFG }=\text { Tot_BFG }- \text { flare }
$$

Where 'flare' is the variable denoting the quantity of BFG flared.

21. The process initializes the variables $(\mathrm{s} 1, \mathrm{~s} 2)$ related to the stoves. These represent the amount of BFG consumed by the stoves. When the stoves are bottled then they do not consume any BFG, thus the variables are set to zero if the stoves are bottled at a particular minute and after the bottling time, it is again set back to its original value. 
Table A5.1: Table of energy related variables

\begin{tabular}{|c|c|c|c|c|}
\hline $\begin{array}{c}\text { Sr } \\
\text { No. }\end{array}$ & Variable & Aspect or Function & Units & Range \\
\hline 1 & User_req_counter & User Demand & $\begin{array}{c}1000 \\
1 \mathrm{bs} / \mathrm{min}\end{array}$ & 13.8 \\
\hline 2 & Noise_var & Noise for User & $\begin{array}{c}1000 \\
\mathrm{lbs} / \mathrm{min}\end{array}$ & $\begin{array}{c} \pm 10 \% \text { of User } \\
\text { Demand }\end{array}$ \\
\hline 3 & Total & $\begin{array}{l}\text { Steam in low pressure } \\
\text { header in } 1000 \mathrm{lbs}\end{array}$ & $1000 \mathrm{lbs}$ & $180-200$ \\
\hline 4 & error & Low pressure header & $1000 \mathrm{lbs}$ & $0-20$ \\
\hline 5 & $\mathrm{~m}$ & $\begin{array}{l}\text { Steam in Tank or } \\
\text { Accumulator in } 1000 \mathrm{lbs}\end{array}$ & $1000 \mathrm{lbs}$ & $8-30$ \\
\hline 6 & MW9 & Steam flow rate of Turbine 9 & $\begin{array}{c}1000 \\
1 \mathrm{bs} / \mathrm{min}\end{array}$ & $1.2-10$ \\
\hline 7 & MW6 & Steam flow rate of Turbine 6 & $\begin{array}{c}1000 \\
\mathrm{lbs} / \mathrm{min}\end{array}$ & $1.2-6.7$ \\
\hline 8 & HP_Steam_var & $\begin{array}{l}\text { Steam in High pressure } \\
\text { header in } 1000 \mathrm{lbs}\end{array}$ & $1000 \mathrm{lbs}$ & $10-22$ \\
\hline 9 & $\mathrm{~m} 2$ & $\begin{array}{l}\text { Rate of flow from } \\
\text { accumulator to low pressure } \\
\text { header }\end{array}$ & $\begin{array}{c}1000 \\
1 \mathrm{bs} / \mathrm{min}\end{array}$ & $0-4.8$ \\
\hline 10 & Vent_var & $\begin{array}{l}\text { Steam vented in } 1000 \\
\text { lbs/min }\end{array}$ & $\begin{array}{c}1000 \\
\mathrm{lbs} / \mathrm{min}\end{array}$ & $0-17.04$ \\
\hline 11 & tp & $\begin{array}{l}\text { Steam pressure in } \\
\text { accumulator }\end{array}$ & psig & $200-1000$ \\
\hline 12 & BOP Steam arrival & BOP & $\begin{array}{c}1000 \\
\mathrm{lbs} / \mathrm{min}\end{array}$ & $0-20$ \\
\hline 13 & desuper & $\begin{array}{l}\text { Steam flow rate of } \\
\text { Desuperheater }\end{array}$ & $\begin{array}{c}1000 \\
1 \mathrm{bs} / \mathrm{min}\end{array}$ & $0-13.32$ \\
\hline 14 & HP_Pressure & $\begin{array}{l}\text { Pressure in high pressure } \\
\text { header }\end{array}$ & psig & $740-830$ \\
\hline 15 & MW30 & Steam flow rate of Turbine 8 & $\begin{array}{c}1000 \\
\mathrm{lbs} / \mathrm{min}\end{array}$ & $0.4-5$ \\
\hline 16 & Boiler_var101 & $\begin{array}{l}1000 \text { lbs of Steam generated } \\
\text { by Boiler } 101\end{array}$ & $\begin{array}{c}1000 \\
\mathrm{lbs} / \mathrm{min}\end{array}$ & $3.3-5.3$ \\
\hline 17 & Boiler_var102 & $\begin{array}{l}1000 \mathrm{lbs} \text { of Steam generated } \\
\text { by Boiler } 102\end{array}$ & $\begin{array}{c}1000 \\
\mathrm{lbs} / \mathrm{min}\end{array}$ & $3.3-5.3$ \\
\hline 18 & Boiler_var3 & $\begin{array}{l}1000 \text { lbs of Steam generated } \\
\text { by Boiler } 3\end{array}$ & $\begin{array}{c}1000 \\
\mathrm{lbs} / \mathrm{min}\end{array}$ & $2.2-5$ \\
\hline 19 & Boiler_var4 & $\begin{array}{l}1000 \text { lbs of Steam generated } \\
\text { by Boiler } 4\end{array}$ & $\begin{array}{c}1000 \\
1 \mathrm{bs} / \mathrm{min}\end{array}$ & $2.2-5$ \\
\hline
\end{tabular}




\begin{tabular}{|c|c|c|c|c|}
\hline 20 & Boiler_var5 & $\begin{array}{l}1000 \text { lbs of Steam generated } \\
\text { by Boiler } 5\end{array}$ & $\begin{array}{c}1000 \\
\mathrm{lbs} / \mathrm{min}\end{array}$ & $3.7-6$ \\
\hline 21 & btu101 & $\begin{array}{l}\text { Fuel requirement of Boiler } \\
101\end{array}$ & MMbtu & $3.8-6.3$ \\
\hline 22 & btu102 & $\begin{array}{l}\text { Fuel requirement of Boiler } \\
102\end{array}$ & MMbtu & $3.8-6.3$ \\
\hline 23 & btu3 & Fuel requirement of Boiler 3 & MMbtu & $2.3-5.8$ \\
\hline 24 & btu 4 & Fuel requirement of Boiler 4 & MMbtu & $2.3-5.8$ \\
\hline 25 & btu5 & Fuel requirement of Boiler 5 & MMbtu & $3.7-6.6$ \\
\hline 26 & eff101 & Efficiency of Boiler 101 & $\%$ & $65-80$ \\
\hline 27 & eff102 & Efficiency of Boiler 102 & $\%$ & $65-80$ \\
\hline 28 & eff3 & Efficiency of Boiler 3 & $\%$ & $65-75$ \\
\hline 29 & eff4 & Efficiency of Boiler 4 & $\%$ & $65-75$ \\
\hline 30 & eff5 & Efficiency of Boiler 5 & $\%$ & $65-75$ \\
\hline 31 & pi101 & Pilot for Boiler 101 & MMbtu & 0.33 \\
\hline 32 & pi102 & Pilot for Boiler 102 & MMbtu & 0.33 \\
\hline 33 & pi3 & Pilot for Boiler 3 & MMbtu & 0.42 \\
\hline 34 & pi4 & Pilot for Boiler 4 & MMbtu & 0.42 \\
\hline 35 & pi5 & Pilot for Boiler 5 & MMbtu & 0.87 \\
\hline 36 & Totalbtu & Total fuel requirement & MMbtu & $33.33-18.33$ \\
\hline 37 & Tot_BFG & $\begin{array}{l}\text { Total amount of BFG } \\
\text { produced per min }\end{array}$ & MMbtu & 20.71 \\
\hline 38 & NG_101 & $\begin{array}{l}\text { Natural gas consumed by } \\
\text { Boiler } 101\end{array}$ & MMbtu & $0-6.3$ \\
\hline 39 & NG_102 & $\begin{array}{l}\text { Natural gas consumed by } \\
\text { Boiler } 102\end{array}$ & MMbtu & $0-6.3$ \\
\hline 40 & NG_3 & $\begin{array}{l}\text { Natural gas consumed by } \\
\text { Boiler } 3\end{array}$ & MMbtu & $0-5.8$ \\
\hline 41 & NG_4 & $\begin{array}{l}\text { Natural gas consumed by } \\
\text { Boiler } 4\end{array}$ & MMbtu & $0-5.8$ \\
\hline 42 & NG_5 & $\begin{array}{l}\text { Natural gas consumed by } \\
\text { Boiler } 5\end{array}$ & MMbtu & $0-6.6$ \\
\hline 43 & NG_tot & $\begin{array}{l}\text { Total amount of Natural gas } \\
\text { consumed }\end{array}$ & MMbtu & $0-30.8$ \\
\hline 44 & NG_cost & Total Natrual gas cost & $\$$ & $0-169.4$ \\
\hline 45 & flare & Amount of BFG flared & $\begin{array}{c}1000 \\
\mathrm{lbs} / \mathrm{min}\end{array}$ & - \\
\hline 46 & s1 & $\begin{array}{l}\text { Amonut of BFG consumed } \\
\text { by stove } 1\end{array}$ & MMbtu & 3.58 \\
\hline 47 & s2 & $\begin{array}{l}\text { Amonut of BFG consumed } \\
\text { by stove } 2\end{array}$ & MMbtu & 3.58 \\
\hline
\end{tabular}




\section{Appendix VI}

\section{Source Code}

\begin{tabular}{|c|c|c|c|c|}
\hline \multicolumn{5}{|c|}{ Locations } \\
\hline Name & Cap & Units & Stats & Rules \\
\hline Boiler101 & $\inf$ & 1 & Time Series & Oldest \\
\hline HP_Steam & $\inf$ & 1 & Time Series & Oldest \\
\hline BP_Turbine6 & $\inf$ & 1 & Time Series & Oldest \\
\hline BP_Turbine9 & $\inf$ & 1 & Time Series & Oldest \\
\hline Turbine_30MW & inf & 1 & Time Series & Oldest \\
\hline De_Sup_Heater & inf & 1 & Time Series & Oldest \\
\hline LP & $\inf$ & 1 & Time Series & Oldest \\
\hline User & inf & 1 & Time Series & Oldest \\
\hline Vent & $\inf$ & 1 & Time Series & Oldest \\
\hline BOP & inf & 1 & Time Series & Oldest \\
\hline Dummy_LP_User & inf & 1 & Time Series & Oldest \\
\hline Dummy_BP6 & $\inf$ & 1 & Time Series & Oldest \\
\hline Dummy_BP9 & $\inf$ & 1 & Time Series & Oldest \\
\hline Dummy_Desup_LP & $\inf$ & 1 & Time Series & Oldest \\
\hline Turboblower & $\inf$ & 1 & Time Series & Oldest \\
\hline Waste_heat_boiler & $\inf$ & 1 & Time Series & Oldest \\
\hline Dummy_turbo & inf & 1 & Time Series & Oldest \\
\hline Boiler102 & $\inf$ & 1 & Time Series & Oldest \\
\hline Boiler3 & $\inf$ & 1 & Time Series & Oldest \\
\hline Boiler4 & $\inf$ & 1 & Time Series & Oldest \\
\hline Boiler5 & inf & 1 & Time Series & Oldest \\
\hline $\mathrm{BFG}$ & inf & 1 & Time Series & Oldest \\
\hline NG101 & inf & 1 & Time Series & Oldest \\
\hline DummyNG102 & $\inf$ & 1 & Time Series & Oldest \\
\hline DummyNG101 & $\inf$ & 1 & Time Series & Oldest \\
\hline DummyNG3 & $\inf$ & 1 & Time Series & Oldest \\
\hline DummyNG4 & inf & 1 & Time Series & Oldest \\
\hline DummyNG5 & inf & 1 & Time Series & Oldest \\
\hline NG102 & inf & 1 & Time Series & Oldest \\
\hline NG3 & inf & 1 & Time Series & Oldest \\
\hline NG4 & $\inf$ & 1 & Time Series & Oldest \\
\hline NG5 & inf & 1 & Time Series & Oldest \\
\hline Combustion & inf & 1 & Time Series & Oldest \\
\hline BFG_flaring & $\inf$ & 1 & Time Series & Oldest \\
\hline DummyBFG & $\inf$ & 1 & Time Series & Oldest \\
\hline Tank & $\inf$ & 1 & Time Series & Oldest \\
\hline Stove & $\inf$ & 1 & Time Series & Oldest \\
\hline Dummystove & inf & 1 & Time Series & Oldest \\
\hline Stove2 & $\inf$ & 1 & Time Series & Oldest \\
\hline Dummystove2 & $\inf$ & 1 & Time Series & Oldest \\
\hline Noise & $\inf$ & 1 & Time Series & Oldest \\
\hline Pilot101 & inf & 1 & Time Series & Oldest \\
\hline Pilot102 & inf & 1 & Time Series & Oldest \\
\hline Pilot3 & $\inf$ & 1 & Time Series & Oldest \\
\hline Pilot4 & $\inf$ & 1 & Time Series & Oldest \\
\hline Pilot5 & inf & 1 & Time Series & Oldest \\
\hline
\end{tabular}




$\begin{array}{lcl}\text { Name } & \begin{array}{r}\text { Entities } \\ \text { Speed } \\ \text { (fpm) }\end{array} & \text { Stats } \\ \text { User_requirement } & 1550 & \text { Time Series } \\ \text { LP_Steam_arrival } & 1550 & \text { Time Series } \\ \text { High_Press_Steam } & 1550 & \text { Time Series } \\ \text { BOP_Steam } & 1550 & \text { Time Series } \\ \text { LP_steam } & 1550 & \text { Time Series } \\ \text { Vent_Arrival } & 1550 & \text { Time Series } \\ \text { turbo_ent } & 1550 & \text { Time Series } \\ \text { NG_boiler101 } & 1550 & \text { Time Series } \\ \text { NG_boiler102 } & 1550 & \text { Time Series } \\ \text { NG_boiler3 } & 1550 & \text { Time Series } \\ \text { NG_boiler4 } & 1550 & \text { Time Series } \\ \text { NG_ent101 } & 1550 & \text { Time Series } \\ \text { NG_boiler5 } & 1550 & \text { Time Series } \\ \text { BFG_ent } & 1550 & \text { Time Series } \\ \text { NG_ent102 } & 1550 & \text { Time Series } \\ \text { NG_ent3 } & 1550 & \text { Time Series } \\ \text { NG_ent4 } & 1550 & \text { Time Series } \\ \text { NG_ent5 } & 1550 & \text { Time Series } \\ \text { BFGflare } & 1550 & \text { Time Series } \\ \text { Stove_arrival } & 1550 & \text { Time Series } \\ \text { Stove_arrival2 } & 1550 & \text { Time Series } \\ \text { Noise_ent } & 1550 & \text { Time Series } \\ \text { Pilotent101 } & 1550 & \text { Time Series } \\ \text { Pilotent102 } & 1550 & \text { Time Series } \\ \text { Pilotent3 } & 1550 & \text { Time Series } \\ \text { Pilotent4 } & 1550 & \text { Time Series } \\ \text { Pilotent5 } & 1550 & \text { Time Series } \\ \text { Water } & 1550 & \text { Time Series } \\ \text { Anci } & 1550 & \text { Time Series }\end{array}$

Path Networks

\begin{tabular}{|c|c|c|c|c|c|c|c|}
\hline Name & Type & $\mathbf{T} / \mathbf{S}$ & From & To & BI & Dist/Time & Speed Factor \\
\hline \multirow[t]{3}{*}{ LP_User_Network } & Passing & Speed \& Distance & $\mathrm{N} 1$ & $\mathrm{~N} 2$ & $\mathrm{Bi}$ & 1 & 1 \\
\hline & & & $\mathrm{N} 2$ & N3 & $\mathrm{Bi}$ & 1 & 1 \\
\hline & & & $\mathrm{N} 2$ & N4 & $\mathrm{Bi}$ & 1 & 1 \\
\hline \multirow[t]{14}{*}{ Boiler_LP_Network } & Passing & Speed \& Distance & N1 & $\mathrm{N} 2$ & $\mathrm{Bi}$ & 1 & 1 \\
\hline & & & $\mathrm{N} 2$ & $\mathrm{~N} 3$ & $\mathrm{Bi}$ & 1 & 1 \\
\hline & & & $\mathrm{N} 2$ & N5 & $\mathrm{Bi}$ & 1 & 1 \\
\hline & & & N5 & N7 & $\mathrm{Bi}$ & 1 & 1 \\
\hline & & & N7 & N8 & $\mathrm{Bi}$ & 1 & 1 \\
\hline & & & N3 & N6 & $\mathrm{Bi}$ & 1 & 1 \\
\hline & & & N6 & N8 & $\mathrm{Bi}$ & 1 & 1 \\
\hline & & & N9 & $\mathrm{N} 2$ & $\mathrm{Bi}$ & 1 & 1 \\
\hline & & & N10 & $\mathrm{N} 2$ & $\mathrm{Bi}$ & 1 & 1 \\
\hline & & & N11 & $\mathrm{N} 2$ & $\mathrm{Bi}$ & 1 & 1 \\
\hline & & & $\mathrm{N} 12$ & $\mathrm{~N} 2$ & $\mathrm{Bi}$ & 1 & 1 \\
\hline & & & $\mathrm{N} 2$ & N4 & $\mathrm{Bi}$ & 1 & 1 \\
\hline & & & N4 & N13 & $\mathrm{Bi}$ & 1 & 1 \\
\hline & & & N13 & $\mathrm{N} 8$ & $\mathrm{Bi}$ & 1 & 1 \\
\hline \multirow[t]{3}{*}{ turbo_network } & Passing & Speed \& Distance & $\mathrm{N} 1$ & $\mathrm{~N} 2$ & $\mathrm{Bi}$ & 1 & 1 \\
\hline & & & $\mathrm{N} 2$ & N3 & $\mathrm{Bi}$ & 1 & 1 \\
\hline & & & N1 & N4 & $\mathrm{Bi}$ & 1 & 1 \\
\hline
\end{tabular}




\begin{tabular}{|c|c|c|c|c|c|c|c|}
\hline \multirow[t]{6}{*}{ BFG_path } & Passing & Speed \& Distance & N1 & $\mathrm{N} 2$ & $\mathrm{Bi}$ & 1 & 1 \\
\hline & & & N1 & $\mathrm{N} 3$ & $\mathrm{Bi}$ & 1 & 1 \\
\hline & & & $\mathrm{N} 1$ & $\mathrm{~N} 4$ & $\mathrm{Bi}$ & 1 & 1 \\
\hline & & & $\mathrm{N} 1$ & N5 & $\mathrm{Bi}$ & 1 & 1 \\
\hline & & & $\mathrm{N} 1$ & N6 & $\mathrm{Bi}$ & 1 & 1 \\
\hline & & & N1 & N7 & $\mathrm{Bi}$ & 1 & 1 \\
\hline \multirow[t]{12}{*}{ NG_path } & Passing & Speed \& Distance & N4 & N5 & $\mathrm{Bi}$ & 1 & 1 \\
\hline & & & N5 & N6 & $\mathrm{Bi}$ & 1 & 1 \\
\hline & & & N7 & $\mathrm{N} 8$ & $\mathrm{Bi}$ & 1 & 1 \\
\hline & & & N8 & N9 & $\mathrm{Bi}$ & 1 & 1 \\
\hline & & & N10 & N11 & $\mathrm{Bi}$ & 1 & 1 \\
\hline & & & N11 & $\mathrm{N} 12$ & $\mathrm{Bi}$ & 1 & 1 \\
\hline & & & N13 & N14 & $\mathrm{Bi}$ & 1 & 1 \\
\hline & & & N14 & N15 & $\mathrm{Bi}$ & 1 & 1 \\
\hline & & & N5 & N1 & $\mathrm{Bi}$ & 1 & 1 \\
\hline & & & N8 & N2 & $\mathrm{Bi}$ & 1 & 1 \\
\hline & & & N11 & N3 & $\mathrm{Bi}$ & 1 & 1 \\
\hline & & & N14 & N16 & $\mathrm{Bi}$ & 1 & 1 \\
\hline \multirow[t]{3}{*}{ NG_path102 } & Passing & Speed \& Distance & N1 & N2 & $\mathrm{Bi}$ & 1 & 1 \\
\hline & & & $\mathrm{N} 2$ & N3 & $\mathrm{Bi}$ & 1 & 1 \\
\hline & & & $\mathrm{N} 2$ & N4 & $\mathrm{Bi}$ & 1 & 1 \\
\hline \multirow[t]{2}{*}{ combustion_path } & Passing & Speed \& Distance & N1 & $\mathrm{N} 2$ & $\mathrm{Bi}$ & 1 & 1 \\
\hline & & & N3 & N2 & $\mathrm{Bi}$ & 1 & 1 \\
\hline \multirow[t]{4}{*}{ BOP_network } & Passing & Speed \& Distance & N1 & N2 & $\mathrm{Bi}$ & 1 & 1 \\
\hline & & & $\mathrm{N} 2$ & N3 & $\mathrm{Bi}$ & 1 & 1 \\
\hline & & & N3 & $\mathrm{N} 4$ & $\mathrm{Bi}$ & 1 & 1 \\
\hline & & & N3 & N5 & $\mathrm{Bi}$ & 1 & 1 \\
\hline \multirow[t]{4}{*}{ Stove_path } & Passing & Speed \& Distance & N1 & $\mathrm{N} 2$ & $\mathrm{Bi}$ & 1 & 1 \\
\hline & & & $\mathrm{N} 2$ & N3 & $\mathrm{Bi}$ & 1 & 1 \\
\hline & & & $\mathrm{N} 1$ & $\mathrm{~N} 4$ & $\mathrm{Bi}$ & 1 & 1 \\
\hline & & & N4 & N5 & $\mathrm{Bi}$ & 1 & 1 \\
\hline
\end{tabular}

$\begin{array}{ccc}\text { Net } & \text { Interfaces } & \\ \text { Node } & \text { Location } \\ \text { LP_User_Network } & \text { N1 } & \text { LP } \\ & \text { N2 } & \text { Dumm__LP_User } \\ & \text { N3 } & \text { User } \\ \text { Boiler_LP_Network } & \text { N1 } & \text { Noise } \\ & \text { N2 } & \text { Boiler101 } \\ & \text { N3_Steam } \\ & \text { N5 } & \text { BP_Turbine6 } \\ & \text { N6 } & \text { De_Sup_Heater } \\ & \text { N7 } & \text { Dummy_BP6 } \\ & \text { N8 } & \text { LP Desup_LP } \\ & \text { N9 } & \text { Boiler102 } \\ & \text { N10 } & \text { Boiler3 } \\ & \text { N11 } & \text { Boiler4 } \\ & \text { N12 } & \text { Boiler5 } \\ & \text { N4 } & \text { BP_Turbine9 } \\ & \text { N13 } & \text { Dummy_BP9 } \\ & \text { N1 } & \text { HP_Steam } \\ \text { N2 } & \text { Dummy_turbo } \\ \text { turbo_network } & \text { N3 } & \text { Turboblower } \\ & \text { N4 } & \text { Turbine_30MW } \\ & \text { N2 } & \text { Boiler102 }\end{array}$




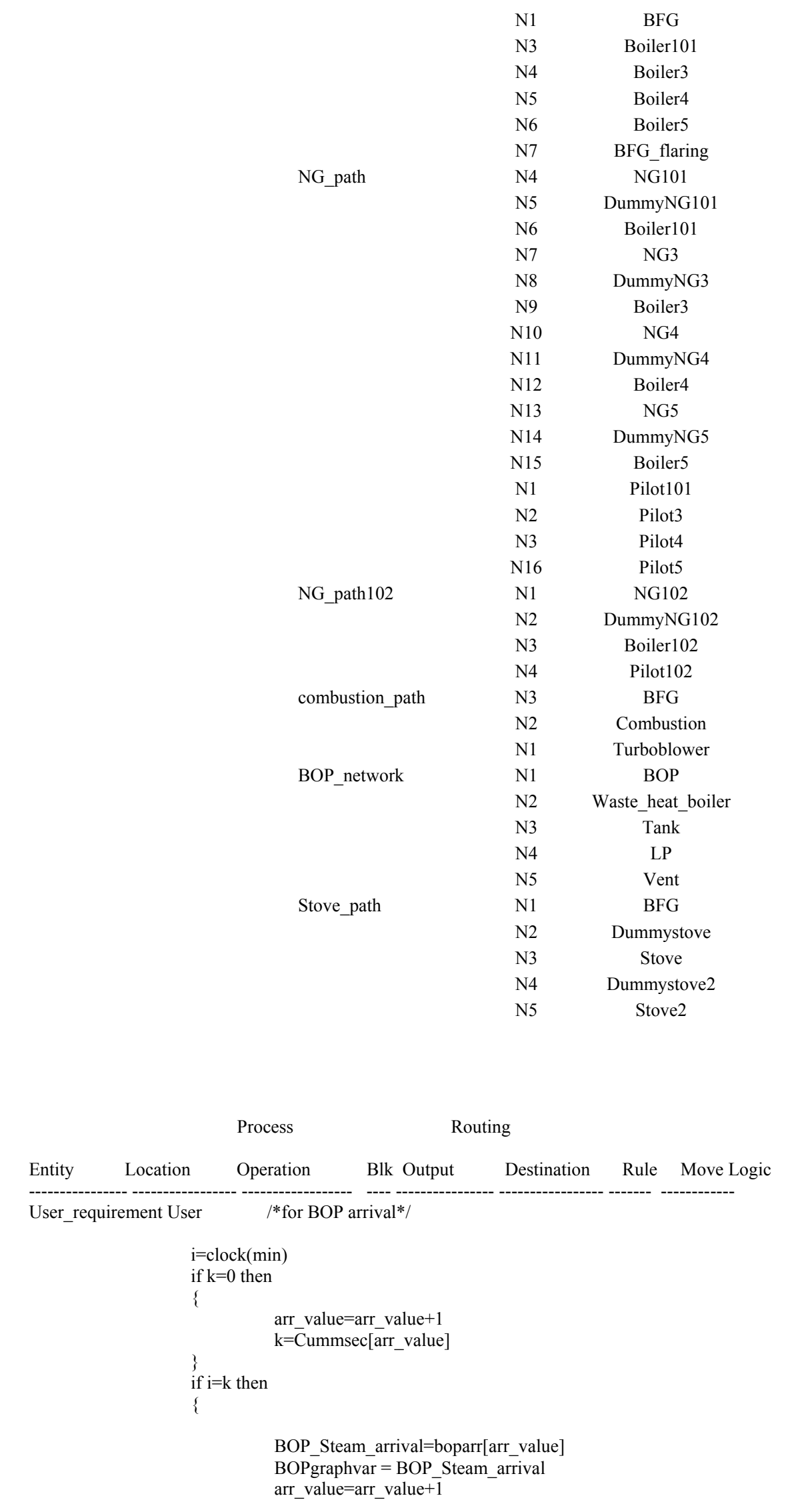


$\mathrm{k}=$ Cummsec[arr_value]

\}

if bol=clock $(\min )$ then

\{

bol=bol +1

/* Pilots */

$$
\begin{aligned}
& \text { pi101 }=\operatorname{arrsetpt}[15] \\
& \text { pi102 }=\operatorname{arrsetpt}[16] \\
& \text { pi3 }=\operatorname{arrsetpt}[17] \\
& \text { pi } 4=\operatorname{arrsetpt}[18] \\
& \text { pi5 }=\operatorname{arrsetpt}[19]
\end{aligned}
$$

/* HP side */

/*\#8 Turbine*/

MW30 $=2.2917 *$ HP_Steam_var -45.417

if MW30 < arrboltur[15] then

\{

\}

MW30=arrboltur[15]

if MW30 > arrboltur[16] then

\{

\}

MW30 = arrboltur[16]

/*Boiler's Steam generation*/

/*Boiler are ramped up in sequences depending upon their efficiencies*/

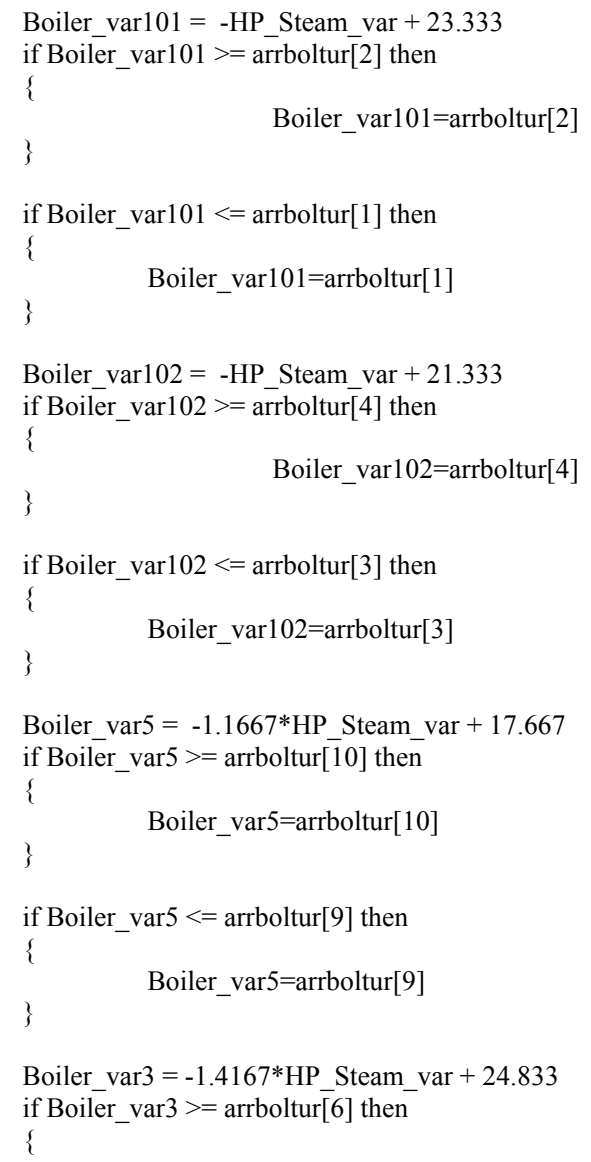




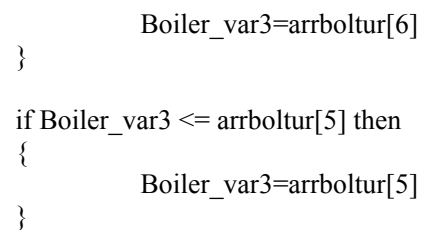

/*Variable for ploting of Steam generation */

Boiler_var101cumm=Boiler_var101

Boiler_var102cumm $=$ Boiler var102

Boiler_var3cumm $=$ Boiler_var3

Boiler_var4cumm=Boiler_var4

Boiler_var5cumm $=$ Boiler_var5

/*Efficiency of the Boilers*/

eff101 $=9.375 *$ Boiler_var101+40

eff102 $=9.375 *$ Boiler var102 +40

eff5 $=8.33 *$ Boiler_var $5+40$

eff3 $=10 *$ Boiler var3 +40

eff $4=10 *$ Boiler_var $4+40$

/*The Fuel required for the Boiler in terms of btu's*/ btu101 $=($ Boiler var101 $/($ eff101/100) $)$-arrsetpt[15] btu102 $=($ Boiler_var102 / (eff102/100) $)$-arrsetpt[16] btu3 $=($ Boiler var3 / (eff3/100) $)$-arrsetpt[17] btu4 $=($ Boiler_var4 / (eff4/100) $)$-arrsetpt[18] btu5 $=($ Boiler_var5 / (eff5/100))-arrsetpt[19]

Totalbtu $=$ btu $101+$ btu $102+$ btu $3+$ btu $4+$ btu 5

/*rate of flow from tank to LP header*/ $\mathrm{m} 2=(\mathrm{m}-\operatorname{arrsetpt}[5]) * \operatorname{arrsetpt}[10]$ if $\mathrm{m} 2<0$ then \{

\} $\mathrm{m} 2=0$

if $m 2>\operatorname{arrsetpt}[4]$ then

\{

\} $\mathrm{m} 2=\operatorname{arrsetpt}[4]$

$\mathrm{m} 2 \mathrm{graph}=\mathrm{m} 2$

/*User req*/

User_req_counter $=$ User_req_counter+arrsetpt[6]

User cumm=User req counter

Total=Total-arrsetpt[6]

User req counter $=$ User req counter-arrsetpt[6]

SEND arrsetpt[6] LP_steam TO Dummy_LP_User

Join arrsetpt[6] LP_steam

/*Noise for the User requirement*/

$/ *$ if Noise $\operatorname{var}<1.2$ then

\{

)

Noise_var $=$ Noise_var +0.2

if Noise_var $>1.1$ then

\{

Noise_var $=0$ 
Total=Total-Noise var

SEND 1 LP_steam TO Dummy_LP_User

Join 1 LP_steam*/

/*LP side */

/*\#9 turbine Steam Flow rate calculation*/

MW9 $=-1.7667 *$ Total +363.33

if MW9 < arrboltur[13] then

\{

MW9=arrboltur[13]

if MW9 > arrboltur[14] then

\{

MW9 = arrboltur[14]

\}

MW9graph = MW9

/*\#6 turbine Steam Flow rate calculation*/

MW6=-0.9167*Total +184.5

if MW6 < arrboltur[11] then

\{

\}

MW6=arrboltur[11]

if MW6 > arrboltur[12] then

\{

\}

MW6 = arrboltur[12]

MW6graph $=$ MW6

/*Calculating the required steam to keep LP header pressure at 200psig*/

error $=$ arrsetpt $[2]$ - Total

/*Deuperheater used only if the turbines are insuffcient to supply the steam*/

if error > (MW6+MW9) then

\{

Steam Flow rate calculation*/

desuper $=-0.9514 *$ Total +184.58

if desuper $<$ arrboltur[26] then

\{

\}

desuper=arrboltur[26]

if desuper $>$ arrboltur[27] then

\{

\}

desuper $=$ arrboltur[27]

desupergraph $=$ desuper

\}

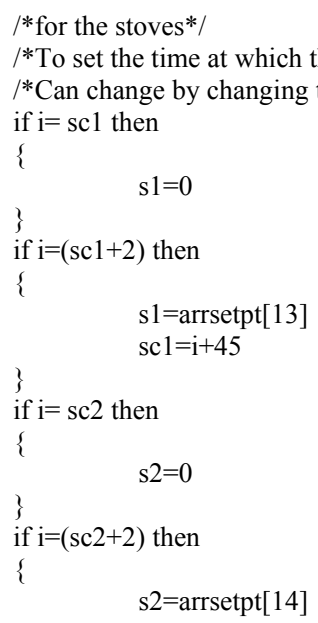


\} $\quad \mathrm{sc} 2=\mathrm{i}+45$

1 User_requirement EXIT FIRST 1 MOVE ON LP_User_Network

LP_Steam_arrival LP

/*Operation of \#9 turbine*/

if bol1 $=\operatorname{clock}(\min )$ then

\{

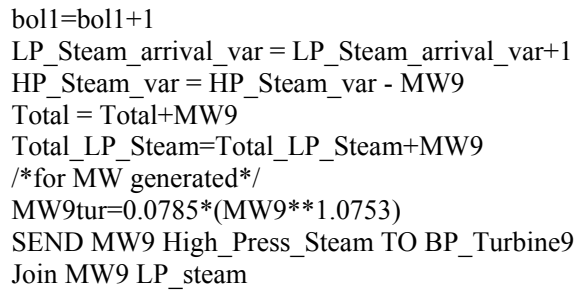

/*Operation of Desuperheater*/

if $\operatorname{bol} 3=\operatorname{clock}(\min )$ then

\{

bol3 $=$ bol3 +1

if error $>$ (MW6+MW9) then

\{

HP Steam var $=$ HP Steam var - desuper

Total $=$ Total + desuper

Total_LP_Steam=Total_LP_Steam + desuper

desuperheater $=$ desuperheater+desuper

SEND desuper High Press Steam TO De Sup Heater

Join desuper LP_steam

\}

1* LP_Steam_arrival EXIT FIRST 1 MOVE ON LP_User_Network

2 LP_steam Dummy_LP_User SEND 1 MOVE ON LP_User_Network

BFG_ent BFG $/ *$ Logic for flaring of $\mathrm{BFG}^{*} /$

/*If the BFG is not utilised completely it is Flared*/

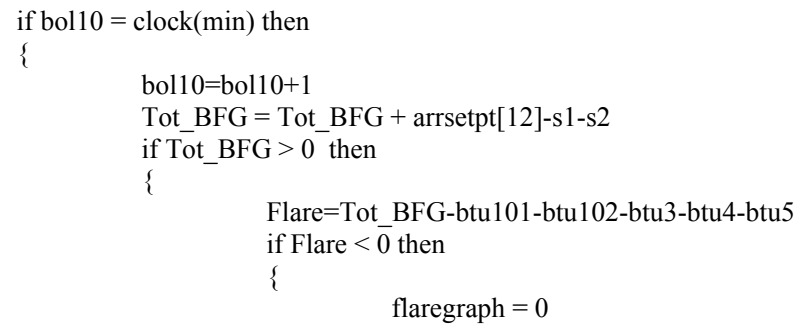




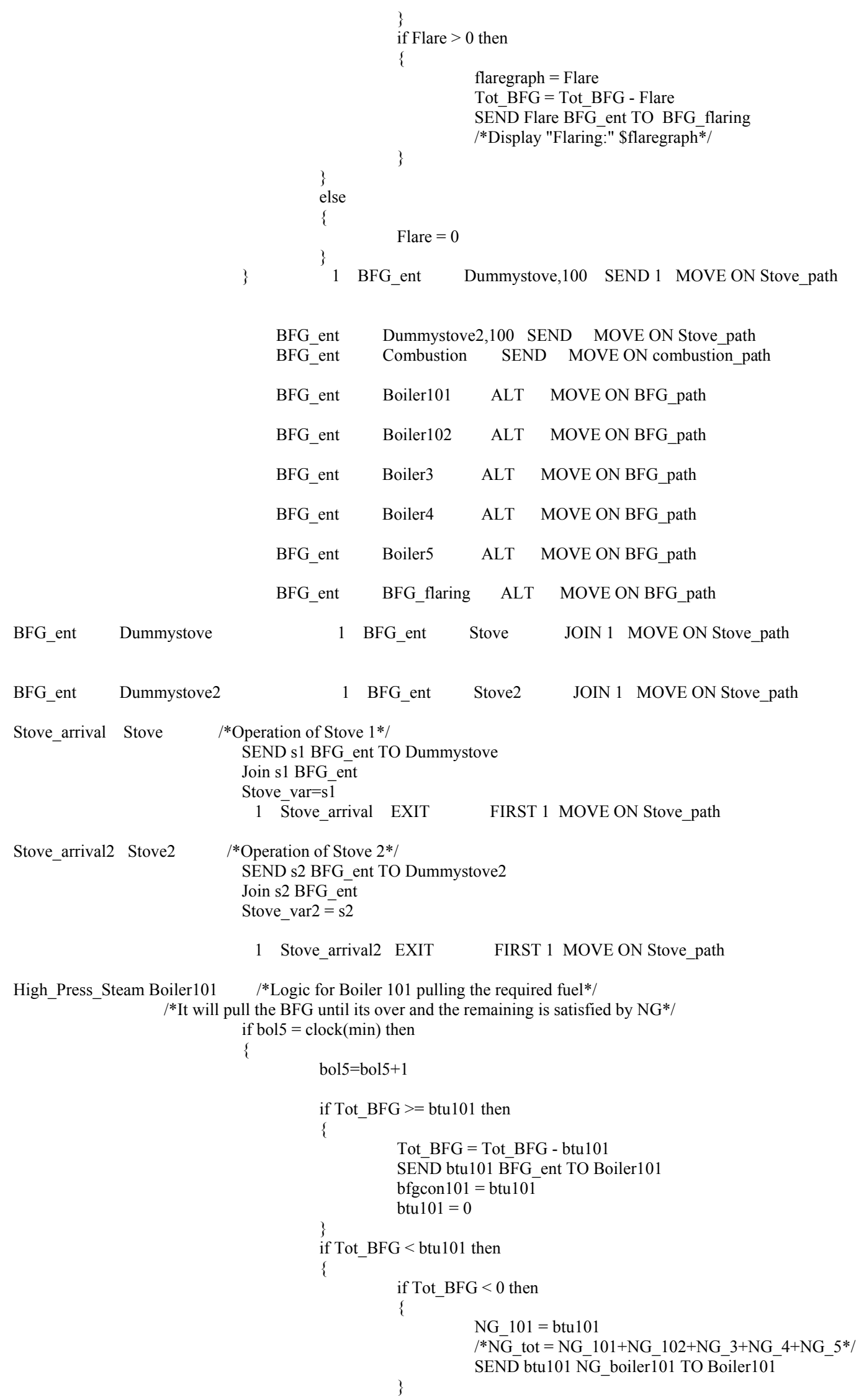




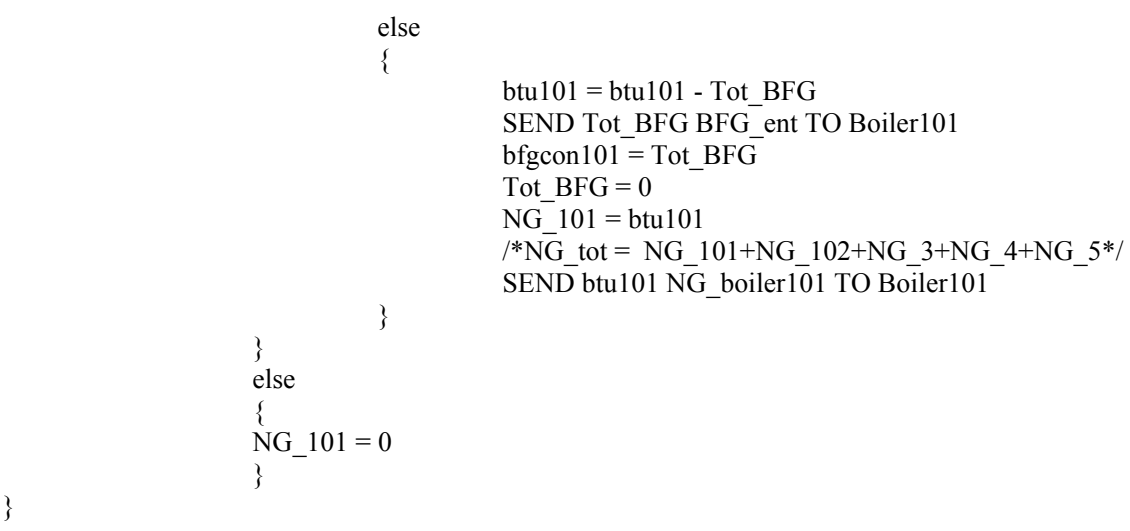

1 High_Press_Steam HP_Steam FIRST 1 MOVE ON Boiler_LP_Network

High Press Steam Boiler102 /*Logic for Boiler 102 pulling the required fuel*/

/*It will pull the BFG until its over and the remaining is satisfied by $\mathrm{NG}^{* /}$ if bol6 $=\operatorname{clock}(\mathrm{min})$ then

\{

bol6=bol6 +1

if Tot_BFG $>=$ btu102 then

\{

Tot $\mathrm{BFG}=$ Tot $\mathrm{BFG}-$ btu 102

SEND btu102 BFG_ent TO Boiler102

bfgcon $102=$ btu 102

btu $102=0$

if Tot_BFG $<$ btu102 then

\{

if Tot $\mathrm{BFG}<0$ then

\{

NG_102 = btu102

\}

SEND btu102 NG boiler102 TO Boiler102

else

\{

btu102 = btu102 - Tot BFG

SEND Tot BFG BFG ent TO Boiler102

bfgcon $102=$ Tot_BFG

Tot $\mathrm{BFG}=0$

NG_-102 = btu102

\}

SEND btu102 NG_boiler102 TO Boiler102

else

\{

NG_102 $=0$

\}

\}

1 High_Press_Steam HP_Steam

FIRST 1 MOVE ON Boiler_LP_Network

High_Press_Steam Boiler3 /*Logic for Boiler 3 pulling the required fuel*/

/*It will pull the BFG until its over and the remaining is satisfied by $\mathrm{NG}^{* /}$

if bol7 $=\operatorname{clock}(\mathrm{min})$ then

\{

bol7 $=$ bol $7+1$

if Tot_BFG $>=$ btu3 then

\{

Tot $\mathrm{BFG}=$ Tot $\mathrm{BFG}-\mathrm{btu} 3$

SEND btu3 BFG_ent TO Boiler3

bfgcon $3=$ btu 3

btu $3=0$

\}

if Tot_BFG $<$ btu3 then

\{

if Tot_BFG $<0$ then 


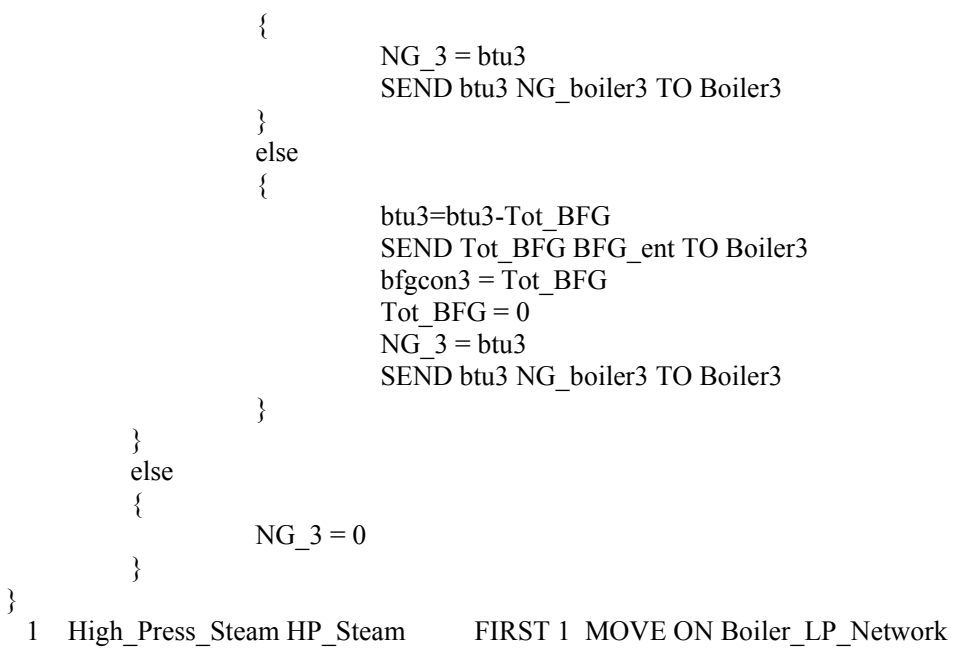

High_Press_Steam Boiler4 $/ *$ Logic for Boiler 4 pulling the required fuel*/

$/ *$ It will pull the BFG until its over and the remaining is satisfied by $\mathrm{NG}^{* /}$

if bol8 $=\operatorname{clock}(\mathrm{min})$ then

\{

bol $=$ bol $8+1$

if Tot $\mathrm{BFG}>=\mathrm{btu} 4$ then

\{

Tot $\mathrm{BFG}=$ Tot $\mathrm{BFG}-\mathrm{btu} 4$

SEND btu4 BFG_ent TO Boiler4

bfgcon $4=$ btu 4

btu $4=0$

if Tot_BFG $<$ btu4 then

if Tot_BFG $<0$ then

NG $4=$ btu 4

\}

SEND btu4 NG boiler4 TO Boiler4

else

\{

btu4=btu4-Tot BFG

SEND Tot BFG BFG ent TO Boiler4

bfgcon $4=\overline{\text { Tot }}$ BFG

Tot $\mathrm{BFG}=0$

$\mathrm{NG}_{4} 4=$ btu 4

\}

SEND btu4 NG boiler4 TO Boiler4

else

\{

NG_4 $=0$

\}

\}

1 High_Press_Steam HP_Steam

FIRST 1 MOVE ON Boiler_LP_Network

High_Press_Steam Boiler5 /*Logic for Boiler 5 pulling the required fuel*/

/*It will pull the BFG until its over and the remaining is satisfied by $\mathrm{NG}^{* /}$

if $\operatorname{bol} 9=\operatorname{clock}(\mathrm{min})$ then

\{

bol9=bol9 +1

if Tot $\mathrm{BFG}>=$ btu 5 then

\{

Tot $\mathrm{BFG}=$ Tot $\mathrm{BFG}-$ btu 5

SEND btu5 BFG_ent TO Boiler5

bfgcon $5=$ btu 5

btu $5=0$

if Tot_BFG $<$ btu 5 then 
Tot_BFG $<0$ then

\{

NG_5 = btu5

SEND btu5 NG_boiler5 TO Boiler5

\}

else

\{

btu5=btu5-Tot_BFG

SEND Tot BFG BFG ent TO Boiler5

bfgcon5 $=$ Tot_BFG

Tot $\mathrm{BFG}=0$

NG_5 = btu5

\}

SEND btu5 NG boiler5 TO Boiler5

\}

else

\{

\}

$$
\text { NG_5 =0 }
$$

NG_cumm $=$ NG_tot

NG_tot $=$ NG_101+NG_102+NG_3+NG_4+NG_5+pi101+pi102+pi3+pi4+pi5

NGcost $=$ NG_tot $* 5.5$

\}

bfgcontot $=$ bfgcon $101+b f g c o n 102+b f g c o n 3+b f g c o n 4+b f g c o n 5$

Tot_BFGgraph $=$ Tot_BFG

1 High_Press_Steam HP_Steam FIRST 1 MOVE ON Boiler_LP_Network

High Press Steam HP Steam /*Calculation of HP header Pressure and KP steam in it*/

/*Opearion of \#8 turbine*/

if bol4 $=\operatorname{clock}(\min )$ then

\{

bol4=bol4+1

HP_Steam_var=HP_Steam_var+Boiler_var101+Boiler_var102+Boiler_var3+Boiler_var4+Boiler_var5

HP_Pressure $=1504.08-(833.33 *(18852 /($ HP_Steam_var*1000) $))$

HP Steam var $=$ HP Steam var - MW30

SEND MW30 High_Press_Steam TO Turbine_30MW

Join MW30 High_Press_Steam

/*MW Generated*/

MW30tur $=0.3803 *($ MW $30 * * 0.9708)$

(

HP_Steam_var1=HP_Steam_var

tur30 $=\mathrm{MW} 30$

1 High_Press_Steam BP_Turbine6 SEND 1 MOVE ON Boiler_LP_Network

High_Press_Steam De_Sup_Heater SEND MOVE ON Boiler_LP_Network

High Press Steam Turbine 30MW SEND MOVE ON turbo network

High_Press_Steam Dummy_turbo SEND MOVE ON turbo_network

High_Press_Steam BP_Turbine9 SEND MOVE ON Boiler_LP_Network

High_Press_Steam BP_Turbine6

1 LP_steam Dummy_BP6 FIRST 1 MOVE ON Boiler_LP_Network

LP_steam Dummy_BP6 1 LP_steam LP $\quad$ JOIN 1 MOVE ON Boiler_LP_Network

High_Press_Steam De_Sup_Heater

1 LP_steam Dummy_Desup_LP FIRST 1 MOVE ON Boiler_LP_Network

LP_steam Dummy_Desup_LP $/ *$ for water addition

watervar $=0.1 *$ desuperheater

desuperheater=desuperheater- $1 * /$

1 LP_steam LP JOIN 1 MOVE ON Boiler_LP_Network

$\begin{array}{lllll}\text { Water De Sup Heater } & 1 & \text { Water } & \text { EXIT } & \text { FIRST } 1\end{array}$

High_Press_Steam Turbine_30MW 
High_Press_Steam BP_Turbine9

1 LP_steam Dummy_BP9 FIRST 1 MOVE ON Boiler_LP_Network

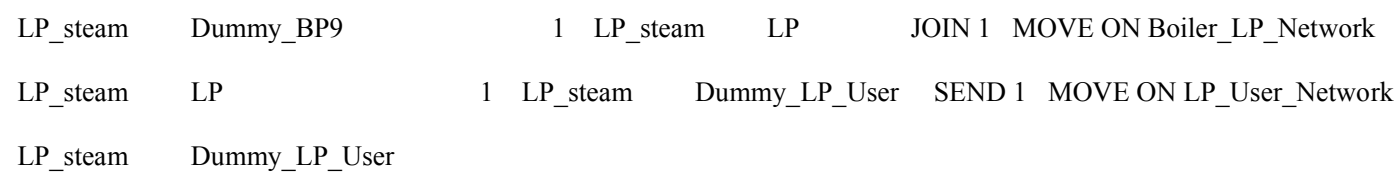

\begin{tabular}{cccccc} 
& 1 & LP_steam & User & JOIN 1 & MOVE ON LP_User_Network \\
& & LP_steam & Noise & JOIN & MOVE ON LP_User_Network \\
Noise_ent & Noise & \multicolumn{2}{c}{ Noise_ent } & EXIT & FIRST 1 MOVE ON LP_User_Network
\end{tabular}

High_Press_Steam Dummy_turbo

1 High_Press_Steam Turboblower JOIN 1

MOVE ON turbo_network

turbo_ent Turboblower /*Operation of turbo blower*/

if bol11 $=\operatorname{clock}(\min )$ then

\{

bol11=bol11+1

turbo blower $=$ arrsetpt [7]

SEND turbo_blower High_Press_Steam TO Dummy_turbo

Join turbo blower High_Press Steam

\}

HP_Steam_var=HP_Steam_var-turbo_blower

1 turbo_ent Combustion FIRST 1 MOVE ON combustion_path

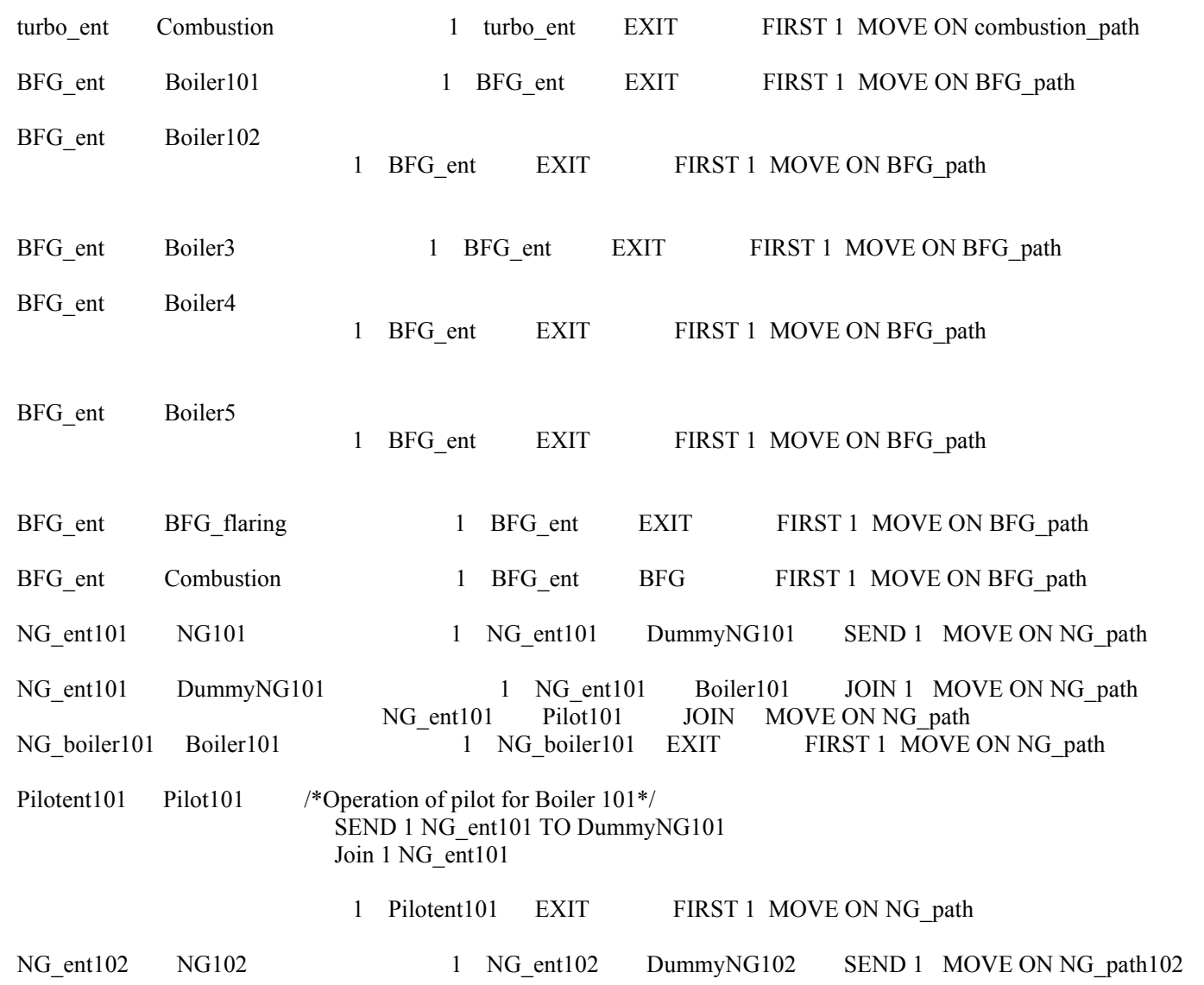




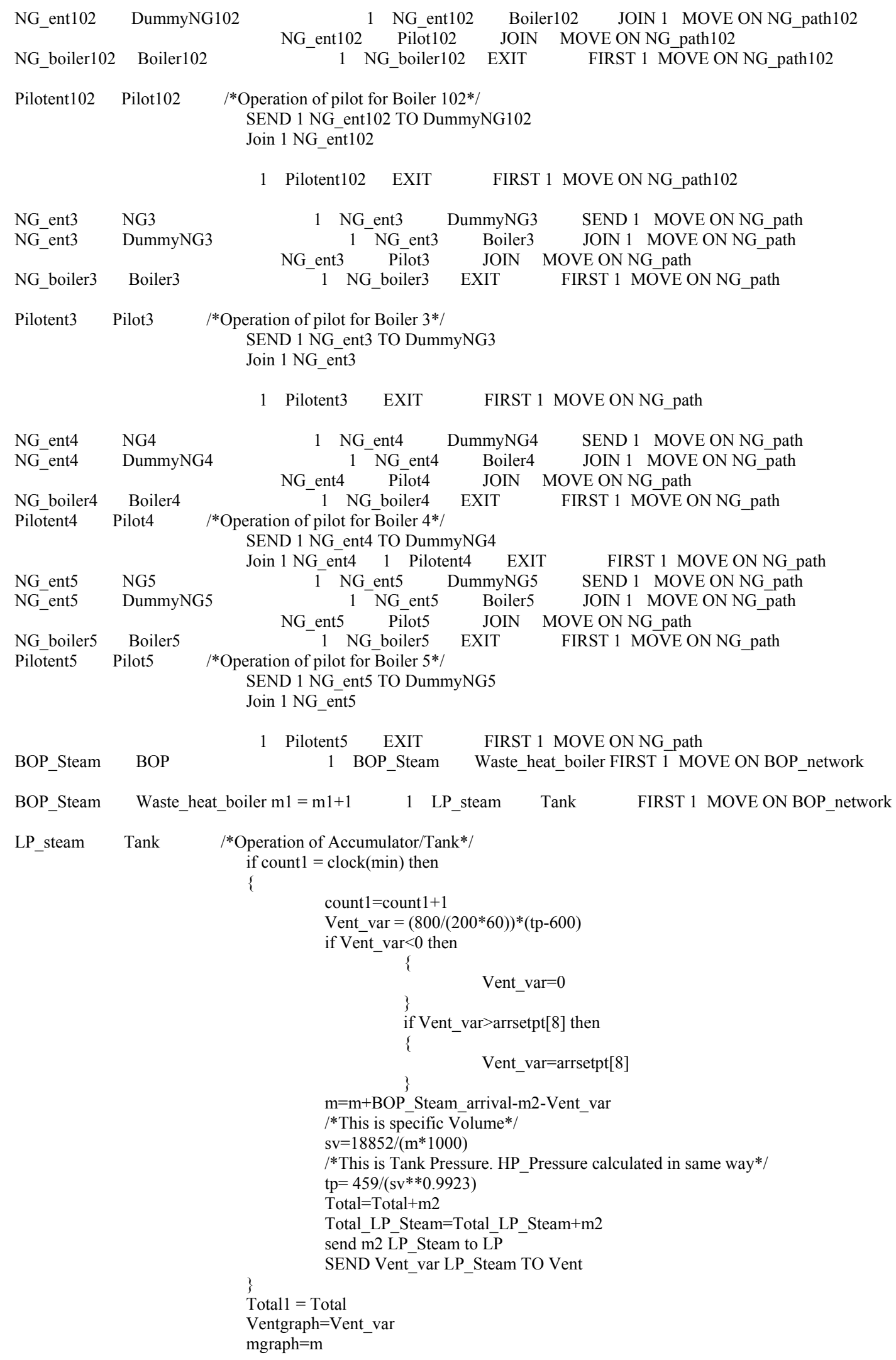




$\begin{array}{cccccc} & 1 & \text { LP_steam } & \text { LP } & \text { SEND } 1 & \text { MOVE ON BOP_network } \\ & \text { LP_steam } & \text { Vent } & \text { ALT } & \text { MOVE ON BOP_network } \\ \text { LP_steam Vent } & 1 & \text { LP_steam } & \text { EXIT } & \text { FIRST 1 MOVE ON LP_User_Network }\end{array}$

\begin{tabular}{|c|c|c|c|c|c|}
\hline \multicolumn{6}{|c|}{ Arrivals } \\
\hline Entity & Location & Qty each & First Time & Occurrences & Frequency \\
\hline User_requirement & User & arrsetpt[6] & 0 & inf & $1 \mathrm{~min}$ \\
\hline LP_Steam_arrival & LP & $\operatorname{arrsetpt}[6]$ & 0 & INF & $1 \mathrm{~min}$ \\
\hline BFG_ent & BFG & $\operatorname{arrsetpt}[12]$ & 0 & $\inf$ & $1 \mathrm{~min}$ \\
\hline BOP_Steam & BOP & BOP_Steam_arrival & 0 & INF & $1 \mathrm{~min}$ \\
\hline turbo_ent & Turboblower & $\operatorname{arrsetpt}[7]$ & 0 & $\inf$ & $1 \mathrm{~min}$ \\
\hline NG_boiler101 & Boiler101 & 1; NG_arrival & 0 & $\inf$ & $5 \min$ \\
\hline NG_boiler102 & Boiler102 & $1 ; \mathrm{NG}$ _arrival & 0 & $\inf$ & $5 \mathrm{~min}$ \\
\hline NG_boiler3 & Boiler3 & $1 ; \mathrm{NG}$ _arrival & 0 & $\inf$ & $5 \mathrm{~min}$ \\
\hline NG_boiler4 & Boiler4 & $1 ; \mathrm{NG}$ _arrival & 0 & $\inf$ & $5 \min$ \\
\hline NG_boiler5 & Boiler5 & 1; NG_arrival & 0 & $\inf$ & $5 \min$ \\
\hline High_Press_Steam & Boiler101 & Boiler_var101 & 0 & $\inf$ & $1 \mathrm{~min}$ \\
\hline High_Press_Steam & Boiler102 & Boiler_var102 & 0 & $\inf$ & $1 \mathrm{~min}$ \\
\hline High_Press_Steam & Boiler3 & Boiler_var3 & 0 & inf & $1 \mathrm{~min}$ \\
\hline High_Press_Steam & Boiler4 & Boiler_var4 & 0 & $\inf$ & $1 \mathrm{~min}$ \\
\hline High_Press_Steam & Boiler5 & Boiler_var5 & 0 & $\inf$ & $1 \mathrm{~min}$ \\
\hline NG_ent101 & NG101 & $\operatorname{arrsetpt}[20]$ & 0 & $\inf$ & $1 \mathrm{~min}$ \\
\hline NG_ent102 & NG102 & $\operatorname{arrsetpt}[21]$ & 0 & $\inf$ & $1 \mathrm{~min}$ \\
\hline NG_ent3 & NG3 & $\operatorname{arrsetpt}[22]$ & 0 & $\inf$ & $1 \mathrm{~min}$ \\
\hline NG_ent4 & NG4 & $\operatorname{arrsetpt}[23]$ & 0 & $\inf$ & $1 \mathrm{~min}$ \\
\hline NG_ent5 & NG5 & $\operatorname{arrsetpt}[24]$ & 0 & $\inf$ & $1 \mathrm{~min}$ \\
\hline Stove_arrival & Stove & s1 & 0 & $\inf$ & $1 \mathrm{~min}$ \\
\hline Stove_arrival2 & Stove2 & s2 & 0 & INF & $1 \mathrm{~min}$ \\
\hline Noise_ent & Noise & Noise_var & 0 & $\inf$ & $1 \mathrm{~min}$ \\
\hline Pilotent101 & Pilot101 & $\operatorname{arrsetpt}[15]$ & 0 & $\inf$ & $1 \mathrm{~min}$ \\
\hline Pilotent102 & Pilot102 & arrsetpt[16] & 0 & $\inf$ & $1 \mathrm{~min}$ \\
\hline Pilotent3 & Pilot3 & arrsetpt[17] & 0 & $\inf$ & $1 \mathrm{~min}$ \\
\hline Pilotent4 & Pilot4 & $\operatorname{arrsetpt[18]}$ & 0 & $\inf$ & $1 \mathrm{~min}$ \\
\hline Pilotent5 & Pilot5 & arrsetpt[19] & 0 & inf & $1 \mathrm{~min}$ \\
\hline Water & De_Sup_Heater & 1 & 0 & $\inf$ & $1 \mathrm{~min}$ \\
\hline
\end{tabular}

\begin{tabular}{lcc}
\multicolumn{1}{c}{ ID } & Arrays & \\
boparr & Dimensions & Type \\
Cummsec & 500 & Real \\
arrsetpt & 500 & Integer \\
arrboltur & 24 & Real \\
& 30 & Real
\end{tabular}

Arrivals

$\begin{array}{lcccc}\text { ID } & \text { Qty / \% } & \text { Cumulative } & \text { Time (Hours) } & \text { Value } \\ \text { NG_arrival } & \text { Quantity } & \text { No } & 1 \text { min } & \text { g1 } \\ & & & 2 \text { min } & \text { g1 } \\ & & & 3 \text { min } & \text { g1 } \\ & & & 4 \mathrm{~min} & \text { g1 } \\ & & & 5 \text { min } & \text { g1 }\end{array}$

